\title{
Resilient journeys: A case study of why and how low-income families practice homeschooling
}

Cheng-Hsien Wu

West Virginia University

Follow this and additional works at: https://researchrepository.wvu.edu/etd

\section{Recommended Citation}

Wu, Cheng-Hsien, "Resilient journeys: A case study of why and how low-income families practice homeschooling" (2013). Graduate Theses, Dissertations, and Problem Reports. 3645.

https://researchrepository.wvu.edu/etd/3645

This Dissertation is protected by copyright and/or related rights. It has been brought to you by the The Research Repository @ WVU with permission from the rights-holder(s). You are free to use this Dissertation in any way that is permitted by the copyright and related rights legislation that applies to your use. For other uses you must obtain permission from the rights-holder(s) directly, unless additional rights are indicated by a Creative Commons license in the record and/ or on the work itself. This Dissertation has been accepted for inclusion in WVU Graduate Theses, Dissertations, and Problem Reports collection by an authorized administrator of The Research Repository @ WVU.

For more information, please contact researchrepository@mail.wvu.edu. 
RESILIENT JOURNEYS: A CASE STUDY OF WHY AND HOW

\title{
LOW-INCOME FAMILIES PRACTICE HOMESCHOOLING
}

\section{Cheng-Hsien Wu}

Dissertation submitted to the College of Education \& Human Services at West Virginia University

Department of Curriculum \& Instruction in fulfillment of the requirements for the Degree of Doctor of Philosophy in Education

\author{
Adriane Williams, PhD, Co-Chair \\ Melissa Sherfinski, $\mathrm{PhD}$, Co-Chair \\ Malayna Bernstein, $\mathrm{PhD}$ \\ Sharon Hayes, $\mathrm{PhD}$ \\ Maja Holmes, $\mathrm{PhD}$ \\ Patricia Obenauf, $\mathrm{PhD}$ \\ Audra Slocum, $\mathrm{PhD}$
}

Morgantown, West Virginia

2013

Keywords: homeschooling, low-income, working-class, mothers 


\section{ABSTRACT \\ RESILIENT JOURNEYS: A CASE STUDY OF WHY AND HOW}

\section{LOW-INCOME FAMILIES PRACTICE HOMESCHOOLING}

\section{Cheng-Hsien Wu}

The purpose of this study is to explore why and how two low-income families practice homeschooling. A qualitative case study of low-income homeschooling mothers' experiences was conducted over the course of four months in Tennessee and West Virginia. The major research question was: How and why working class families decide to homeschool their children? Specifically, I believed that a qualitative examination of this topic would allow me to answer a number of attendant questions:

1. How and why do local contexts of "choice" shape low-income homeschoolers' experiences?

a. How do local public school experiences shape homeschooling experiences, motivations, and practices?

b. How do low-income homeschooling families experiences confirm, discredit, and complicate established theories of families' educational experiences, motivations, and practices?

2. How do low-income, homeschooling families manage homeschooling?

a. How do families network and negotiate homeschooling in local contexts?

Based on the nature of the questions, a case study methodology was selected. In order to find answers to these questions, I used a case study method using layered data sources (questionnaires, interviews, observation, and document analysis) and wrote up the findings as portraits of the two participants.

The findings indicated that the two participants were motivated to homeschool for various reasons that were more pragmatic in one case and more instrumental in the other. Interestingly, although both participants were low-income, their child-rearing styles and homeschooling practices were similar to those of middle class families, and in line with their education levels.

Identity, pedagogy, and agency were central themes in both cases. Both mothers were determined to fit their cultural identities into their children's education and carefully considered pedagogical strategies for productive learning. The two mothers supported parents' right to choice in education and orchestrated their own rights to home school, demonstrating that low-income mothers can and do 
demonstrate significant agency regarding educational choices and practices. I argue that homeschooling, with its capacity for mothers and children to engage educational agency, is a form of self-determination that has the potential to become a space in local communities from which democratic education may develop in the future. This is a democratic education that promotes deliberation and the inclusion of groups historically excluded, while building relationships among the state, parents, and children. This is democratic education that unfortunately for many families and children is not currently a reality. 


\section{AKNOWLEDGEMENTS}

With humility and gratefulness, I dedicate this dissertation to my husband, Ian, and my mother-in-law, Hsiu-Mei Lin, offer emotional support and encouragement toward completion of this desired goal.

My heartfelt thanks to my two advisors, Dr. Adriane Williams and Dr. Melissa Sherfinski, for supporting me every step of the way. Thank you, Adriane and Melissa, for inspiration, guidance, insight, and support. I am particularly grateful for Adriane's assistance with the conceptual framework and Melissa's efforts in working with me to edit my writing.

I am very grateful to my committee members, Malayna Bernstein, Maja Holmes, Sharon Hays, Pat Obenauf, and Audra Slocum, for scholarly advice and guidance in helping shape this study.

Though my committee members and advisors had different ideas and positions than I did quite often and there was argument and discussion about the data and findings in this project, all the insights gained from them were incredibly helpful in undertaking and completing this project. 
I would especially like to express my gratitude to the mothers who participated in this study. This work would not have been possible without you. I thank you for your trust, and for sharing your stories with me. 


\section{TABLE OF CONTENTS}

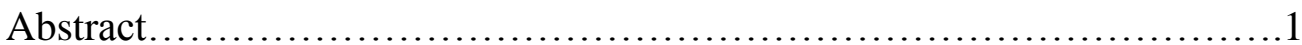

Acknowledge...........................................................

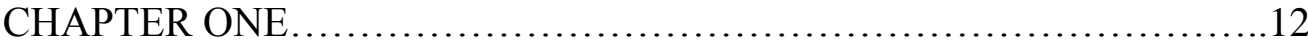

Definitions of Low Income and Working Class............................13

Statement of the Problem............................................15

Research Questions.................................................17

Homeschooling: Background and Context..............................18

Historical Overview of Homeschooling................................19

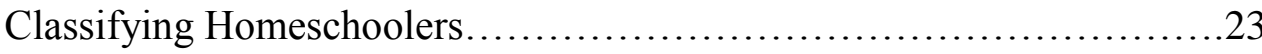

Homeschooling as a Social Movement...............................25

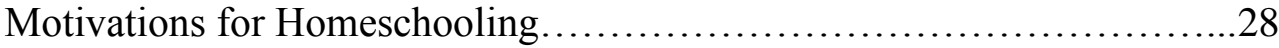

Social Class, the Family, and Homeschooling............................... 32

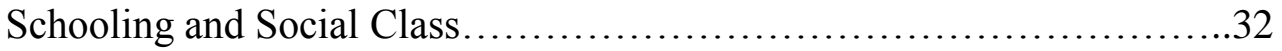

How My Study Addresses the Relevant Literature......................44

Study Significance................................................. 44

CHAPTER TWO: CONCEPTUAL FRAMEWORK .......................46 
The Context of Schooling

Education vs. Schooling

Democratic Participation as a Political Goal

Americanization

Labor as an Economic Goal. . .56

Democratic Education and Attendant Implications. .57

Social Reproduction/ Stratification .61

Factory Model. .64

Dominant Culture/Oppressed Cultures .66

Interactions between Democratic and Market-Based Educational Forms.

No Child Left Behind. .70

School Choice Plans. .72

Problems with NCLB and school choice programs .74

An Evolving Democratic Education. .78

Identity, Pedagogy, and Agency in Homeschooling. .83

CHAPTER THREE: METHODOLOGY .85

Introduction to the Methodology: Qualitative Case Studies... .86 
Emergent Research .87

Research Design....................................................... 88

Research Questions............................................ 89

How the Multiple Case Study Method Fits This Research...............90

Context........................................................92

Participants................................................... 92

Zoe's Demographics........................................94

Renell's Demographics......................................97

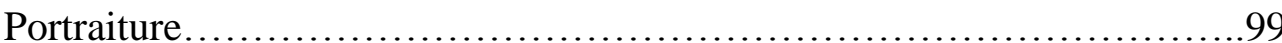

Research Techniques...............................................100

Document Analysis................................................ 102

Observations...................................................... 103

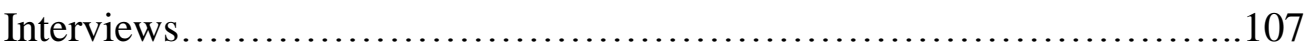

Formal Interviews........................................... 107

Informal Conversations.............................................110

Data Analysis......................................................111

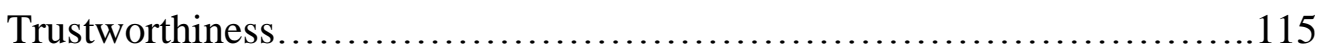

Researcher Identity.............................................117 
A Reflective Account

A Chronology of Our Experiences with the Public School System.

A Vulnerable Observer.

CHAPTER FOUR: ZOE'S STORY 126

Caring. 126

Zoe

Nature as Teacher 130

Acts of Care. .132

Caring and Motivation 134

Limited School Choices 141

Role of Class in Caring. 146

A Low Income Family. 146

Reasons to Discontinue Homeschooling. 148

Caring in the Local Context.

Between Homeschooling and Public School 151

Local Resources for Low Income Families. .156

Roles of Social Networks in Constructing Care 157 
Caring Through Teaching. 159

Homeschooling Environments

Racial Others

Culturally Relevant and Responsive Teaching in Individualism. 165

No Child Left Behind: Anti-Individualism and Anti-Caring. 169

Child Agency. 172

The Father's Role. 175

Discussion. 178

Zoe and Public Schools. 179

Zoe and Dominant Culture 180

Zoe and Neoliberal Ideology 182

Zoe's Capital and Its Use 184

Zoe and Social Class 185

Zoe's Theories 186

Summary. 186

CHAPTER FIVE: RENELL'S STORY 189

Desire .189 
Activism

A Passion for Learning .194

The Context of Educational Choice in Memphis .197

Private School 197

Traditional Public School. 198

Public School Choice Programs .202

Homeschooling .203

Homeschooling Desire 204

Desiring Private School. .204

Desiring Opportunity for a Black Male Student 211

Desiring Cultural and Economic Capital. 214

Networking Desire 216

Culturally Responsive and Relevant Teaching .221

Cultural and Heritage Studies .224

The Husband's Role in Homeschooling. .230

Preparing for Child Agency. .232

Discussion. .233

Renell and Afrocentrism .234 
Renell and Neoliberalism

Renell's Unresolved Contradiction

CHAPTER SIX: CONCLUSION

Overview

Cross-Case Discussion.

Identity, Pedagogy, and Agency. .246

Renell. 248

Zoe .250

Pedagogy, Language, and Cultivation .252

A Test of Democratic Capabilities. .252

Conclusions and Final Reflections. 256

Postscript .259

REFERENCES 263

Appendix A. .294

Appendix B .296

Appendix C 302

Appendix D. . .305 
Appendix E

308

Appendix F

Appendix G.

Appendix H.

Appendix I........................................................... 316

Visual Conceptual Framework......................................... 318 


\section{CHAPTER ONE}

\section{Resilient Journeys: A Case Study of How and Why Low-Income Families Practice Homeschooling}

There were 1.5 million homeschooled students in the United States in 2007 according to data from the National Household Education Surveys Program (NHES, 2007). From 1999 to 2007, the number of homeschooled students in the United States increased from .85 million to 1.5 million, with the number of students growing as much as $15 \%$ to $20 \%$ per year (NHES, 2007). The number of families homeschooling in the US has nearly doubled in the last decade, and has grown at a rate more than twelve times the increase of public school enrollments, and much faster than the growth rate of charter schools as well (Isenberg, 2006).

Homeschooling is becoming increasingly popular in the US, but little research has focused on the phenomenon to date. Almost no research has inquired as to how low-income and/or working-class families practice homeschooling. This is unfortunate, as it seems likely that parents who do not have rich economic resources and formal education may require additional supports to promote strong homeschooling outcomes. In response to this concern, this study examines homeschooling as accomplished by low-income families. Specifically, the study 
examines what low-income and/or working-class homeschoolers are like, why low-income and/or working-class parents turn away from brick-and-mortar schooling, and how they implement homeschooling practices.

This chapter consists of three parts. This first part presents the definition of low-income and/or working-class in this study, the statement of the problem, and the research questions. The second part provides an introduction to homeschooling history, traditional classifications of homeschoolers, homeschooling as a social movement, and parents' motivations for homeschooling. The third part introduces pertinent perspectives regarding homeschooling, including researchers' views on schooling and social classes, and roles of families in educational outcomes.

\section{Definitions of Low Income and Working Class}

According to Marx and Engels (1848), the notion of "class" was established by dividing people into two classes: one did the wage labor to produce goods and the other owned the production facilities and profits. Marx and Engels emphasized the power of one class over the other and went on to explain that unequal power resulted in conflicts between the two classes.

That notion of class has been extended and complicated by Warner, Meeker, and Eells (1949), who conceptualized multiple socioeconomic status levels. 
Socioeconomic class" is terminology used to group people whose social interests are situated in similar levels of wealth, occupation, social prestige, and cultural identity (Hannerz, 1992; McDermott, 1995; Ensminger \& Fothergill, 2003). Although it is difficult to establish principles to sort individuals into socioeconomic classes, the most common way to designate class is by income bracket. The "working class" is usually associated with manual labor and limited educational attainment (Hauser \& Huang, 1997; Ensminger \& Fothergill, 2003).

In this study, the perception of lower income and working class is defined by participants' self-identification. Identity is a dynamically ongoing process that individuals engage in. Individuals self-assess and take actions based on those perceptions and evaluations (Schvaneveldt, 1973; Rapp, 1992; Roschelle, 1997; Kiter Edwards, 2004). Historical circumstances, social context and conditions, and cultural ideology shape individual interactions constructing their realities and forming their cultural identifications (Blumer, 1969; Kiter Edwards, 2004).

The participants in this study represented themselves within the boundaries created by their social and cultural contexts. Individual participants' accounts, therefore, reflect the broader definitions of lower income and/or working class. To 
avoid repetitions and confusion of terminology, I will use the term "low-income" as I discuss lower-income and/or working-class individuals in the following chapters.

\section{Statement of the Problem}

Educating one's children at home is a significant individual choice (Davis, 2005; Morton, 2010). The definition of choice includes personal freedom and abundance of opportunities (Henig, 1995; Davis, 2012; Morton, 2010). The decision for homeschooling presents a choice constituted in the context of family life (Davis, 2012). Starting in the 1990s, researchers using national surveys, such as National Household Education Survey (NHES) (Bauman, 2002) and the National Center for Education Statistics (NCES) have regularly updated demographic information about the homeschooling population. Using data from the 2003 NHES survey, the most recent study by Princiotta and Bielick (2006) showed that homeschooled children were most likely to be White, reside in two-parent families, have parents whose highest educational attainment was a bachelor's degree or higher, and have annual household incomes of less than $\$ 75,000$. According to NCES, educating children at home in the US has been most often a middle-class phenomenon.

Homeschooling parents typically want their children to attend college (Cogan, 2010). In terms of their academic and economic status, homeschooling parents are often 
discerning enough to choose homeschooling, as they typically have solid educational attainment and above average income levels (Cogan, 2010; Saunders, 2010).

In order to homeschool their children, typically at least one of the parents must possess the ability to remain at home throughout the day to teach and supervise the children (Bauman, 2005). Although any adult family member may do the teaching, it is usually the mother who holds the primary responsibility to homeschool children (Apple, 2006). As a result, the feasibility of homeschooling has been presented in the literature as being tied to financial, educational, and temporal resources. On the other hand, the homeschooling movement has been influenced by a surprisingly broad and sometimes diverse spectrum of religious, social and intellectual groups (Stevens, 2001). Homeschooling is becoming more diverse. A variety of subgroups are emerging with different goals that range from maintaining minority identities to meeting special educational needs (Kunzman, 2009). Despite the fact that homeschooling logistics may be much more difficult for low-income families than for wealthier ones, the broad range of homeschoolers' socioeconomic statuses includes poor and rich, as well as urban and rural (NHES, 2007). However, there are relatively few single, working-class and low-income homeschooling parents (Kunzman, 2009). Nonetheless, for many families who may lack material resources, local circumstances may be 
challenging enough to push them to homeschool. Indeed, the fastest-growing groups of homeschoolers are now African Americans and Muslims, two groups that historically have been marginalized in the US (Apple, 2006).

A few studies have examined homeschooling practices among

African-Americans, Latina/os, and Caucasian Appalachians by rendering insights into their beliefs, concerns and desires for their children's education (Kunzman, 2009; Llewellyn, 1996; Rao, 2012). None mention experiences of how families practice homeschooling based on their finances, how parenting styles influence the way that parents homeschool, or their expectations for their children's outcomes, however. These studies begin the conversation about minority and low income homeschooling, but there are still miles to go towards understanding the context fully.

The purpose of this study is to address the gap in the literature that had thus far provided little information regarding the homeschooling practices of low income families. This study aims to reveal the difficulties low income homeschooling parents encountered, the strategies they used, and the resilience they demonstrated.

\section{Research Questions}

Given the goals for the study outlined thus far, the following set of research questions are designed to support the inquiry. 
Primary question: How and why do low-income families decide to homeschool their child(ren)?

The primary question suggests the following attendant questions:

1. How and why do local contexts of educational choice shape low-income homeschoolers' experiences?

a. How do local public school experiences shape homeschooling experiences, motivations, and practices?

b. How do low-income homeschooling families' experiences confirm, discredit, and complicate established theories of low-income families' educational experiences, motivations, and practices?

2. How do low-income homeschooling families manage homeschooling?

a. How do families network and negotiate homeschooling in local contexts?

\section{Homeschooling: Background and Context}

The following section will present a homeschooling history, briefly introducing its historical trajectory. The section then shifts to an exploration of contemporary contexts. It presents the more recent story of how US homeschoolers fought for the right to homeschool in the 1970s-1990s. This is important to relay, 
given the focus in this project on understanding the contextual factors that have produced—and still produce—-families' motivations for homeschooling.

\section{Historical Overview of Homeschooling}

Homeschooling has a long heritage, beginning in the seventeenth and eighteenth centuries in Europe and North America (Gaither, 2008). Children from the upper classes were educated at home either by parents or by tutors. The beginning of public schooling in the mid-nineteenth century altered perceptions about informal and home-based education in that early forms of formal education sought to unite immigrant Americans in the pursuit of a national identity (Knowles, Marlow \& Muchmore, 1992).

According to Gaither (2008), a homeschooling resurgence began in the 1970s, spurred by a number of contextual factors and forces. Due to the social and political changes during the second half of the twentieth century, anti-institutionalism resulted in the rise of the small community and quest for self-fulfillment on both the political right and political left. Segments of the right and segments of the left rejected public schools and Christian schools. Meanwhile, suburbanization led to segregation caused by the effects of class, race, cultural styles, etc. But suburbanization also offered privacy and the space for homeschooling. The media exposed the "risks" of the times. These were inflammatory stories regarding the context of education in the public schools, and 
included sexual harassment by teachers and occult brainwashing. In this way, the media fortified the notion that home was a safe shelter to in which to nourish children. As many conservatives and libertarians saw it, alienation between schools and families resulted from more bureaucratic systems, which were less responsive to parents and less adaptable to individuals in schooling. Many conservatives and free-thinkers believed that the institutionalization of public schooling damaged children's minds. During the 1960s and 1970s, the debates over control of what children would learn manifested in two visible formats: homeschooling and the establishment of strongly biblical Christian schools (Carper, 2000; Gaither, 2008).

Hostility towards individualism was heightened when fundamentalist parents began to teach their children in homeschools (Arons, 1986; Kirschner, 1991). In response, homeschooling advocates inferred that local public school bureaucrats acted as though a few homeschooling families were a major threat to public education and the survival of democracy (Arons, 1986; Angelis, 1998). School officials oftentimes expressed the fear that homeschooling neither promoted American pluralism nor prepared children for academic or work preparation (Angelis, 1998; Gaither, 2008). Moreover, the battle between state and private regulation of Christian schools produced 
a heated debate. The conflict became a symbolic struggle over a binary: the creation of public orthodoxy versus the preservation of individual idiosyncrasy (Angelis, 1998).

Questions about the legitimacy of homeschooling loomed in the early 1970s. A number of states and the Supreme Court decisions regarding the issue of parental rights to homeschool emerged rapidly (Arons, 1986; Gaither, 2008). It was an era of judicial rulings that challenged homeschooling.

But not every case of conflict with a school district resulted in a lawsuit (Gaither, 2008). Usually, middle-class, White parents had the capital to negotiate with school authorities, had access to attorneys, and were able to choose homeschooling for their children (Gaither, 2008). Clearly, lawsuits were not tools used by all families seeking to homeschool early on. For example, in 1978, a White, middle-class mother from Cape Cod, Massachusetts named Elaine Mahoney received permission from her local school district to homeschool (Gaither, 2008). She used savvy negotiation with local officials to obtain access to homeschooling. First, she tried to build a bridge of understanding between herself and the local school officials. Then, she presented her home education plan to the school committee members. The committee, in turn, was impressed and allowed Mrs. Mahoney permission to homeschool. From the example of Mrs. Mahoney, we can see that parents who knew how to work with school 
administrators in the educational system likely had better opportunities to homeschool during that period than parents who did not. Historically, many homeschoolers developed good communication with school officials, demonstrated concrete homeschooling plans, and won the right to homeschool.

Homeschooling was still a marginal phenomenon in the 1970s.

Homeschooling occasionally was discussed in publications by homeschoolers, such as The Home Education of a Boy by a homeschooling father, William Barrett, and $A$ Mother's Letters to a Schoolmaster by Rita Sherman, but it was still an outlying topic (Gaither, 2008).

The practice has gained legal ground over the past three decades and has gradually become more accepted by the public. Media coverage played an important role in public acceptance regarding homeschooling (Gaither, 2008; Stevens, 2001). When homeschooling received media exposure, the public started paying attention and wanted to learn more about the phenomenon (Stevens, 2001).

The contentious relationship between homeschoolers and school officials has changed over time (Angelis, 1998; Gaither, 2008). Most litigation proceedings were initiated by school officials, but they lost more cases than they won (Angelis, 1998; Gaither, 2008). Litigation was costly for school boards, and even when they won, they 
received little in return (Angelis, 1998; Gaither, 2008). Once homeschooling became less taboo, lawsuits regarding access to homeschooling abated.

Current research on homeschooling shows that teaching one's children at home has been practiced legally in all 50 of the United States since 1993 (Ray, 1997, 2002). The laws relevant to homeschooling differ throughout the country. In some states, the parent simply needs to notify the state that the child will be educated at home. In other states, the parents are not free to educate at home, unless at least one parent is a certified teacher, and yearly progress reports are reviewed by the state.

The next section examines what the literature has concluded thus far regarding the motivations of parents for homeschooling.

\section{Classifying Homeschoolers}

Van Galen (1986) divided homeschooling parents into two categories:

Ideologues and Pedagogues. Van Galen (1986) described Ideologues as those parents, largely conservative Christian in their religious beliefs, who "object to what they believe is being taught in public and private schools and seek to strengthen their relationship with their children" (p. 23). In contrast, Pedagogues believe that "schools teach whatever they teach ineptly" (p. 24) and that, based on their respect for their children's intelligence and creativity, "children learn best when pedagogy taps into the 
child's innate desire to learn" (p. 55). But, Van Galen's terminology cannot draw a distinct line among religious parents and parents seeking freedom from rigid pedagogies (Gaither, 2008; Stevens, 2001). Both groups used an array of pedagogies in homeschooling and also obviously invoked various ideologies (Gaither, 2008). Stevens (2001), a sociologist and author of Kingdom of Children: Culture and Controversy in the Homeschooling Movement, used the term "believers" to refer to conservative Protestants and the term "inclusives" to refer to other homeschoolers in his book. As I believe that this is a useful division, I will explain a bit more about Stevens' conception.

Conservative Protestant believers see people as both good and bad, needing authority to point them in the right direction (Gaither, 2008; Stevens, 2001). Moore (1986), a leader in the early evangelical homeschooling movement, argued that children were not autonomous beings. Instead, children needed appropriate authority to instruct them (Gaither, 2008). In this way of thinking, parents are positioned to guide their children's lives under God's influences, while schools cannot offer a godly environment (Gaither, 2008; Moore \& Moore, 1986). In these homes, homeschooling relations and pedagogy is hierarchical, with the parents determining the curriculum and guiding the learning process. Compared to child-centered methods, there is relatively less room for children's agency. 
Inclusives generally believe that people are good and do not make good decisions until they are interested (Gaither, 2008; Stevens, 2001). They perceive that individuals are autonomous and will choose the right direction on their own (Stevens, 2001). Holt, a famous homeschooling advocate associated with this camp, promoted children's rights to self-determination (Gaither, 2008; Knowles, Marlow, \& Muchmore, 1992; Stevens, 2001). According to this view, schools typically operate in a bureaucratic mode and are unable to motivate children (Stevens, 2001). In contrast, the concepts of individual autonomy and self-motivation prevail in the inclusives' homeschooling philosophies as they endeavor to resist government schooling.

Opposing institutional schooling based on their different ideologies and pedagogies is one common characteristic of believers and inclusives. John Holt (an early homeschooling leader associated with the inclusives) and Raymond Moore (a homeschooling leader associated with the believers) have had similar ideas about the parent-child relationship, and both have encouraged parents to pull their children out of public schools (Gaither, 2008; Knowles et al., 1992). Moreover, both of these leaders developed complementary frameworks explaining the benefits of homeschooling, which supported the fledgling homeschooling movement early on (Gaither, 2008; Knowles et al., 1992). The following section presents how the believers and the 
inclusives organized their networks and how their approaches were defined as social movements.

\section{Homeschooling as a Social Movement}

Social movements occur when people are dissatisfied with a situation or social policy, seek alternatives, and ultimately select one that they feel is for the better (Bates, 1991; Collom \& Douglas, 2005; Lyman, 2000; Stevens, 2001). According to Sexson (1988), homeschooling qualifies as a social movement based on five key factors identified in Gerlach and Hine's (1970) definition: organization, ideology, recruitment, commitment, and opposition. Organizational units linked by various personal, organizational, and ideological ties are characteristic of many homeschooling families.

When people have common interests, they gather together to form an organization (Stevens, 2001). That is how homeschoolers have mobilized and formed their support organizations. Gender has played an interesting role in homeschooling organizations. Generally, mothers have been positioned to educate and support homeschooling politics from within the home, while fathers have taken the lead in the organizations (Kintz, 1997; Wilcox \& Robison, 2011). Phyllis Schlafly, a well-educated homeschooler and advocate for the traditional Christian family, has been a rare, visible female leader

(Gaither, 2008). 
Ideology, as a conceptual framework, supports homeschooling movements. The recruitment of friends through existing social networks has been common in the homeschooling arena (Gaither, 2008). The phone line for homeschooling inquiries at Illinois Christian Home Educators exemplifies the element of recruitment. Callers (typically prospective homeschoolers) obtain detailed information packets about homeschooling and this organization, such as a list of curriculum supplies, a copy of The Teaching Home (a conservative homeschooling magazine), and also a membership application to the Home School Legal Defense Association (HSLDA) - the major legal organization supporting homeschoolers in the US. A phone call can connect the inquirer to the web of homeschooling.

Finally, opposition to the established order leads toward separation and determination in the pursuit of goals (Gerlach \& Hine, 1970). For Holt (an inclusive) and Moore (a believer), schools have devalued children's individualism and functioned like factories, ultimately not meeting children's needs (Gaither, 2008; Knowles et al., 1992). Following Holt and Moore, homeschooling supporters may typically oppose institutionalized education for young children.

By the mid-1980s, believers and inclusives formed networks of support groups to offer assistance to fellow homeschoolers around the US. These organizations were 
born to support and propagate the parental right to homeschool (Gaither, 2008;

Knowles et al., 1992). The now defunct National Homeschool Association (NHA)

consisted of the wide spectrum of homeschoolers (rather than only conservative

religious homeschoolers) and presented itself as a highly democratic organization. For

example, the NHA bylaws stipulated that decisions must be made by consensus instead of majority vote. Since the constituents of the NHA consisted of diverse demographics, this form led to struggles in slow decision-making and organizational functions (Gaither, 2008). NHA was disbanded in 2000. Then, the American Homeschool Association (AHA), which functions like a predecessor of NHA, was started to mainly represent the inclusive group. AHA has not been as influential and well-functioning as the Home School Legal Defense Association (HSLDA), whose leadership consisted of believers. The HSLDA has become a powerful agency in politics, influencing homeschooling regulations and cases. Unlike NHA or AHA, HSLDA's efficient systems have maintained members' commitments and have formed strong networks among members. HSLDA's effective strategy in marketing has drawn public attention as well (Gaither, 2008).

In addition, the homeschooling movement is an integrated network of diverse constituents coming together to form a coalition to achieve a common goal (Gaither, 
2008; Stevens, 2001). The common goal of directing the education of their children, instilling religious and family values, and establishing close, positive familial relationships drives homeschooling families to the continuance and expansion of this alternative, educational social movement. As homeschooling organizations have grown bigger and the media frequently has featured positive homeschooling issues and practices, homeschooling as a social movement has flourished across the US.

\section{Motivations for Homeschooling}

According to The National Center for Education Statistics (NCES), parents have mentioned a number of different reasons for homeschooling their children. In 2007, the number one reason for homeschooling was a desire to provide religious or moral instruction (noted by $36 \%$ of respondents). This reason was followed by a concern about the school environment (such as safety, drugs, or negative peer pressure) (21\%), dissatisfaction with academic instruction (17\%), and "other reasons," including family time, finances, travel, and distance (14\%). The following section presents details of those motivations of homeschooling.

Some conservative parents worried about school textbooks and courses that might "contaminate" children's minds and challenge their religious beliefs. Whether or not there was a good basis for these anxieties, sex education, life adjustment, witchcraft, 
and evolution were several reasons that provoked fear in some religious parents

(Gaither, 2008; Kunzman, 2007). In addition, these parents were dissatisfied with the curriculum in the public schools and wanted to teach their children specifically religious values instead (Gaither, 2008; Green \& Hoover-Dempsey, 2007; Kunzman, 2009; Stevens, 2001).

On the other hand, a number of very liberal parents worried about pedagogy in schools. Although their views may not have been completely representative and may not have acknowledged the resource constraints that public schools endured nor the potential of the schools, this group of parents believed that conventional classrooms made learning a chore or even boring, filled with inflexible curricula and inappropriate discipline, or even incapable teachers (Holt, 1982; Stevens, 2001). Some parents were not satisfied with the teaching styles, finding them unsuitable for their children. Since a classroom teacher in some settings had to take care of many students, they usually did not use child-centered teaching, but rather military-like teaching (Rambusch, 2010; Tzuo, 2007). This factor, these parents believed, led to their children's schooling problems. Many parents have not seen rigid teaching styles as complementing and supporting their children's learning styles. Therefore, their children often have been 
homeschooled after their children failed to fit into the school environment (Anthony \& Burroughs, 2010; Stevens, 2001).

Another group that has felt a mismatch between their children's needs and what the schools could provide is African-American parents. These parents have often reported that teachers and administrators frequently have lower academic expectations for their children than they do for White children (Alridge, 2003; Fields-Smith \& Williams, 2009; McDowell, Sanchez, \& Jones, 2000). In addition, the curricula in many public schools has undervalued African-American culture (Alridge, 2003; Fields-Smith \& Williams, 2009; Llewellyn, 1996). Those two factors have likely contributed to the rise of the homeschooling phenomenon among African-American families.

Two recently completed resources have shed light on the roles of religion in non-Christian and non-White homeschooling. First, a recent New York Times article by MacFarquhar (2012) entitled, "Resolute or Fearful, Many Muslims Turn to Homeschooling," sheds light on the lives of Muslim homeschoolers in Lodi, California. These homeschoolers have attempted to conserve Muslim culture while shielding their children from school climate issues such as drugs and bullying. Second, a dissertation, "Taiwanese homeschooling families in the USA" (Tsai, 2010) detailed 
the lives of Taiwanese immigrant homeschooling families in the Southwestern US.

The Taiwanese parents' reasons for homeschooling included instructional self-efficacy, their colleagues' or relatives' urging, religious guidance and support, teaching style implementation, and their children's academic levels. Religion was an important factor for homeschooling in the Muslim families and Taiwanese families discussed.

Finally, some parents have been concerned about the negative peer interactions in public schools (Rosin, 2007; Princiotta, Bielick, \& Chapman, 2008). They may have heard of violent incidents and drug use in schools. While impoverished neighborhoods - and in fact all neighborhoods and all homes - experience some degree of problems, sometimes parents see the schools as the root cause of social ills. In an attempt to promote safety for their children and to prevent their children from becoming involved in gangs, parents have increasingly withdrawn their children from public schools to homeschool them (Basham, Merrifield, \& Hepburn, 2007; Princiotta, et al., 2008).

Social Class, the Family, and Homeschooling 
In this section, I will discuss various perspectives that illustrate the relationships between schooling and social class. These perspectives play influential roles in how parents make decisions regarding homeschooling involvement.

\section{Schooling and Social Class}

Education is a major source of human progress, a structure that can promote moral commitment and cognitive development that can serve to improve society (Walters, 2007). The agreement and common bonds among members of society, taught and reinforced in schools through socialization and shared norms, unites groups as they work toward common goals and keep groups from disintegrating (Lareau \& Weininger, 2003).

On the other hand, education also shapes people to fit into a way of life and a particular position in society. Educational institutions have become increasingly important in training people for new roles in society. Pierre Bourdieu's (1973, 1977, 1984) cultural and social reproduction theory asserted that the process of schooling is a means to maintaining hierarchical positioning among the social classes. Schools facilitate class domination and strongly influence the distribution of dominant values (Ballantine \& Hammack, 2009). In this context, classroom experience and school knowledge are bound to benefit those who are middle and upper class (Lareau, 2000). 
However, new work from educational sociology has emphasized poor and working class families' agency that they have engaged both in and outside of brick and mortar schools. In this section, I first review old ways of thinking about educational opportunities for the working class, and then move on to describe new models that emphasize parents' assets and self-determination towards their children's educations.

Historically, it has been noted that school curricula and classroom procedures reflect the institution of class-differentiated skills and experiences and transfer those characteristics to subsequent generations (Bourdieu, 1973). According to Bourdieu's cultural and social reproduction theory, school is a place to reproduce social class for generations through education and is a means both for securing for every person as much as possible of what the individual wants and for minimizing the injustices caused by social inequities in its original purpose. Bowles and Gintis' (1976) book, Schooling in Capitalist America, also provided an analysis of schooling that corresponds to Bourdieu's theory. They proposed that the dominant class creates and maintains a schooling system that secures students from the privileged classes to succeed while preventing low-income students from reaching successful paths.

Meanwhile, Bourdieu's theory explained how parents from various social classes influence children's decision-making capacities. He noted that capital takes time 
to accumulate, and that the distribution of capital is reflective of the social world. There are different forms of capital: cultural, social, and economic. Cultural capital can be described as the background, skills, and knowledge passed from one generation to the next generation based on social class. Certain kinds of cultural capital prove to be more valuable than others depending on the social context (Bourdieu \& Passeron, 1977). Social capital is the aggregate of the actual or potential resources which are linked to the possession of a durable network of a "membership in a group" (Bourdieu, 1973). Social capital provides its members with the backing of the collectivity-owned capital, a "credential" which entitles them to credit in the word. All capitals link back to economic capital, rooted in socioeconomic status.

From different forms of capitals, Bourdieu discussed how the social structure of domination is perpetuated through the transmission of cultural capital among the social classes (Bourdieu, 1984). Cultural reproduction is the transmission of obtainable cultural values and norms from generation to generation (Bourdieu, 1973). Cultural reproduction requires continuity in cultural experiences across time (Bourdieu \& Passeron, 1977). Typically, cultural reproduction leads to the process of transferring facets of society, such as class, from generation to generation (Lareau \& Horvat, 1999). Some groups with privilege take actions to reproduce the current social structure to 
maintain their advantages (Bourdieu, 1984). According to this theory, the different actions which are carried out by families from various social classes are practiced within society to transfer a cultural advantage or disadvantage so that the distinct outcomes occur based on cultural contribution among these classes.

According to this view, parents of different social classes often have different child-rearing styles (Lareau, \& Horvat, 1999). If upper- and middle-class parents have jobs where they are expected to collaborate with fellow employees or create new solutions to problems, they are more likely to talk to their children in open-ended ways that differ from how parents address children if their own jobs simply require following orders (Lareau \& Horvat, 1999). Children raised by middle-class parents will, on average, have more inquisitive attitudes toward academic material than children raised by low-income parents (Lareau \& Horvat, 1999).

In this framework, how parents acted in the home to raise their children has a large effect on how children interact in social institutions. According to this literature, parents also influence their children's academic performance in school (Feinstein, Duckworth, \& Sabates, 2008). Parents from the middle and upper classes often practice rigorous cultivation and endeavor to enrich their children's lives by filling their schedules with organized activities (Lareau, 2000; Feinstein et al., 2008). Due to the extent of their 
interactions outside of the home and their academic capabilities for nurturing in the home, middle-class children overall often develop a greater mastery of standard language and are instilled with a sense of entitlement, both of which allow them to comfortably interact with institutions (Lareau, 2000; Feinstein et al., 2008). Essentially, the practice of educational learning tactics among the upper and middle classes is highly instrumental as they seek to maintain — and grow—-their social class status.

On the other hand, Bourdieuian theorists have argued that many low-income parents practice the accomplishment of natural growth, where children have more control over their free time and are exposed to fewer interactions with adults outside of the home (Lareau, \& Horvat, 1999; Lareau, 2000). The practice of learning in working-class and low-income homes, according to this literature, is less strategic. Low-income children often do not play formalized learning games. They are often either passive or exclude themselves from interactions in classroom settings (Lareau \& Horvat, 1999). In other words, they are deficient in the eyes of dominant society.

The knowledge presented in schools favors students from at least the middle class, because it is part of the "game" of the status quo reproduction of social classes (Bourdieu, 1984). Children from backgrounds where their languages and cultures do 
not correspond to that of schooling may be disadvantaged. They usually feel alienated and disengaged in learning.

The deficit perspective has carried over to analyses of relationships among parents of various social classes in competition for the best education within the schools. And competition for resources has intensified as the class structure has shifted recently due to economic constraints. America has both become vastly richer and vastly more unequal in recent decades (Bartel, 2008, Kelly, 2009). The share of total income going to the top one percent of income-earners has tripled and the income growth rate is now stagant or has even declined amongst middle and low income families (Bee, 2012; Kelly, 2009).

Meanwhile, the relationship between educational attainment and economic rewards is now less evident in the US. Highly educated individuals are disproportionately represented among different income levels (Bartels, 2008; Dewan, \& Gebeloff, 2012; Zwing, 2004). Given the growing lack of continuity between high educational status and income, it is important to consider the effects of not only economic capital, but the interrelationship between economic and cultural capitals when considering how they affect parents' agency regarding their children's futures. 
The ample literature pertinent to the relationship between parental education and children's achievement consistently has demonstrated that the more education parents have, the more academic success their children will have (Duncan \& Murnane, 2011; Feinstein et al., 2008). This literature has contributed to positioning poor, working class, and minority families as deficient. This literature on family processes posits three categories of family-level influences on child development. These categories are proximal family process, distal family factors, and internal features of the family environment (Feinstein et al., 2008).

Proximal processes, which are processes that have a direct effect on children's outcomes, are interactions between individuals. In the family and in the context of education, parenting styles and language use are treated as important proximal processes. According to this literature, language use in the upper and middle classes has a profound impact on children's academic performance (Lareau, 2003). Children from higher social classes tend to have higher academic performance than their counterparts from lower social classes (Lareau, 2000).

Distal factors are social, economic, and demographic features of the environment that are more remote from actual interaction, but that influence interaction (Feinstein et al., 2008; Zeisler, 2012). These distal factors include family background 
measures, such as parents' occupation and income (Feinstein et al., 2008). These factors indicate that, generally, the higher the parent's educational credentials, the more income they make, and the more social resources children obtain (Feinstein et al., 2008; Zeisler, 2012). Again, this line of reasoning positions poor, working class, and many minority families as lacking.

The internal environment of the home features parental cognition, parental mental health, well-being, and material resources (Duncan \& Murnane, 2011; Feinstein et al., 2008). These factors imply that parents with stable mental health can raise children with sound mental development (Feinstein et al., 2008). An important element in this category is self-efficacy; when parents feel that they can be there and have a positive impact on their children's educational outcomes, the children will perform better. This literature necessarily couples good mental functioning with one's class position, a view that seems quite narrow, and thus problematic.

According to this body of literature, parents' education has a direct effect on children's outcomes. Based on the three categories of family-level influences on child development, families with higher economic and educational resources are better able to have a positive influence on their children's academic performance (Duncan 
\& Murnane, 2011; Feinstein et al., 2008). This literature positions parents who do not have high levels of education as deficient parents.

In an educational policy context that positions parents to act "accountably" as tutors who are ultimately responsible for their children's success, children usually are more likely to achieve greater academic success if their parents have higher educational attainment (Lareau, 2003; Feinstein et al., 2008; Zeisler, 2012). By contrast, low-income parents are not as able to help their children succeed academically. In the early literature on culture, class, and achievement, sociologists noted that compared to their counterparts from the upper and middle classes, low-income parents prefer and desire to leave the job of teaching to teachers (Lareau, 2003). Parents and children with low incomes were said to feel a sense of constraint that left them confused regarding how to "work the system" and often caused them to become hostile towards schooling (Lareau \& Horvat, 1999).

Because, according to this literature, low-income parents are uncomfortable around the school system, they are less likely to communicate with their child's teacher or become involved in the school (Lareau \& Horvat, 1999; Lareau, 2003). Some honor the preparation and experience of the classroom teacher and may not believe that it is their role to help with academics (Lareau, 2000). Another view is that low-income 
parents want to help with homework, but may become frustrated by the difficulty of assignments. According to this research, while low income parents value education as an important path toward success, these parents' restricted academic ability may result in their dependence on teachers' professionalism (Lareau \& Horvat, 1999; Lareau, 2003). This shows how upper- and middle- class parents are positioned to contribute to unfair advantage over other parents by supplementing the schools, while low-income families instead, according to this literature, may need to rely more on teacher expertise to manage their children's learning.

More recently, educational researchers focusing on cultural strengths have designed frameworks that dialogically connect homes and schools in ways that inform a mutually constructive flow of ideas, one that provides a space for the self-determination of minority and poor and working class families. The instructional model called funds of knowledge (Moll, Amanti \& Gonzalez, 2005) has demonstrated that classroom instruction and curriculum can be developed to fit into low-income or minority students' needs if teachers glean and apply knowledge of family strengths to their classroom practices. In this framework, teachers view students as competent individuals and have elevated their expectations for students' abilities. According to Moll et al. (2005), "funds of knowledge" refers to the "historically accumulated and 
culturally developed bodies of knowledge and skills essential for household or individual functioning and well-being" (p. 133). When teachers take on a new role as learner, they realize how funds of knowledge operate in families' and students' daily lives. With the rich cultural and cognitive resources embedded in students' families, teachers link and adjust classroom lessons to students' funds of knowledge. When school teachers and administrators begin to value different cultures possessed of rich resources and connect classroom practices to students' funds of knowledge, minority, poor, and working class students flourish.

Incorporating a funds of knowledge framework in the classroom is dependent upon the teacher not viewing teaching as "an agenda to cover" (González et al., 2005, p. 103). Instead, cultural resources from families can be used to develop creative programs which both encompass family cultures and integrate academic subject matter in school settings (Kiyama, 2011). Cultural integrity is a critical element within the funds of knowledge framework. This implies that traditional schooling is not the sole process of passing on information and knowledge, but that a reciprocal process of identity construction between learners and instructors is also important (Moll et al., 2005; Tierney \& Jun, 2001). 
Overall, the work on social class and capital theory that I have outlined in this chapter shows how, in the past, researchers and theorists have viewed poor and working-class parents' abilities to transmit productive class-based knowledge, values, and habits to their children as lacking. In the future, the relations between home and school may shift so that home-based capital is valued, and traditional patterns of social and cultural reproduction favoring the status quo may change as well. Unfortunately, valuing home-based capital of poor and working-class families still remains a rare occurrence in US schools. In order to counter views that position poor, working class, and minority families as less than capable, a growing amount of scholarship has contextualized the hardships and structural constraints that minority parents have confronted (Diamond \& Gomez, 2004; Koonce \& Harper, 2005; Lewis \& Forman, 2002). These studies have shown that school-based educators' deficit-based views of African American and other minority mothers from educators can lead to biased and discriminatory perceptions of these mothers and their families in school systems (Cooper, 2003, 2007; Thompson, 2003). Meanwhile, researchers have found that educators typically do not welcome, or expect power sharing practices with families who are low-income and of color (Abrams \& Gibbs, 2007; De Gaetano, 2007; Noguera, 2001). Moreover, low income parents who have challenged the status quo to protect 
educational equity have been described as "bad" parents ( Abrams \& Gibbs, 2007;

Lewis \& Forman, 2002). Scholars such as Lareau and Bourdieu might predict that low income families would be able to put forth very little agency towards education. But, indeed, the absence of dialogic relations between home and school (an absence structured by resource constraints as well as systemic classism and racism) has sometimes served to push these families who have often been characterized as having little agency to become even more self-determining. While Lareau and Bourdieu would likely not predict it, more and more poor and working class minority families have turned to homeschooling (Fields-Smith \& Williams, 2009). These parents, recognizing their own funds of knowledge, are now constructing their own take on democratic education through homeschooling as an intense form of self-determination, as I will explain in Chapter Two.

\section{How My Study Addresses the Relevant Literature}

I wish to examine the strengths, or funds of knowledge, that low income families bring to the table as they step outside the box of institutional schooling and engage with what I see as a radical democratic project of self-determination though homeschooling. 
Pursuing a deeper understanding of how low-income homeschoolers address their financial strain and the alternatives they choose to deal with is a valuable inquiry and contribution to homeschooling research. Specifically, I will explore how low-income homeschoolers make meaningful connections between learning and real-life situations, how they integrate information, and how they develop social networks to support their project of homeschooling.

\section{Study Significance}

Studies of low-income, homeschooling parents are rare, although Fields-Smith \& Williams (2009) and Kunzman (2009) have provided some limited data in this vein. Many day-to-day issues, such as how low-income parents find the time and divide the labor required to educate their children, as well as how they implement homeschooling practices with restrained resources, have not yet been addressed.

My proposed dissertation study aims to fill this gap in the literature. I will explore why and how low-income families homeschool their children. My study will explore the pedagogical choices and experiences of low-income homeschooling families, and will examine the kinds of interactions the families have had with their local public school systems. Further, the study will examine the information and resources obtained from official homeschooling administrators (county or public school 
district bureaucrats responsible for providing parents with information and guidance around their rights and responsibilities as homeschoolers) in order to show the local contexts of support for low-income homeschoolers. 


\section{CHAPTER TWO: CONCEPTUAL FRAMEWORK}

As I have stated in the introduction to this project, low-income parents have

been unjustly positioned in a double-bind. They have cultural resources and want their children to have good educations and lives. Unfortunately, the socio-political, economic, and historical conditions of schooling have often not recognized the assets that low-income families possess. Homeschooling, while often an educational form used by the middle and upper-middle classes, has increasingly been used by low-income families in a way that shows their strong self-determination towards attaining good education for their children in line with their values, culture, and expectations. In this chapter, I link low-income and minority families' project of self-determination through homeschooling to current conceptions of democratic education. In so doing, I argue that low-income homeschooling can provide a safe space from which a democratic education for low-income and minority families that is self-determined, culturally rooted, community based—and that reconceptualizes power among traditional state-parent-child linkages_ can take hold and spread.

This chapter examines the historical goals of schooling as related to current conceptions of homeschooling in a democratic society. Democratic education is then addressed to present how conceptions of democratic education are practiced in public 
schools and how current practices place groups at a disadvantage in the context of No

Child Left Behind (NCLB) and market-based policies. Within the context of democratic education, the groups who have been pushed out of this zone are discussed.

The contours of the interactions around the right to parental choices in education, informed by critical and socio-historical understandings, shape the conceptual framework of this study. Figure 1 serves as a visual tool to enable readers to visualize the conceptual framework of this study.

\section{The Context of Schooling}

Within the political, social and economic contexts of schooling, I will discuss four prominent discourses that have influenced how we view the role of homeschooling. These discourses are: (a) democratic participation, (b) "Americanization," (c) maintaining the social structures of society, and (d) promoting labor. I begin this discussion by first considering the meanings and purposes of education and schooling in the United States.

\section{Education vs. Schooling}

According to Webster, the word "education" (from the Latin, educere) means "the act or process of imparting or acquiring general knowledge, developing the powers of reasoning and judgment, and generally of preparing oneself or others intellectually 
for mature life." Thus, it should be clear that education does not necessarily mean schooling. In ancient times, education was thought to be accomplished by the whole range of experiences a human being goes through during his/her life time (Aries, 1962). So, for many centuries the story of education has been the story of humankind developing potentialities for life. From this definition, children learn by experience, by practice, and by imitating adults (Aries, 1962). During a very long period of history, no separation was established between life and education, or between places for dwelling and places for educating.

John Dewey (1916) stated that education is the means of the "social continuity of life" (p. 3) in the opening chapter of his classic work, Democracy and Education. Education is the process of exploring ways of thinking, believing and expressing one's self. Individuals can obtain a piece of knowledge when they interact with others and accumulate experiences to acquire new knowledge. In Gatto's (2002) book, Dumbing Us Down: The Hidden Curriculum of Compulsory Schooling, Gatto (a former, award-winning teacher in New York City) vividly presented how three girls from his public school classroom learned new pieces of knowledge from their self-knowledge education. According to Gatto, the girls did not need to attend school to learn how to be editors, but explored ways to get a chance to apprentice with professional editors 
and to educate themselves. Education depends on dialogue between people as equals (Friedman, 2001).

On the other hand, schooling depends on there being an authority (teachers, the textbooks, administrators, etc.) to authorize what is going to be counted as correct and worthy of a certificate or some other symbol of accreditation (Spring, 2010). Education, on the other hand, is about freedom of thought, judgment and action. "Schooling" is a term that points out the historical, cultural, political and social processes of transforming people into citizens and members of particular social groupings (Spring, 2010; Kaestle, 1983). This is a form of shaping people, of molding them to "fit in" to the demands of their social groups (Bourdieu, 1984). The function of the school is thus to shape the minds, bodies and behaviors of people - both individuals and groups (Foucault, 1986). It employs instruction in what is right and wrong, in what are facts and what are not, in what is good and what is bad. Emphasis is given to learning information and repeating this information in tests that are marked according to the extent that the repetition is faithful to some original text (Spring, 2010). Schooling can be connected historically to practices of controlling, forming and fashioning the minds and behaviors of students, as in the factory model of education (Nichols-White, 1996; Tozer, Senese, \& Violas, 2009). Schooling is about 
following norms of behavior and thinking that has been legitimated by authorities

(Foucault, 1986).

Compulsory schooling is a modern development in the US, but

family-based learning historically has been the custom from generation to generation.

Learning from one's parents or elders is a cross-cultural, widespread phenomenon

(Urban \& Wagoner, 2004; Gaither, 2008). In Native American education, the entire

tribe serves as teachers, and Native American children learn survival skills and

cultural lessons beginning in infancy. Education is not separated from life but

integrated into life (Urban \& Wagoner, 2004). A second example of

learning-in-the-community is the apprenticeship. The apprenticeship existed in

Medieval Europe, in which children assisted and learned from local craftspeople. The

apprenticeship system functioned as community social control and welfare relief to

lessen the burden of the poor (Main, 2001; Tozer, Senese \& Violas, 2009).

Apprenticeship laws from these English precedents were enacted in all American

colonies and empowered government officials to mediate both family and community

welfare (Urban \& Wagoner, 2004). In sum, education has traditionally been

inseparable from life. Historically, three agencies have played important roles in

education: the family, the community and the church. 
In the mid- $19^{\text {th }}$ century, perceptions about education and schooling gradually began to mix into one term when public schooling became accessible in the United

States. When more young citizens attended common schools, parochial schools or private schools, schooling became directly linked with education (Tozer, Senese \& Violas, 2009). The following section will present the goals of public school in America.

\section{Democratic Participation as a Political Goal}

Education emerged as an essential consideration after the Revolutionary War, in light of the need to maintain newly proclaimed rights and liberties (Cremin, 1980). Thomas Jefferson's commitment to the idea of a system of education came from his concept of classical democracy. He believed that individuals were able to improve their virtue and thus secure themselves against tyranny if they were engaged in proper civic education and active community life (Hellenbrand, 1990; Urban \& Wagoner, 2004). In doing so, schooling was the best means of identifying democratic participation based on Jefferson's plan (Hellenbrand, 1990). This proposal assumes that the educational system is fair in its judgments. In light of fairness of selection, judgment is determined by talent demonstrated in school, instead of by other social factors, such as race, religion, and social class (Cremin, 1980; Spring, 2010). 
Jefferson's plan for a system of education included both democratic and meritocratic principles (Hellenbrand, 1990). He argued that his plan would offer opportunity for virtuous and talented members of the "natural aristocracy," from among White males of every social class. If given an equal opportunity, children from undistinguished backgrounds might compete successfully against those of the "artificial aristocracy," which refers to people from privileged social classes (Hellenbrand, 1990; Urban \& Wagoner, 2004). This latter group, Jefferson said, often lacked either virtue or talent. Jefferson was aware that children born into wealth not only had the advantage of a head start in life, but also were guaranteed a spot at the finish line. By examining Jefferson's educational philosophy, we can see a philosophy of education in action in historical context. Not only did he articulate the social and political goals of education for democracy and for social progress, but he wanted to educate for individual goals as well (Tozer, Senese \& Violas, 2009). He believed that human beings had the capacity for reason and right action if they were educated (Hellenbrand, 1990). Nevertheless, his conceptions of race and gender were at times both limiting and deeply disturbing.

Through using Jefferson's idea of schooling, individuals have been able to judge circumstances for themselves and have resisted government interference and undue 
influence. Conversely, Jefferson's concept of meritocracy fails if schools favor individuals from certain racial, religious and economic groups. In the section on the social goals of schooling, I will discuss the issues that arise when schooling is controlled by dominant class, race and gender groups.

\section{Americanization}

One of America's founding fathers, Benjamin Rush, stated in 1786:

I conceive the education of our youth in this country to be peculiarly necessary in Pennsylvania, while our citizens are composed of the native of so many different kingdoms in Europe. Our schools of learning, by producing one general and uniform system of education, will render the mass of the people more homogeneous, and thereby fit them more easily for uniform and peaceable government. (Rudolph, 1965, p. 9)

His words express the goal of (European) "Americanization," or assimilation into one (Eurocentric) melting pot through schooling. The Americanization of ethnic minorities and lower-class members of society was the central purpose of America's earliest public schools (Cremin, 1978; Kaestle, 1983). Schooling served as a means to solve the problem of assimilation and to unify the nation. This process sought to "remove the stamp of ethnic cultures and individuality that immigrant family-related 
learning environments propagated” (Knowles, Marlow, \& Muchmore, p. 201).

Common schools became a means to assimilate immigrant youths to American values such as patriotic loyalty.

When a great number of Catholics immigrated to America in the mid-nineteenth century, many Protestants were worried about their loyalty to the Pope in Rome that could have damaged the faltering nation (Kaestle, 1983). When the common schools were founded, reading the Protestant Bible was a requirement in school curriculum, and it was also an attempt to assimilate immigrants from different cultures and religions into Protestant America (Gaither, 2008; Reich, 2002). Conflicts between Catholics and Protestants over the choice of scripture in common schools caused havoc. Eventually, a Catholic Church of Baltimore in 1884 built a school near the church for Catholic children to attend, and then Catholic schools rapidly expanded between the 1880s and 1890s (Kaestle, 1983; Reich, 2002).

Native Americans were viewed as a problem by the White Americans who attempted to educate them. Thomas Jefferson both respected and hated them. He suggested that if they could not be assimilated, they should be killed (Grinde, 1999). Many years later, the American government used formal schooling and social education (agricultural and industrial policy) to assimilate Native Americans to 
American society (Tozer, Senese \& Violas, 2009). Between 1866 and 1887, only a small portion of them attended formal schools and resisted the government's assimilative policy. Then, an allotment policy was enacted by the federal government to teach Native Americans how to be farmers. Meanwhile, Native American youth were forced to attend boarding schools supported by the government that sought Indian assimilation to dominant American values (Urban \& Wagoner, 2004). The assimilation approach contributed to devastating effects on individuals and to decimating tribal unity and identity (Spring, 2010).

\section{Maintaining the Structure of American Society as a Social Goal}

During the 1840s, Horace Mann proposed a set of arguments to support common schools (Kaestle, 1983). Mann's arguments were persuasive because of the different messages they carried to various segments of the population (Glenn, 1988). To the worker, the message was: Send your children to school so they may become rich. To the employers, the message was: The common schools will provide employers with workers who are not only more productive, but also obedient and unlikely to resort to strikes. The overall implication of Mann's argument was that schools were places to create wealth and mitigate the plight of the poor without cost to the affluent (Kaestle \& Vinoski, 1980; Glenn, 1988). 
Mann's political and social objectives were to some extent to be achieved through socialization within the school. In general, socialization refers to the processes regarding how students participate in school social events, how they react to school environments, and how their behaviors and thoughts are shaped in the school (Kaestle \& Vinoski, 1980).

The common school was an institution used to wield social control through the wealthy in society who intentionally sought to control the lower classes and to give them poor opportunities for social advancement (Kaestle \& Vinoski, 1980; Glenn, 1988; Spring, 2010). The structure of control was accomplished to reinforce the principles of factory work, such as respecting authority, monotony and punctuality (Kaestle, 1983).

\section{Labor as an Economic Goal}

Society requires a steady stream of trained workers to "keep the wheels of industry turning” (Spring, 2010, p. 20). Since there are many necessary layers and levels of training in society, the process of sorting and distribution begins at school. As a result, by assuming a level playing field, the public school system is expected to elevate everyone's chances for a better life, to provide equality of opportunity, and to 
identify those who are most qualified for becoming members of the most powerful group in society, regardless of social class (Glenn, 1988).

Based on this concept of schooling, Horace Mann constantly emphasized how individuals benefitted from attending the common school and tried to get poor or working people to support the common school movement (Katz, 1968; Kaestle \& Vinoski, 1980). He argued that schools were the institutions that would prevent class divisions in America, and help all individuals obtain necessary skills, and offer them a dream for a better life (Kaestle \& Vinoski, 1980).

As common schools expanded, the division of labor between those who controlled resources and those who were controlled by the system was formalized and resulted in significant and devastating inequalities. Common schools served to perpetuate class distinctions between the capitalists and the working class (Cremin, 1978; Kaestle \& Vinoski, 1980; Apple, 2000). The nature of common schools has been class-based. The practices of schooling usually favored (and still favor) advantaged students (Carey, 2004; Apple \& Beane, 2007; Lipman, 2004; Smith et al., 2004). Under the umbrella of "democratic common schools," schooling has been, in reality, a hegemonic institution. Schooling has helped some children move up; at the same time, 
it has locked many into low-level positions in society. Of course, it need not always be this way.

\section{Democratic Education and Attendant Implications}

This section will discuss the concepts of democratic education and the implications of schooling in a democracy. Three major themes are addressed in the implications. They are: (a) social reproduction (stratification), (b) the factory-model, and (c) dominant and oppressed culture. NCLB and market choice policies present the inequality among social classes in the democratic process. The perspectives of educational interests from the family, the state, and the child are addressed to respond to critiques for homeschooling regarding its potential as a democratic educational form.

Democracy, defined in Webster's dictionary, primarily means (a) a government in which the supreme power is vested in the people and exercised by them directly or indirectly through a system of representation usually involving periodically held free elections, or (b) a political unit that has a democratic government. Democracy means that people exercise their power to determine the nature of their society and government, in which certain values and rules are supported by people and may be implemented by the government (Macedo, 2000). Usually, the sovereignty of the 
people, human rights, and a number of other more subordinate values are attached to the definition of democracy (Acemoglu \& Robinson, 2005). One of the fundamental values within democracy is the sovereignty of the people. Gutmann (1999) called this "collective self-determination" (p. 289). In a democratic process, people have the right and the power to establish, control and change the government. Democracy demands consensus and runs the mechanisms to deliver it (Gutmann, 1999; Reich, 2002). However, values or ideologies shape how people view and deal with problems. Reaching the consensus to determine values results in conflicts, because values are attached to people and are not accepted by everyone in society (Macedo, 2000). Dewey (1916) believed that democracy was important not only because it stood for freedom and equality but because of its educational consequences. To begin with, he recognized Jefferson's view that for a democracy to be successful, the people must be educated enough to express their own interests. Dewey (1916) believed that the school could be a laboratory for democracy in which children developed the skills and dispositions demanded in a democratic life. Therefore, schooling was one means to deliver values within a democracy (Gutmann, 1999). In the previous section, I traced the history of common schools as they were designed to promote fundamental democratic concepts and to carry out those ideals. 
To fulfill the democratic purposes of education, Gutmann (1999) proposed that the family, the state, and children themselves all should have agency when it came to educating democratically, and she argued that rational deliberation of the good life is an indispensable component of education in democracy. What constitutes a good life is determined by students with the capability of autonomy, which is fostered both in schooling and in the family (Gutmann, 1999). This indicates that schools and families teach the capacity of moral reasoning and choices without providing a restrictive version of a particular way of life, and children have the capacity to develop themselves as they grow.

According to Gutmann (1999), two principles are needed to place deliberation in the context of democratic education. These are non-repression and non-discrimination. Non-repression is the principle that inhibits the state or other groups from shaping rational deliberation regarding the good life and the best possible society (Gutmann, 1999). Gutmann (1999) gave the example that under non-repression, schools would be prohibited from building a xenophobic environment influencing students' minds and decisions. Non-discrimination means that students are able to get involved in political processes and to develop the choices of the good life (Gutmann, 1999). Under non-discrimination, no one should be excluded from the 
political process, and all people should be well equipped with capabilities for decision-making. Under her theory, democratic education should create equality of opportunity for every student in schooling and nourish individuals' abilities to shape autonomy in their lives (Gutmann, 1999).

However, in reality most US schools operate on anti-democratic principles: favoring students from the dominant group, while excluding students from disadvantaged groups (Apple, 2006; Bowles \& Gintis, 1976; Feinberg \& Soltis, 2009; Spring, 2010), although this is certainly not always the case and schools do have democratic potential (Apple \& Beane, 2007). Indeed, while none is perfect, there are hundreds of publicly supported schools and classrooms around the world that reflect the positive deliberative democratic principles outlined by Gutmann (1999).

But overall, since school is a powerful institution that promotes the ideology of the dominant group, schools are oftentimes agents playing an unfair game. School is an institution that reproduces inequalities (Lipman, 2004; Smith, et al., 2004; Apple, 2006). School may present economic and cultural functions and embed ideological rules that maintain an existing set of relations. These relations perform a certain function to help some groups and serve as a barrier to others. School is caught up in its connection with other influential elements, such as politics, economy and culture. 
Schools exist through these relations that generate structural inequalities of power and access to resources. Therefore, inequalities are reinforced and reproduced by schools. Through their curricular, pedagogical and evaluative activities in day-to-day life in classrooms, schools play a significant role in maintaining inequalities.

\section{Social Reproduction/ Stratification}

Schools not only control and limit the opportunities visible to people but they also work to establish and promote societal standards (Espeland \& Sauder, 2007; Apple, 2006). Schools are in the position to maintain criteria that stem from specific groups, so they may imbue those who have more power with legitimate knowledge and cultural legitimacy (McNeil, 2000). Usually, the dominant group prevails in political and economic arenas (Bourdieu, 1998). Under these circumstances, schooling positions the privileged group well and tends to neglect the underprivileged groups (Apple, 1995). As a result, culture and knowledge are intertwined, and schooling serves to reproduce social inequalities and class divisions to continue the domination of the advantaged class (Bowles \& Gintis, 1976).

Stratification refers to our position in society, and works throughout all social structures (Collins, 1979). Social class is determined by several variables, including wealth, power, and prestige; educational attainment is closely associated with these 
variables (Bourdieu, 1998; Brantlinger, 2003). In addition, educational achievement is used to sort people into societal roles (Brantlinger, 2003). Hence, individuals rely on their educational attainment to maintain or improve their status in society. The status-attainment model is viewed as a means of the cultural legitimation hypothesis in schooling, and scholars have proposed the cultural legitimation hypothesis to justify how this model operates in schooling (Stevens, 2008). The cultural legitimation hypothesis consists of two elements: cultural experience and cultural knowledge (Stevens, 2008). These two elements facilitate established family privileges and have influential effects on life outcomes.

There are two major theoretical explanations of stratification systems: those espoused by functional theorists and those set forth by conflict theorists. Functional theorists (e.g., Collins, 1977; McDermott, 1982) see inequality as inevitable, with schooling playing a role in selecting and training people for unequal positions in society. Functional theorists assume that inequality in society justifies the perpetuation of the status quo. Schooling has a tendency to strengthen existing social structures and social stratification. Conflict theorists (e.g., Collins, 1977; Feinberg \& Soltis, 2009) disagree with the assumption that inequality is inevitable. They argue that status groups dominate schooling in standards and curricula, and that the 
representation of specific interests leads to inequality. Conflict theorists have argued that schooling perpetuates the inequality in society (Collins, 1977; McDermott, 1982). While each group struggles for a greater share of those parts of society that make up the good life, such as fortune and power, inequalities are reproduced (Feinberg \& Soltis, 2009). Some regard schooling as a means to reducing inequality; however, according to conflict theorists, schooling in reality serves to reproduce the inequalities based on social status.

As I have already explained in Chapter One, there is potential for families and the state (e.g., teachers) to work together in partnership in order to engage a dialogic relationship that promotes democratic education. Unfortunately, this kind of approach is currently not happening in all contexts. The current school context of testing and standardization under NCLB has set up a no-win situation for many, many schools across the US. These schools are grossly under-resourced and schools and teachers particularly struggle in states like West Virginia and Tennessee where the local tax base for schools is especially meager. Because school districts and teachers in these locales may not yet have received education about hopeful possibilities like funds of knowledge and have often not yet had opportunities to reflect systematically upon their local communities and the assets that they can bring and to learn about rich 
culturally relevant pedagogies and community-based practices, there is a substantial gap between public schools' potential and current practices. However, that is not to say that there are no models of democratic schools in under-resourced areas that could help promote positive change. Indeed, the issue is in many ways recognizing the local resources that do exist and then figuring out together how to transform current practices.

\section{Factory Model}

The term "factory model" was established during the Industrial Age (Tyack, 1974). During that time, society needed many individuals to fit into the factory worker role, a model that has dominated $21^{\text {st }}$ century US schools (Gatto, 2002).

The factory model was used as a metaphor for the operation of schooling. Based on this concept, the school is a place to sort students into different divisions to foster some in the management level and to train others in the skilled workforce.

Schools not only transmit cognitive skills, such as reading and mathematics, but also deliver non-cognitive objectives, such as behavior norms and values (Stevens, 2008). Bowles and Gintis (1976) proposed that the structure of the experiences concerning attitudes and behaviors in schooling is well matched with those in the labor force. 
In the factory model, school experiences refer to training that renders its response predictable according to the goal of trainer. Standardization is one of the salient features in schooling (Feinberg \& Soltis, 2009). When schools practice standardization, students are allocated to different courses based on their academic achievement. Management courses related to managerial skills and personal assertiveness are available for students with high scores, and practical courses related to clerical knowledge and docility are offered to those with lower scores (Anyon, 1980; Spring, 2010).

Factory-like schools are fraught with authority hierarchies and curricula with organizational objectives not designed for students (Gatto, 2002; Kohl, 1969). This factory model views children rigidly and assumes that they should be taught in a structured way. Here, education is a product and not a process. Students' curiosity for learning can be dampened and students are being institutionalized under a "one size fits all” approach (Spring, 2010).

Again, there are many, many schools that promote rich cognitive learning that is based in students' interests and cultures, intellectually engaging, relies on problem posing and problem solving methods, and promotes high levels of student learning. While standardization and the factory model remain dominant forms of education in 
the US, there are certainly other possibilities. Unfortunately, in some local contexts (including West Virginia and Tennessee) there is relatively little opportunity to experience and learn from alternative, progressive models. In some contexts, there may be an entrenched history of standardized schooling (e.g., statewide textbook adoptions), a widespread socially conservative ideology that inhibits child-centered and progressive curricula and pedagogies, and deep worries about test performance and sanctions under NCLB. In such settings, there may have been few real opportunities for the development of local public schools that promote democratic goals.

\section{Dominant Culture/Oppressed Cultures}

Michael W. Apple (2000) studied the culture of schools and contemporary society, focusing especially on the cultural politics of schooling. He critiqued schooling that has not represented minority interests:

The current call to "return" to a "common culture" in which all students are given the values of a specific group - usually the dominant group - does not to my mind concern a common culture at all (Apple, 2000, p. 127).

According to Apple (2000), the values or perspectives of common cultures are decided by the group with power, and are permeated throughout the curriculum. From 
this perspective, Apple (2000) illustrates his theory of hegemony as it affects schools. Hegemony refers to a predominance of influence by authority or the dominant group. As he explained with his co-author, James Beane, "Rather and crucially, it requires not the stipulation of lists and concepts that make us all 'culturally literate,' but the creation of the conditions necessary for all people to participate in the creation and recreation of meanings and values" (Apple \& Beane, 2007, p. 70). What is more, minorities cannot share in a common culture dominated by political and economic interests other than their own (Apple, 2000).

Apple and Beane (2007) have drawn heavily upon recent work in the culture of schooling to demonstrate that the relations of schooling are lived relations. Ideally, knowledge and cultures should be critical and multicultural; however, they are in reality delivered through the ideology of the dominant group (Apple \& Beane, 2007). As a result, the knowledge and cultures in schooling tend to present the hegemony of dominant group (Apple, 2000).

The critical educator Paulo Freire (1970) saw domination as multi-faceted, one side of which is "the way in which power, technology, and ideology come together to produce knowledge, social relations, and other concrete cultural forms that indirectly silence people" (p.115). For Freire (1970), the nature of the educational system 
increases the cultural conflicts between the dominant group and subordinate group. Freire (1974) has stressed that the educational process is never neutral. Schooling either performs as an instrument to facilitate the integration of generations into the present system and brings about conformity to it, or it becomes the practice of freedom, the means by which individuals discover how to participate in the transformation of their world (Freire, Macedo, \& Giroux, 1985). Conversely, the former function manifests the latter one, and it attempts to transform individuals' perspectives to ones of the dominant group. According to Freire (1970), the system of dominant social relations creates a culture of silence that instills a negative, silenced and suppressed self-image into the oppressed. The learner must develop a critical consciousness in order to recognize that this culture of silence is created to oppress (Freire, 1974). Further, a culture of silence can result in the dominated individuals losing the means by which to critically respond to the culture that is forced on them by a dominant culture. Finally, according to Freire (1970), social domination of race and class are interwoven into the conventional educational system.

These documented concerns strengthen the need for a new consciousness that goes beyond traditional notions of how class hierarchies must be, and instead relies on the strengths of low-income families in the project of democratic education. These 
authors have each laid out rich examples of how critical democratic education has been done and is being done in the US (Apple \& Beane, 2007) and Brazil (Freire, 1970; Gandin \& Apple, 2011).

\section{Interactions between Democratic and Market-Based Educational Forms}

In 1990, John E. Chubb and Terry M. Moe wrote a book called Politics, Markets, and America's Schools. Their intent was to make qualitative distinctions between public and private schools in terms of how they are governed and controlled. The core of Chubb and Moe's argument is the basic distinction between democratic and market control between public and private schools.

Public schools are democratically governed through the political process, and in reality the interests of parents and students are usually ignored, although as should be evident, this is clearly not always the case. Chubb and Moe proposed that parents and students will have less influence due to the structure of political process in educational system. Public schools consist of regulations and guidelines that lead to a rigid bureaucratic structure. Highly hierarchical bureaucracies impede the effective use of professional personnel. To attract students, private schools must be responsive to the felt needs of students and requests of the middle- and upper-class parents who most often use them. Chubb and Moe therefore suggested that the present system of 
public school governance be replaced in favor of a market-driven one in which parents are, in their eyes, empowered.

Robertson (2000) noted that proponents of choice and markets argue that “efficiency and equity in education can only be addressed through 'choice' and where the family or individuals are constructed as the customers of educational services" (p. 174). As this observation has increasingly been practiced in the US, democracy and the markets have, in the eyes of conservatives following market-based logic like Chubb and Moe, become more aligned within educational policies because market-based education subsumes opportunities for parents to "vote with their feet," by the school choices that they make. What proponents of choice often fail to reveal, however, is that market systems relying on competition are driven by the interests of families with capital - those who can afford to walk out on the public schools or can figure out a way to homeschool—while the vast majority of families are left behind to deal with the constraints of the public schools if they do not have the resources nor the models to craft democratic alternatives.

No Child Left Behind. No Child Left Behind (NCLB) passed with large majorities in both the Senate and the House when President Bush signed it into law in 2002. NCLB was viewed as a reflection of the popularity and dominance of neoliberal 
and neoconservative policy discourse supporting standardized testing, accountability, school choice and privatization (Harvey, 2005; Lipman \& Hursh, 2007; Tabb, 2002). The conservative coalition generally supporting policies like NCLB may consist of several groups, including: neoliberals, neoconservatives, and the professional/managerial middle class (Apple, 2006). The neoliberals, of whom Chubb and Moe are an example, emphasize free markets, individual choice and the expansion of consumerism (Leys, 2003). The neoconservatives uphold a strong state that promotes conservative policies, deregulation, and limited social services funding (Wells, Slayton \& Scott, 2002). The professional-managerial, middle class is represented. Apple (2006) also included authoritarian populists (religious conservatives) in the conservative coalition; however, their involvement in support of NCLB is unclear, underscoring the complex nature of this power movement.

Through standardized tests rendering information about student learning and the accountability of public schools, NCLB promotes the idea that competition leads to better schools, the improvement of educational opportunities for all students, and parental empowerment through choice in education. In terms of NCLB provisions, students in the failing schools have the opportunity to transfer to higher performing schools. NCLB requires that parents have a right to choose a better performing public 
school for their children if the current school repeatedly does not meet Adequate Yearly Progress (AYP) (if there is a district school available that meets AYP and has openings). Additionally, when Title I schools don't meet AYP, supplemental educational services, such as after-school tutorial programs, must be available.

Software and publishing companies market products and services such as software and instructional designs to bolster tutorial programs in the "failing" schools (Ascher, 2006). Supplemental educational services that respond to low test scores also fulfill the philosophy of the free market, opening the door for school privatization (Bracey, 2004). In this way, NCLB could be seen as democratic, although in reality likely little in the way of redistributed outcomes has come from its privatizing elements.

School choice plans. School choice is a term used to describe a wide array of programs aimed at giving families the opportunity to choose the school their children will attend, and has been adopted to provide parents with different public school options without requiring families to move to different neighborhoods (Fuller, 2000). School choice programs presume variety in the characteristics of schools.

Choice plans sometimes involve developing schools with different themes and curricula. And sometimes choice plans include voucher programs. The educational voucher system allows the government to make payments to families, so that they may 
have the choice to allow their children to attend public schools or private schools. The most common options offered by school choice programs are open enrollment laws that allow students to attend other public schools, public or private virtual schools, private schools including parochial schools, charter schools, and magnet schools, or to use vouchers (Lubienski, 2001).

Choice programs allow parents to select from among schools. The logic here is that parents are consumers of education, and should have different schools from which to choose. Like any market, this thinking goes, competition among those offering education should improve it. In this logic, part of the problem of public education has been its monopoly over the provision of educational services.

Many choice advocates believe that public schools will improve educational quality by competing with other schools for students and scores (Andre-Bechely, 2005). Meanwhile, parents in school choice programs may be bound by sharing the same interests and values (Smrekar \& Goldring, 1999). By a self-selection process, these parents solidify a sense of commonality around a particular set of values and expectations toward schools (Dunk \& Dickman, 2003). The advocates of school choice also believe that low- and moderate-income families can benefit from school choice programs (Smith, 2001). Many low- and moderate-income parents do not have 
the ability to move to a better school district or to pay full tuition at a private school

(Andre-Bechely, 2005). Their children are often restrained by failing schools. School choice programs may empower parents to choose their children's schools. On the other hand, choice is limited because there are few good options for parents (e.g., there are often lotteries or admissions criteria for relatively better programs) and the families with the least resources are the unlikely to be able to access much-needed quality education. In addition, there is no guarantee that the curriculum or pedagogy of "choice" programs will be more democratic in the sense of promoting a critical multicultural society.

Problems with NCLB and school choice programs. Critics point out that

NCLB does not close the achievement gap but rather results in higher drop-out rates and lower academic expectations towards disadvantaged students. Many states and NCLB apply the same tests and test scores to determine whether schools should be rewarded or punished. Though the test scores fall, a school is considered passing as long as its scores surpass the threshold. But, schools that begin with initially low test scores may still be viewed as failing ones even if they significantly improve their test scores but stay below the threshold. The determination of whether a school is making AYP demonstrates little about whether a school is improving. 
In addition, Rothstein (2004) recognized that test scores are likely to reflect a student's family income, and they have little to do with teaching or curriculum. As a result, the largest percentage of failing schools in New York can be found in poor, urban school districts. Relevant reports also have reflected that most falling schools are located in the inner cities, which consist of populations from lower income levels or poverty (Smith, Miller-Kahn, Heinecke \& Jarvis, 2004; Valenzuela, 2005).

In McNeil's (2000) study of several Houston schools serving low-income students of color, she found that disadvantaged students received more basic skill drilling and mitigated academic expectations from teachers and administrators. When schools expected less of disadvantaged students, they fell further behind.

Moreover, failing schools are likely to focus on test preparation rather than on the rich learning content that students need, and schools are likely to reduce or eliminate subjects, including the arts (McNeil \& Valenzuela, 2001; Nichols \& Berliner, 2005). The pressure to raise scores leads schools to push out disadvantaged students. In Texas, urban students have been more likely to be retained in school before standardized exams (Valenzuela, 2005). In New York, disadvantaged students have been listed as having transferred to another school or have been listed as having a Graduate Equivalency Diploma before administration dates for high-stakes exams 
(Lewin \& Medina, 2003). Research has also suggested that the New York school curriculum was narrowed to a sharp focus on test preparations, while the delisted disadvantaged students received less challenging learning content (e.g., Cawelti, 2006; Jane, 2011).

Even though NCLB was supported by legislation via a democratic voting process and has offered parents in failing school districts the option to choose another public or private school for their children, many parents in failing schools, while they have certain significant personal and cultural resources, lack time and knowledge concerning how the system or structure functions.

There is a similar issue at play regarding school choice initiatives, whether they are part of NCLB or separate initiatives. But the most critical element behind school choice is that the principle of choice is based on the assumption of an informed consumer (Andre-Bechely, 2005). Parents need detailed knowledge of the processes and practices that will give them access to the schools of their choice (Smrekar \& Goldring, 1999). Understanding the operations of school choice demands a great deal of work and knowledge. The procedures for entering the choice system and the informational descriptions may be intensely complicated and may serve to stack the 
deck against poor and working class parents seeking better options (Dunk \& Dickman, 2003).

In order for the logic of choice to work so that parents feel like they are truly choosing well, they need to have information about differences among schools so as to make informed choices for their children. Getting access to this information is not always easy. And school choice may increase social segregation along race and class lines (Andre-Bechely, 2005; Dunk \& Dickman, 2003). Not only do school choice applicants have purportedly higher educational aspirations for their children than parents who are not active choosers, but choosers' social and cultural resources also ease their navigation of school choices (Smrekar \& Goldring, 1999). The parents who apply for the school choice system are often significantly better educated and more active in their children's schools than parents who do not apply (Andre-Bechely, 2005). This does not mean that parents who have less education, however, cannot contribute to education in unique and important ways.

If choice programs only respond to parents who are informed applicants, the parents who are less informed will have fewer opportunities that may result in lower quality education. In other words, parents who have fewer social and cultural resources are less likely to be able to self-determine their children's education. 
Considerations like these call into question the supposedly democratic nature of neoliberal and neoconservative policies. In other words, market-based education, while public or quasi-public, may structure relationships among the state, parents, and children that serve to perpetuate inequalities by class and race and thus limit opportunities for self-determination as it purports to promote them.

Given this background of the larger context of privatization, then, what can be said about the democratic nature of what has been called the ultimate in school choice, the practice of homeschooling?

\section{An Evolving Democratic Education}

Homeschooling holds a curious position in debates about educational choice.

On one hand, it seems to be the ultimate in social constraint whereby all ties to the state are severed and it is up to individual families to decide whether to allow their children almost no agency (as is the case with the classic Ideologues) or it is up to parents to allow children almost unrestrained autonomy (as with unschoolers, the original Pedagogues). Are there opportunities for homeschooling to fit within a democratic project that connects the state, parents, and children? And if so, what could this look like? 
Let me back up a bit to explain what I mean by democratic education. Amy Gutmann (1987) suggested that in a democracy, "education focuses on what might be called 'conscious social reproduction' - the ways in which citizens are or should be empowered to influence the education that in return shapes the political values, attitudes, and modes of behavior of future citizens" (p. 14). She argued that values and modes of behavior should be debated, developed and scrutinized by the members of society and subject to change through deliberation and consensus. So, democratic education presents a shared trust of the family, the state, and the individual and no one interest group can claim ownership of possible knowledge and values.

Democratic education requires curriculum and pedagogy that promotes democratic values and dispositions that are dialogic in nature and promote relationships that mutually regard the assets of parents, children, and the state. Apple and Beane (2007) laid out a theory for a democratic curriculum. According to Apple and Beane (2007), democratic schools have the following characteristics:

1. The open a flow of ideas, regardless of their popularity, that enables people to be as fully informed as possible.

2. Faith in the individual and collective capacity of people to create possibilities for resolving problems. 
3. The use of critical reflection and analysis to evaluate ideas, problems, and policies.

4. Concern for the welfare of others and for the common good.

5. Concern for the dignity and rights of individuals and minorities.

6. An understanding that democracy is not so much an ideal to be pursued as an idealized set of values that we must live and that must guide our life as a people.

7. The organization of social institutions to promote and extend the democratic way of life. (pp. 6-7)

Apple and Beane (2007) recognized that a democratic curriculum should avoid the selective knowledge and meanings validated by the dominant culture and that it should present a wide spectrum of angles and voices. A democratic curriculum incorporates lives, knowledge and even the concerns of students, as well as what adults think is important. Students take the lead to reshape curriculum and make it meaningful to their learning with teachers' assistance. Knowledge is delivered to children, not from a dominant culture, but filtered through the multiple cultural lenses of issues and ideas for living (Beane, 1993) in a way that recognizes their funds of knowledge. 
In these public school cases, communities and schools are allies, because these agencies share the mission to enrich children's educations. Meanwhile, students are engaged in reconstructing a curriculum that connects to their worlds. Through Apple and Beane's (2007) democratic education, people gained knowledge by both studying relevant sources and engaging in activities that assist them to construct their own knowledge. Apple and Beane (2007) stated, “These stories remind us that the most powerful meaning of democracy is formed not in glossy political rhetoric, but in the details of everyday lives" (p. 103).

This kind of curriculum should be possible in homeschooling, particularly given the possibilities that homeschoolers may have to organize into co-op like communities of families who may engage with resources from the state. There are more and less opportunities for these kinds of relationships among the state, the parents, and the children to engage with flexible and potentially democratic schooling options. Indeed, this is a glaring absence in the homeschooling literature regarding democratic potential. However, theoretically there is the possibility that such democratic arrangements may occur. The kind of democratic education that I imagine that incorporates a homeschooling-hybrid model is in some ways like the Citizen School project in Porto Alegre, Brazil (Gandin \& Apple, 2011). I want to be very 
clear that the citizen school is not homeschooling. But, the Porto Alegre project is explicitly designed to radically change both the municipal schools and the relationship between communities, the state, and education. The Citizen School is aimed at constructing not only better education for the excluded, but it is also a project of radical and thick democracy. The Citizen School project reflects a process of democratic and collective construction, with participation from families who have historically been excluded from education, the school, and the state: In the process, a new conception of respect for the diversity of cultures is generated. Challenging the elitist belief that impoverished people from poor neighborhoods or slums cannot participate because they are 'ignorant', the Citizen School inverts this logic, placing the ones who live the problems at the center as the people in a privileged position to construct alternatives. (Gandin \& Apple, 2011, p.12).

The Citizen School project and those like it connect identity, pedagogy, and agency to promote democratic curriculum and pedagogy of the kind described by Apple and Beane (2007) above. Unfortunately, as I have argued, while democratic education is the kind of education that is ideal for all students and families, it is not seen as a possibility in all public school districts. When this is the case, it is useful to consider 
other educational forms that may spur or spark possibilities among low-income and minority families who have, as I have described, historically been kept out of the kind of public schooling that would allow them the best chances of having flourishing lives. The reason that I believe that homeschooling, although it seems to be an education that separates from public education through privatizing, offers possibilities for democratic beginnings, is because it offers parents the freedom to use their funds of knowledge to freely create curricula and pedagogy that is democratic and that honors and reflects their cultural backgrounds as well as allows them to access the culture of power. In other words, homeschooling offers the potential space to for constructing identity, pedagogy, and agency in ways that may not be possible in some local contexts and that may in certain cases be the only foreseeable possibility for educational transformation.

\section{Identity, Pedagogy, and Agency in Homeschooling}

In homeschooling, parents' and children's democratic identities are shaped by the self-determining act of choosing to homeschool when there are no other, better, options that will allow for democratic education. In these cases, prospective homeschooling families contemplate their identities, rights, and obligations in their social contexts when they make decisions (Dahl, 1989). In fact, Dahl (1989) argued 
that the individual's right to self-determination is a condition for democracy.

According to Dahl (1989), individuals can judge their own interests based on their autonomy in the process of self-determination. The contextual components needed to implement self-determination include social factors, individual goals, self-awareness of strengths and weaknesses, and responsibilities (Mill, 2011; Thoma et al., 2002). Because I look through an asset-based lens, I believe that self-determining parents who choose to homeschool because they see no other democratic options in their contexts would consider pedagogical approaches to facilitate their children's learning in line with their cultural background and the educational resources they can offer. I believe that all parents want their children to develop individual intellectual identities, and that all parents want their children to know how to take full advantage of the fact that they are always in control of their own learning, as well as for all children to develop their personal learning styles.

While homeschooling represents a departure from education in dialogue with the state, that need not be the case. In fact, it has been common for families to engage with both homeschooling and brick-and-mortar schooling at times (Bauman, 2005; NHES, 2007). And in cases of low-income families, who may not have good possibilities for engagement in accessible brick and mortar schools, I see 
opportunities within homeschooling that promote relationships among parents, children, and supportive teachers if not in the local context, then through creative means such as virtual relationships. I see these relationships as a self-determining form of democratic education that is an example of parents' agency. This kind of innovation by parents who have historically been disenfranchised by traditional schooling may now provide opportunities to engage an education worthy of its name. It may even be possible that homeschooling that is at this moment private will begin local change that looks to homeschools with rich community-based components as models that can then re-invigorate the local public schools with fresh ideas for change toward more democratic practices that will provide a rich education and futures for all students. 


\section{CHAPTER THREE: METHODOLOGY}

This chapter explains the design for my dissertation study of low-income, homeschooling families. In this chapter, I detail the comparative case study method chosen because of the nature of my questions. I was curious about the context of homeschooling for low-income families and I also wanted to examine comparatively the particular role that local resources played in parents' identities, pedagogies, and agency as democratic educators. The content includes the rationale for the qualitative case study design, the research questions, recruitment procedures, the demographics descriptions from two participants, a description of data collection and analysis procedures, and a discussion of trustworthiness during the process. The subjectivity of the researcher is also addressed in this chapter.

The purpose of this study was to explore the homeschooling experiences of two low-income families. In light of this purpose, a qualitative case study with ethnographic methods was conducted over the course of four months to reveal the homeschooling experiences of low-income families. Three methods of data gathering were employed: in-depth interviews, observations and document analysis.

Three in-depth interviews were conducted with each of two homeschooling parents in comfortable places in their homes. Four to five half-day observations of 
homeschooling or parenting practices were also conducted by observing the participants' daily activities. The document analysis was used to supplement the interviews and observations. Inductive analysis brought up themes that emerged from the interviews, observations and document analysis. Triangulation was done using my field notes, observations and documents to verify and interpret the findings resulting from participants' responses during the interviews, observations and member checking process.

\section{Introduction to the Methodology: Qualitative Case Studies}

Qualitative research, broadly defined, means "any kind of research that produces findings not arrived at by means of statistical procedures or other means of quantification" (Strauss \& Corbin, 1990, p. 17). Qualitative research focuses on insight, exploration, and understanding of phenomena rather than on testing hypotheses (Patton, 1990); Patton argued that qualitative methods can be used to better understand any phenomenon about which little is known. Qualitative methods can also be used to gain new perspectives on things that are already known, or to gain more in-depth information. Therefore, qualitative researchers seek understanding, and extrapolation from similar situations. 
According to Yin (2009), a case study can be defined as "an empirical inquiry that investigates a contemporary phenomenon in depth and within its real-life context, especially when the boundaries between phenomenon and context are not clearly evident" (p. 18).This definition clearly states that a case study is used to understand a real-life phenomenon in-depth, including important contextual conditions of the phenomenon. In other words, the case study method allows the holistic and meaningful characteristics of real-life events to be retained (Yin, 2009) and observes how people interact within their natural settings.

For that reason, case studies often favor qualitative methods, because they are considered particularly beneficial for the generation of intensive, detailed examinations of a case (Yin, 2009). Yin (2003) proposed that the protocol of a case study should show the participants' personal beliefs, as well as daily social and instructional experience. The case study approach offered distinct advantages for me to ask multiple "how" and "why" questions of lower income and/or working class families regarding the homeschooling phenomenon. Specifically, the case study approach was chosen for an in-depth exploration of low-income parents' reasons for deciding to home school, how they accessed homeschooling-related information, what 
difficulties they encountered, and what strategies they implemented to manage homeschooling.

\section{Emergent Research}

An emergent component is identified as one of the prominent characteristics of qualitative research (Patton, 1990; Eisner, 1991). Qualitative research has an emergent (as opposed to pre-determined) design, and researchers focus on this emerging process as well as the outcomes or products of the research (Patton, 1990).

Because the researcher seeks to observe and interpret meanings in context, it is neither possible nor appropriate to finalize research strategies before data collection has begun (Patton, 1990).

Since the emergent nature of the qualitative study may leave open the possibility of substantial revision, emergent insights may require new sampling plans, different kinds of data and different analytic strategies. However, qualitative research proposals should specify primary questions to be explored, and plans for data collection strategies (Patton, 1990). If new themes or problems emerged in this study, I had a strategy to reexamine the data collection methods in order to revise and address the research questions. 


\section{Research Design}

This section presents the research questions, introduces the reasoning behind why the multiple case study method fit my project, explains the criteria for selecting participants and the recruitment procedures, presents the basic research techniques and details regarding interviews, details logistics of the observations and document analysis, and conveys how the data was analyzed.

\section{Research Questions}

The research questions, as developed in the earlier chapters, are revisited below:

Primary question: How and why do low-income families decide to homeschool their child(ren)?

I was also interested in the following secondary questions that were related to the primary question:

1. How and why do local contexts of "choice" shape low-income homeschoolers" experiences?

a. How do local public school experiences shape homeschooling experiences, motivations and practices? 
b. How do low-income homeschool experiences confirm, discredit, and complicate established theories of low-income families' educational experiences, motivations and practices?

2. How do low-income homeschooling families manage homeschooling?

a. How do families network and negotiate homeschooling in local contexts?

\section{How the Multiple Case Study Method Fits This Research}

As Creswell (1994) stated, "in qualitative studies the research problem needs to be explored because little information exists on the topic" (p. 10). Contemporary homeschooling research has mostly highlighted Evangelical homeschooling and homeschooling by the White middle- and upper-middle classes, instead of exploring low-income homeschooling.

To better understand the homeschooling phenomena more completely, qualitative research is appropriate. More specifically, I chose the multiple case study approach. This approach provides an in-depth analysis of personal narratives and observations from each participating family. I will explain the rationale for the multiple case study approach next. 
According to Yin (2009), the researcher receives a better understanding of the participants' actions in a particular context by studying a small group in the case study design. Creswell (1994) argued that case study inquiry sheds light on a phenomenon related to the contexts of groups and processes and reveals the detailed aspects of a phenomenon through data collection over time. The case study design allows the researcher to gain insights gleaned from intensive descriptions of a process or a situation.

To uncover the homeschooling phenomena from the low-income families, I obtained information not only from the participants' environments, but also their social relations. By conducting the qualitative case studies, I have been able to collect, examine, and tell participants' stories and to present their processes and philosophies of homeschooling. In this study, I wanted to disseminate the mothers' stories and voices and to trust their voices. I have not worried about the truth value of what the mothers said, but their interpretations. People may have practiced in ways that are inconsistent with the ways in which they were perceived, which may be interesting to note if this is the case. Using multiple methods of data collection and analysis has strengthened the internal validity and reliability of the study (Merriam, 1998; Yin, 2003). Moreover, my targeted audience for publication is homeschool researchers, 
many of whom work within research paradigms, where concerns such as the validity of truth claims are very important, and thus layering data makes sense.

Yin (2003) pointed out, "Generalization of results, from either single or multiple designs, is made to theory but not to population" (p. 11). I perceived that the multiple case study analysis would have merit in helping to understand these families, and thus would contribute to the research community's knowledge of the phenomena.

\section{Context}

The data collection occurred over four months (September through December 2012). Because of my family, work, limited monetary funds, and the independent nature of my qualitative study, I needed to think carefully about how to orchestrate the data collection. Due to the condensed time period of the case study, intense field work and layered data collection were used to get to know the participants and their settings as intimately as possible in a relatively short period. I did not have any established relationships with homeschoolers from low-income backgrounds prior to this study. In part, this was because the segment of homeschoolers that I have been interested in has made up a small segment of the homeschooling population (NCES, 2008). Therefore, I networked with colleagues from West Virginia University who knew of homeschoolers in multiple US states who were low-income. Ultimately, I 
connected with two participants representing the case of low-income homeschoolers in Memphis, Tennessee and rural West Virginia.

\section{Participants}

The participant families were selected using convenience and purposeful sampling techniques (Merriam, 1998). The participants recruited were two homeschooling parents (from separate families) meeting the following criteria: (a) parents who were currently homeschooling or had homeschooled in the past year, (b) families that were situated in the low-income bracket, and (c) parents who were willing and able to articulate their homeschooling experiences.

In order to recruit participants, I contacted potential participants referred to me by WVU colleagues via email and/or phone (see Appendix A for the recruitment script). The participants contacted me via phone or email if they were interested in this study. I explained the study and gained their consent and signatures on the official IRB forms. Participants were provided with a description of the research, written details of their rights as participants and details regarding data use and handling (see Appendix C). I also explained that they would receive a $\$ 50$ gift certificate to a local store or service upon completion of the study. Then, I emailed the surveys to them, and they returned the surveys by email. I arranged for convenient schedules of (a) 
three interviews, and (b) four to five half-day observations with each participant. The arrangement of interviews and observations was negotiated along the way based on participant's schedules. Meanwhile, consent was ongoing for the duration of the study, so that participants could leave the study at any time.

Participants for this research are referred to by pseudonyms to protect their confidentiality.

\section{Zoe's Demographics}

Zoe was a 35-year-old White mother who manages her house with an organized personality and radiant smile. Zoe had recently been accepted by a Masters program in a nearby college, and her husband, Aaron, had a Masters degree and was from a suburban area near Washington D.C. in Maryland. Aaron was 37-years-old-a White father working around 50 hours a week. Aaron was a high school history teacher in the county school, a coach in the youth soccer team, a McDonald's employee, a postal worker, and also a youth pastor at their church. Zoe's job was full-time, stay-at-home mother to their six children: Iris, Wyatt, Kaylie, Erica, Ella and Gavin.

Iris was a 12-year-old docile pre-teenager, who acted like the right hand to Zoe and assumed her mother's job to take care of the younger children when her 
mother was busy. Nine-year-old Wyatt was a clever boy, whose math and science skills outperformed his peers. Kaylie was an eight-year-old girl, outgoing and friendly girl, whose working memory was not so good. Erica was a seven-year-old girl, arrogant and a bit rebellious, whose mother still tried to understand her. Five-year-old Ella had a sweet smile and mellow voice. Gavin was a two-year-old, a naughty and talkative toddler who fought a lot with his sister, Ella.

Zoe moved back to her hometown ten years ago, after tutoring three little girls from my country as an undergraduate. She also taught ESL (English as a Second Language) in Ghana and Zimbabwe. She met her husband, Aaron, in college, and they moved to Oklahoma after getting married. Iris and Wyatt were born in Oklahoma. Four years later, they moved to Minnesota, where their second daughter, Kaylie. was born. Her younger children, Erica, Ella and Gavin, were all born after returning to West Virginia.

The rural county where Zoe lived has an approximate population of 10,000, of which $99 \%$ were White and $0.2 \%$ were Black. There was no cell phone reception all the way to Zoe's hometown. The winding, hilly, and almost car-less road seemed to lead me to a mysterious place. I parked the car in the parking lot of a local store to buy drinks before going to Zoe's house. Once I stepped out of my car, one mother 
with her two children sitting in the grocery cart asked me, "Did you recently move in here?" with joyful faces. I knew I stood out immediately, since I was the only Asian face in this "plain White" area. The other racial groups didn't even appear in the county's demographics, so no wonder I was so easily "caught!"

The median family income of her county in West Virginia was around $\$ 34,000$. The total income of all persons in Zoe's household over the past year, including salaries or other earnings, interest, retirement, etc. was $\$ 36,000$. Zoe's household income was below the federal poverty guidelines due to her family size. Even though Zoe's household income was slightly higher than the county median, she was still considered as a low-income family according to the federal poverty guidelines. Zoe and Aaron were raised in working-class families, and they identified themselves as working class and upheld those values. She sometimes referred to themselves as a "working-class family," due to their upbringing and cultural context; they also sometimes referred to themselves as a "low-income family" due to their meager take-home income and large family.

In Zoe's school district, public school and homeschooling were the only two educational choices for childhood education. The local church planned to open a Christian school in the future. School choice programs were being discussed in the 
state legislature, but private schools (including parochial schools and school choice programs) were not available in reasonable commuting distance.

Zoe and Aaron were no longer homeschooling any of their children, but had homeschooled children between 2007 and 2011 when Iris was in third grade, Wyatt in first grade, and Kaylie in kindergarten in public school. Iris was in the seventh grade, Wyatt in fifth, Kaylie in fourth, and Erica in first grade when the children resumed education at public school. Erica was homeschooled in her preschool and kindergarten.

\section{Renell's Demographics}

Renell was a 36-year-old Black, passionate Doula, and a talkative and natural leader in her homeschooling group. She was an avid homeschooling mother with excellent resources. She liked wearing head-wraps in the African style, wore glasses, played guitar, and was a vegetarian. She had a college degree and completed all her education in her hometown. At the time of this study, Renell was a full-time, stay-at-home mother.

Her husband, Jace, was a waiter completing his Master's degree in English. Jace was born in the Midwest and grew up on the West Coast until high school. He then moved to the South with his family, where he and Renell were introduced by one of 
her college friends. Renell and Jace were married when their son turned three. My

first impression of seeing Jace in his badly battered hoody was that he had a scholarly disposition . Jace was a quiet Black father who was adamant when disciplining Kevin. Jace worked 25 to 30 hours a week at the restaurant.

Kevin, Renell and Jace's only son, was a well-behaved nine-year-old boy with a reserved personality. Kevin was also a cultivated and exploratory boy who sang a lot in the bathroom. Kevin was very excited to meet with my eight-year-old son when we visited them the first time. Kevin showed the cool stuff in his room and also talked a lot when the two boys met. Renell was pleased to see how happy Kevin was and how hard he laughed. I could totally understand how happy she was, because my older son was an only child for six years.

The racial makeup of the city in Tennessee where Renell resided was $61.41 \%$ African-American, 34.41\% White, 1.46\% Asian, 0.19\% Native American, 2.97\% Hispanic or Latino, and $1.45 \%$ from other races. Historically, the feud between Black and White has persisted in Renell's city. Therefore, two separate public school systems coexisted until recently. The city school system was made up of mostly Black students of low income or below the poverty line. The county school system was comprised of predominately White students from the middle or upper class. The racial 
strife continued when the two public school systems merged. There were four educational choices for children's education in Renell's city: private schools (including parochial schools), public schools, school choice programs and homeschooling.

My husband and sons visited the city zoo, art museums, and also Memphis' famous city park a couple of times while I was working there for a week. While playing at the city park, my son asked my husband, "Why don't I see many African-Americans in the zoo, or other places we've visited?" He tried to correct his observation before my husband answered, "Well, I did see many of them [African-Americans] walking downtown.” We could feel segregation still existed there, and poverty has plagued African-Americans in this city.

Renell's total household income over the past year, including salaries or other earnings, interest, retirement etc. was $\$ 25,000$ or less. The Median Household Income in Renell's Tennessee county was around $\$ 45,000$ dollars. Renell was low income according to federal poverty guidelines. Renell and Jace grew up in working-class families and connected themselves to the cultural context of the working class family. Renell switched from "working-class family" to "low-income family" back and forth when she talked about their social background. 
Renell and Jace have homeschooled Kevin since 2008, when he was in kindergarten. Kevin was in the fourth grade and has never attended public school.

\section{Portraiture}

The writing method from portraiture was applied in chapters four and five to present two participants' characteristics and experiences within their unique context. Portraiture was first introduced by Sara Lawrence-Lightfoot (1983) and later developed with Jessica Hoffman Davis (Lawrence-Lightfoot \& Davis, 1997). The purpose of portraiture is to unveil a vivid portrait or story that lies in the specifics and complexity of everyday life and also that reflects meanings from the perspective of both participants and researcher. The researcher is not only listening to stories but also participating in the stories that he/she co-creates with participants in their particular context. As the personal relationship between the researcher and the participants develops, the researcher's experiences become part of the portrait. While I did not design my field research to use this method, looking back I find that my relationships with the participants did reflect some of the aims of the method. Mostly, though, I used the method as a way of reflecting on the data and writing up.

For Lawrence-Lightfoot and Davis (1997), portraiture is also a distinct type of qualitative research "in its focus on the convergence of narrative and analysis, in its 
goal of speaking to broader audiences beyond the academy, ... [and] in its explicit recognition of the use of self as the primary research instrument” (p. 14). I used creative writing to carefully craft a narrative that integrates my analysis of the data while also leaving the text open for interpretation. This focus makes portraiture particularly useful as an exploratory method in this study. I should also point out that while a predominant motivational theme emerged for each mother (care for Zoe and desire for Renell), there were clearly elements of both of these motivations driving their practices. Both Zoe and Renell cared and desired, as I will explain more about.

\section{Research Techniques}

Three qualitative research techniques were used in this study: (a) survey, (b) document analysis, (c) participant observations and (d) interviews. The survey (see Appendix B) was sent to the participants via email in the first month of the study to gather basic demographic information. Survey data helped me to better determine how to approach the research process with each participant. I wrote down the profiles based on participants' responses to the survey and also started the memo-ing and field notes process. The process of writing up memos and field notes helped me reorder and consider how to approach the formal interviews. The discipline between parents exemplified the rising questions when I observed homeschooling context. This angle 
was brought up in the interview to gain holistic relationship between homeschooling and parenting styles. Or, the question about mother's maternal assistance in homeschooling context was also focused to obtain deeper information about the bond between mother and family. Some emergent questions arose and were noted from the survey data. After I completed the basic survey demographics, I had questions about the fathers' long working hours combined with their responsibilities in homeschooling. Therefore, some interview questions were shaped by the emergent questions to address the research questions and also the conceptual framework. Due to the interactive nature of my study, I continued to read the newest literature to feed my inquiry. Interviews and participant observations were primary methods of data collection. The document analysis_-including homeschooling curricula and local homeschooling policies and regulations, etc.- - was a secondary source to supplement the interviews and observations and to increase the richness and depth of the data.

\section{Document Analysis}

Another source of information that can be vital to qualitative researchers is the analysis of documents. Such documents might include official records, letters, newspaper accounts, diaries, and reports, as well as the published data used in a review of literature (Patton, 1990). 
Along with observations, I conducted a document analysis to enrich the data. I conducted a document analysis of homeschooling regulations in my participants' states of Tennessee and West Virginia, homeschooling regulations of participants' local counties/school districts, the homeschooling information packages offered by the counties, the relevant curriculum materials that participants use for their homeschooling practices, and supporting homeschooling materials participants receive from the homeschooling networks. Questions were raised from the children's portfolios, the parents' homeschooling portfolios, and the children's workbooks, and I wrote down the memo to include them as a follow up in my interviews. Through the document analysis, I gained insight into what challenges parents have faced when deciding to homeschool. Also, I analyzed local homeschooling policies and this influenced the way I developed interview questions in order to understand the decision-making processes of the participants.

After reading the local policies for a better context of homeschooling support, I asked to observe my participants in their homeschooling communities to help me better understand how their networks work and influence their homeschooling practices. Then, I could ask more specific questions that emerged during document analysis and interview observations. I participated in one homeschooling field trip and 
several family activities with both participants' family, and further questions emerged to be brought up in subsequent interviews.

\section{Observations}

The classic form of data collection in naturalistic or field research is the observation of participants in the context of a natural scene (Patton, 1990).

Observational data are used for the purpose of description: settings, activities, people, and the meanings of what is observed from the perspective of the participants.

Observation can lead to deeper understandings than mere interviews alone, because it provides knowledge of the context in which events occur, and may enable the researcher to see things that participants themselves are not aware of, or that they are unwilling to discuss (Patton, 1990).

The rationale for gathering observational data through participation and active involvement in homeschooling family activities was to uncover rich ethnographic data. My observational data reflected my interview questions and research literature, and informed my own interpretations.

I wrote emails to each participant before our first home visits. I gave the families brief biographic information about my family and me and also shared our 
interests. Then, I conducted home visits with each participant's family before the observations and interviews. I brought my family to meet with theirs, so they could feel comfortable with my families and me and ask us questions. I brought Taiwanese treats and a map, so they could learn about our cultural backgrounds and facts. Participants also shared their thoughts with us when we chatted. To break the ice between our families and to build ease and trust, I didn't bring a notebook for the first home visits, but wrote down a memo immediately after returning home.

I stayed with each homeschooling family for one week to observe their daily activities related to homeschooling, parenting, and general education. I acted as a full participant in the situations whenever possible and exercised active control over the observations to elicit information. Not only did I observe the contexts in which they were situated during homeschooling, but I also witnessed how they responded to situations and what practices they implemented. This eyewitness approach further strengthened the authenticity of the study, by building good relationships with my participants and making them feel comfortable during observation. Due to the differences in the two mothers' experiences, I listened to their voices and their dialogues and tried to write them down literally. 
The target audience for publications from this work is the homeschooling community, as well as researchers who tend to be post-positivist in orientation. Thus, the study is more credible in the eyes of its intended audience if traditional methods of trustworthiness have been used.

The observations (see Appendix E for the protocol) took place during the natural flow of the family activities. Therefore, I did not record conversations on audio, but relied on my field notes. Emerson, Fretz and Shaw (1995) demonstrated that "writing fieldnotes that are sensitive to members' meanings is primarily a matter not of asking but of inferring what people are concerned with from the specific ways in which they talk and act in a variety of natural settings" (p. 140). I jotted field notes in a notebook while observing and recording participants' natural interactions and dialogues. Not only did my field notes show participants' interactions in context but also represented how they constructed meanings and responded to the context (Emerson, Fretz, \& Shaw, 1995). After each observation session, I reviewed field notes and developed thick observation notes. Below is a brief example of my field notes regarding Renell's homeschooling practices, to show the level of thick description I captured: 
It was 9:43AM. "Let's talk about the immune system," Renell said with the book of Nutrition 101 in hand. "Immue what?" Kevin asked. Renell pronounced the word again. "Do you what immune system means?" Renell asked Kevin who sat on the sofa. Renell gave a brief introduction of the immune system and gave Kevin the book. Renell also sat by Kevin and started reading chapter 3 . She pointed to words when reading. "What's strep throat?" Kevin asked when hearing this term from the reading. "It's a virus and makes the throat hurt and uncomfortable," Renell told him, and then corrected her answer. "I am sorry. It's not a virus, but bacteria." All observations were framed around the participants' practices with a focus on their social and cultural interactions related to education. These included play, religious activities, technology, curriculum activities, sports, friendships and family activities. Observing academic instruction in action in homeschooling demonstrated parents' culturally responsive teaching styles, how the parents customized their curriculum to fit the needs of their children, and what resources they employed based on their financial states. Observations outside of the home presented how parents socialized with others to influence homeschooling and educational practices. 
Observations were crucial to the development of my interview questions

(formal and informal). My observations during social networking events allowed me to (a) test existing theories about the identities and agency of low-income families, and (b) understand the roles of consent in the agency of low-income school choice/homeschooling.

\section{Interviews}

There were two types of interviewing techniques used: formal and informal. I detail the specifics of each method used below.

Formal discussion. Qualitative interviewing uses open-ended questions that allow for individual variations (Patton, 1990). My interviews acquired information about how and why the low-income families decided to homeschool and to find facts and themes for local contexts of homeschooling choices, difficulties they encountered, the homeschooling approaches they implemented, and homeschooling networks.

The form of formal interviews in this study combined conceptual and discursive interview. Kvale and Brinkmann (2009) proposed, "The questions in conceptual interviews explore the meaning and the conceptual dimensions of central terms, as well as their positions and links within a conceptual network" (p. 151). Conceptual interviews serve as a means to unveil interviewees' discourse models. From the 
observations and document analysis, I could observe participants' perceptions of phenomena, such as the relationship between homeschooling and public schools, parents and teachers, and resource availability. Kvale and Brinkmann (2009) mentioned, "A discursive approach to interviewing highlights the local and dynamic meaning production of the interview situation itself in contrast" (p.158). Discourse analysis emphasizes how knowledge is built within contexts and the power relations of contexts. After observations, I learned how participants use language to refer to specific activities with their child/children, and how they created homeschooling environments based on their contexts of social class and educational achievement. During interviews, I elicited more concrete descriptions based on their conceptual structure shown in observations and brought up some contrasts for participants to reflect and clarify.

The interviews acquired information about how the low-income families managed homeschooling, their motivations for homeschooling, difficulties they encountered, and their homeschooling approaches.

All of the formal interviews were conducted in the homes of participants. Each of the two family participants agreed to be interviewed and described their homeschooling involvement. The mothers from two families were the participants and formal interviewees. Three interviews (see Appendix D) were conducted with each 
mother during the four months of study. I conducted my first interview following the document analysis and two home observations. The second interviews came after the third and fourth observations. I completed the final interviews with participants after the fifth observations. Interview questions emerged from the document analysis regarding local context: public schools and homeschooling, homeschooling curriculum, homeschooling supports, and observations that corresponded to the research questions. The first interview was about the parents' personal education background, reflections on their economic positions and resource availability, motivations for homeschooling, experiences with the local schools (including relations with administrators, teachers and other families), and ideas about who can be a good homeschooler and why. The second interview was about curriculum and pedagogy as it unfolds in daily life, particularly as it relates to culturally relevant and responsive practice. The third interview was about identity/agency and broader involvement in education, opinions about school choice, how they saw themselves in relation to other homeschoolers, and participation in homeschool supports/networks, etc.

The interviews focused on themes and ideas informing my research questions. My interview technique was designed to draw out participants' voices and to allow 
them to express their experiences deeply and clearly. I asked the following question to prompt conversation: "Tell me some of your unforgettable school memories all the way back in your own education, including good and bad memories." I attempted to get the participants to render concrete examples of their experiences and feelings. Among my probes was the question, "Can you tell me more examples?" My goal in these formal interviews was to obtain an authentic telling of their experiences and to reflect on their experiences.

All the interviews were audiotaped. Note taking was also used for observational recording and clarification of ideas and attitudes. I chose to use recordings, because they have the advantage of capturing data more faithfully than hurriedly written notes, and made it easier to focus during the interview.

These tapes were transcribed using a word processor/computer by both a professional transcriptionist and me. Additionally, the transcripts were returned to the participants for verification and then returned to me for analysis. I scheduled convenient phone meetings to share the transcriptions, when the participants didn't have time to review them. All tapes were destroyed upon completion of this project. Upon request, each participant received a copy of the data when it was finalized for the dissertation. 
Informal discussion. In qualitative studies, informal interviews are also important sources for context (Kvale \& Brinkmann, 2009). My informal discussions included conversations with participants that took place during home visits, on the telephone, and through emails and texts. I informally shared my personal interest in homeschooling with the participants. Conversations with participants could stimulate them to reflect or to form the inquiry of their conceptions or actions regarding homeschooling. Then, I brought up questions that complemented the more formal interview questions.

I worked to create an atmosphere that was friendly and open. Through the informal discussions, I attempted to get the mothers to provide rich examples of practice and experience. Often, my prompts were, “Can you give me examples?” or "What did that feel like?" My goal in these discussions was to obtain a holistic context of their situations and authentic telling of their experiences.

Field notes were recorded during and after the informal discussions. These included insights, interpretations, surprises, and other information that surfaced for contextualizing the interviews and their meanings (Emerson et al., 1995; Patton, 2002).

\section{Data Analysis}


Analysis began with the identification of the themes emerging from the raw data from interviews, observations, document analysis and memos. The goal was to create descriptive, multi-dimensional categories, which formed a preliminary framework for analysis. Words, phrases or events that appeared to be similar could be grouped into the same category. Themes emerged from the personal narratives. Responses to the research questions were coded and categorized to determine homeschooling practices in the aspects of educational information, difficulties encountered either in the public school system or homeschooling (or both), and strategies employed in homeschooling. The research was undertaken using an initial conceptual framework that proved essential in the data analysis phase of the study. Findings were presented to respond to the empirical data, the conceptual framework, research questions and objectives.

During the data analysis, I tried to imagine multiple interpretations of the data. I had a hard time grappling with the data based on my religious identity. I view myself as an atheist and sometimes wonder how religion plays out people's lives. The religious influences in Zoe's case troubled me. I tried to imagine how religion mattered in Zoe's homeschooling practices because there was frequent involvement in church activities and one of her husband's jobs was as a youth pastor in the church. 
On the other hand, the data also showed how religious beliefs played a modest role in Zoe's practices. I was confused and struggled when the data around religious influences seemed contradictory to me. For instance, some of my colleagues told me that the terms Zoe used for her child-rearing philosophies were related to Christianity. I did not know enough about Christianity to see all of the connections between it and Zoe's practices, I imagine. I have to admit that this is likely a significant weakness in my analysis.

Researcher memos were also an important component because they allowed me to write down any ideas concerning data (Glaser, 1978). I wrote memos to record my thoughts, questions and observations. They captured my thoughts on the data at that time and were linked to coding. Writing itself was a critical element to presenting homeschooling practices as practiced by the low-income families. Van Maanen (2002) described the challenge of phenomenological writing: “...entering and traversing the space of the text, of darkness, where one dwells alone. These writings do not yield absolute truths, or objective observation. The writer at best gains an occasional glimpse of the meaning of human existence" (p. 6).

To approach life experiences, I wrote integrative memos of each of the two cases as part of the analytic process. I developed these memos based on participants' 
responses to interview questions, observations and document analysis. First, I transcribed four interviews verbatim, and the professional transcriptionist transcribed two interviews verbatim. Then, I organized the information from the interviews and field notes from the observations and relevant documents. Next, I developed the memos and referred back to the original transcripts and notes to ensure the accuracy of the participant's accounts. Through writing down participants' stories in these memos, I was forced to reflect on the participants' back-stories of their own schooling experiences, the motivations that drove homeschooling, and the financial realities and cultural environments that influenced their homeschooling practices. The in-depth and detailed description of each of the two cases, as well as a cross-case analysis, corresponded to themes developed from the grounded theory across the cases.

When I read the data from the two cases, themes from the grounded theory could be modified and new themes could emerge as the study progressed.

Correspondent themes could emerge within the cases, as threads woven through themes formulated from the research questions.

The primary focus of cross-case analysis was both reading the case reports and implementing findings related to the research questions (Stake, 2006). Developing 
patterns while searching for correspondence between cases was another form of analyzing the cross-case data (Stake, 2006).

I modified Stake's worksheets to facilitate the cross-case analysis. The data was accessed from the transcripts, case reports, field notes, write-ups and memos. The application of worksheets functioned to keep track of all data, revealed the correspondent themes from cross-case analysis, and composed the assertions to write the final report.

I filled out worksheet 1 (Appendix G) and compared it to the matrix (see Appendix F) to help me organize the data from each case. Worksheet 2 (Appendix H) and Worksheet 3 (Appendix I) were helpful tools used in the analysis of data across cases with the supplements and references from Worksheet 1 and the matrix. During this process, I looked for the binding concepts that held the cases together, as well as the concepts that corresponded to themes emerging as grounded theory, and formed a list of cross-case assertions. With the aid of Worksheet 3, I began listing temporary assertions and decided which assertions should be highlighted, which should be secondary, and which should be abandoned. Worksheet 4 (see Appendix J) functioned as a visual tool that I used to comprise assertion statements at this stage of the cross-case analysis. 
The two participants' cases are presented in Chapter Four (Zoe) and Chapter Five (Renell). The discussion, conclusions, and recommendations for future studies are represented in Chapter Six.

\section{Trustworthiness}

In a qualitative study, the researcher often acts as the major data collector and attempts to perceive the meaning that people construct from personal values, beliefs and experiences. It is necessary to establish trustworthiness by using careful explanations of how data were collected, analyzed and interpreted (Merriam, 1998). After gathering and reviewing all of the information as transcribed, validation was conducted through triangulation of themes, descriptions, and assertions, by member checking and peer feedback.

To support the internal validity of this study, I used the following three methods: (a) triangulation, (b) member checks, and (c) peer feedback. First, triangulation is "a means through which multiple types of data are related to each other to support or contradict the interpretation and evaluation of a state of affairs" (Eisner, 1998, p. 110). The data of this study came from three major sources: the in-depth interviews, observations, and document analysis. Multiple sources of data collection helped increase the internal validity and trustworthiness of this study (Stake, 1995). 
Secondly, member checking is the process by which information is returned to participants to ensure correct transcription of data in portraying their perspectives of the homeschooling experience, a key verification step in analysis (Creswell, 1998; Stake, 1995). After observations and interviews, I shared my interpretations of participants' activities to ask for their feedback to increase the internal validity of this study. I sent the transcripts via email to each participant to check whether coded responses were relevant to the meaning. The participants reviewed what had been transcribed and coded. After viewing coded data, they e-mailed the data back, along with open-ended comments. When this was not possible, we conferred via telephone. The participants' comments and suggestions for changes demonstrated that most data coding was authentic.

Peer review (Creswell, 1998) is the third method utilized to add the trustworthiness in this study. I asked Dr. Adriane Williams and Dr. Melissa Sherfinski for their feedback on my interpretations. Dr. Williams' and Dr. Sherfinski's peer review generally supported the conclusions I drew from my analysis, but we have had some different perspectives regarding my findings and conclusions. 
Overall, these three methods helped me to understand my data more deeply.

But, I have had to acknowledge that I have ongoing questions regarding the data and my interpretations and conclusions.

\section{Researcher Identity}

In qualitative inquiry there are always problems of interpretation. The presence of an observer is likely to introduce a distortion of the natural scene, which the researcher must be aware of and work to minimize (Creswell, 1998). Since interpretation is absolutely essential, the nature of qualitative inquiry presents a number of difficulties. Van Maanen (1988) described issues, concerns and ideals in doing qualitative work. In portraying culture, the fieldworker must hear, see and write what is presumably witnessed and understood during data collection. "Most crucially, ethnography irrevocably influences the interests and lives of the people represented in them —individually and collectively, for better or for worse (Van Maanen, p. 32).

Because my knowledge and personal experiences sometimes conflicted with what I saw and heard during the processes of data collection and analysis, I had to recognize how my personal biases have influenced the way I collected and analyzed data. The following section discusses my subjectivity and position in this research. 
The heart of this discussion is the story of my older son, Hercules, and our families' experiences with public school.

\section{A Reflective Account}

My story is, I suppose, a kind of resilient journey in itself. I am a certified Chinese teacher at the elementary school level, and I taught school for three years in Taiwan. I came to West Virginia in 2005 with my husband, Ian, and my son Hercules. Once in America, I quickly came to find that the educational systems in Taiwan and the US were quite similar. Upon beginning to engage with US schools, I could easily understand how the US educational system functions. In large part, I could understand the US system easily because of my educational background and experience as a teacher. Typically, public school educators are considered opposed to homeschooling. However, I possess a liberal attitude toward homeschooling and am quite sensitive to individual parental decisions for homeschooling. My stance toward homeschooling is, in large part, a product of the difficult issues that Hercules, my husband and I encountered in the US public school system.

\section{A Chronology of Our Experiences with the Public School System}

August, 2009. August of 2009 promised to be an exciting month for our family, because Hercules was going to kindergarten! My husband, Ian, and I were 
also preparing for the birth of our second child. We were surprised to learn, on that first day of school, that Hercules was one of 35 kindergarteners in class. We voiced our concern about the class size for kindergarten to the principal. In retrospect, this was the beginning of a long line of conflicts between our family and the school administration. From the very beginning, when we questioned school policies, we were discriminated against by school personnel. Here is one example: Just one month after school started, Hercules wanted to wear a cap to school. He told us that his black hair looked "stupid," and he also questioned why he had brown eyes instead of blue eyes. He recognized that his friends with blond hair and blue eyes were the most popular with the teachers.

Early February, 2010. Unfortunately, we started seeking a new school for Hercules due to the unfriendly school climate and crowded kindergarten classroom. After a good bit of searching, we found another school in the county that we thought would suit Hercules better. But Hercules turned down our proposal of transferring schools, insisting that he had some good friends that he did not want to leave behind.

Late March, 2010. Hercules started riding the school bus in March, but he was always sulky after getting off the bus. One day, on the bus ride home, a third grader kicked Hercules in the cheek, hard enough to leave bruises. Hercules was not 
the only victim and immediately reported the bullying to the bus driver. The bus driver ignored the incident, because she was talking with someone at that time. I called the County Office of the Superintendent of Schools first. We were transferred by the Superintendent's Office to the County Transportation Office. The officials there refused our request to review the surveillance video from the school bus taken on the day of the assault. The county transportation officer told us that parents were not allowed to review the video, but that their office would respond soon. I never heard back from County Transportation. And unfortunately, I could not follow up, because after the incident, Hercules started acting strangely, and a series of overwhelming incidents ensued.

Early May, 2010. Hercules started turning his neck approximately every two seconds and blinking his eyes about every three seconds soon after the school bus incident. He told us that his neck felt stiff and sore. "Can you stop turning your neck?" we asked. "I just can't stop it, I have to do it" he insisted. We took Hercules to physician after physician, but they could not explain his symptoms. Meanwhile, the blinks and head contortions continued.

Late May, 2010. It was near 9:00 PM, and I was reading books with Hercules before he went to bed. "I can't breathe, and my breast is hurting!!!” Hercules yelled 
hysterically. He then burst into crying. We rushed to the emergency room, fearing that something very serious was going on. The doctors ran many tests on Hercules, including X-rays, blood tests, and other tests that we cannot name. As I waited, I heard him whining and crying in the other room. I was terrified for the first time in my life as I helplessly waited for the results of my son's tests.

Meanwhile, as we waited and waited, Hercules was getting anxious with his exhausted body. "I can't yawn, and I can't breathe, and my breast hurts, so I can't sleep!" We were perplexed by his reactions. We were half relieved after learning that all of the test results were normal, but Hercules' reactions left the pediatricians dumbfounded. He kept asking the doctors to give him medicine to cure his yawning problem. We arrived home around 2:00 AM, and I could not sleep one wink that night.

I returned to the emergency room again three days later, because I lost a great amount of blood in my eighth month of pregnancy. The midwife looked worried, while examining my belly to hear the baby's heartbeat. I experienced a frightening moment for the second time in my life, just three days after our trip to the emergency room with Hercules. Aristotle, my second son, was born one month before his due 
date. There were more than a dozen professionals, including a group of pediatricians, obstetricians and nurses in the labor and delivery room.

June, 2010. Hercules often felt panic — out of the blue, it seemed — because he could not yawn. We traveled from pediatric clinic to pediatric clinic. His behaviors of neck turning and blinking persisted. Finally, we met a doctor who deciphered the myth of Hercules' reactions and behaviors. He shared his daughter's story, who had symptoms just like those our son was experiencing. The doctor explained that the symptoms, called tics, were formulated when individuals experienced great pressure or trauma. Those symptoms, the doctor assured us, would lessen once Hercules felt secure in his environment. Indeed, the frequency of his tics gradually reduced during summer vacation.

July, 2010. We believed that Hercules developed the tics in response to the school bus incident. Seeking truth and justice, I called the County Transportation Office again and was informed that they had suspended the student who assaulted Hercules for three days and that all of the paper documents regarding the incident could be found at the school. However, upon pursuing the matter, I found that there was no suspension, no paperwork, and I began to doubt whether the Transportation Office Officials or school personnel reviewed the surveillance video. I asked for help 
from a Board of Education member and received a phone call from both the superintendent and the principal one week later. The superintendent told me to move on and gave no explanation for the transportation official's fabrication.

Early August, 2010. Since Hercules had no intention of transferring to a new school, we had a meeting with his assigned first grade teacher and the principal to explain the bus bullying incident, to describe the resultant tics, and to share tips for addressing the tics. However, once school resumed, Hercules' tics came back full force, and he complained of his new teacher's unfairness. Hercules received punishments every time we sent reminder notes to the teacher. Eventually, Hercules refused to go to school, even though he had many good friends there.

Late October, 2010. We had a second meeting with the first grade teacher along with the vice principal and the school counselor to seek a solution, but the first grade teacher told us that she had no idea how and what had happened to make Hercules refuse to attend school, and we could not find a solution between her and us. We transferred Hercules to another school, where he was treated fairly. He started to show us his happy face again, and since then, minor tics have returned only when he has felt especially nervous. 


\section{A Vulnerable Observer}

I can still feel the pain while writing this story. "Who will give me back a healthy Hercules without any symptoms?" I still ask myself this question two years after those crazy incidents. The school-based trauma that I have described was one of motivations that drove my interest in homeschooling. I was one of the characters in this story with my son, and as a mother, I would do everything for my children to receive the best possible education. Now, I have embarked on homeschooling research, taking with me my emotions and an academic background that would affect how I conducted my fieldwork, analyzed the data, and wrote up the text. I would use Ruth Behar's (1996) concept of The Vulnerable Observer to theorize my subjectivity and position in this study more explicitly.

Ruth Behar, an anthropologist, is a prominent scholar who has fought hard for the right to speak personally in her fieldwork. She questioned the traditional freedom of the anthropologist to pretend that her/his story and personality do not matter in research. Behar also struggled with how personal emotion is channeled into an empathetic awareness of the observed, and how personal revelation presents in research studies. 
Because I can juxtapose my own story with my participants' stories, I am a "vulnerable" observer in this study. And I will surely encounter the question of boundaries — of how my voice is present in the dissertation text. Behar (1996) proposed that the ability to deal with the autobiographical voice is critical: "efforts at self-revelation flop not because the personal voice has been used, but because it has been poorly used, leaving unscrutinized the connection, intellectual and emotional, between the observer and the observed" (p.14).

I believe that the emotional and intellectual connections between the observer and the observed are essential, and that letting the dialogue exist on both sides matters. In this study, I have not only examined my relation to my participants in terms of motivations, psychology, and emotion, but also have scrutinized the perceptions between the participants and me.

Behar stated, "It does require a keen understanding of what aspects of the self are the most important filters through which one perceives the world and, more particularly, the topic being studied" (p.13). It is my ethical responsibility to identify my subjectivity and position, as they have influenced my interpretations. I believe that my interpretations were not only enriched by personal experiences, but also contributed to the understanding of this unique homeschooling phenomenon. I have 
continually examined my assumptions and prejudices, aimed to identify them and have kept them in my mind as I have moved forward. 


\section{CHAPTER FOUR: ZOE'S STORY}

The relation of natural caring is the human condition that we, consciously or unconsciously, perceive as 'good.' It is that condition toward which we long and strive, and it is our longing for caring - to be in that special relationship that provides the motivation for us to be moral. We want to be moral in order to remain in the caring relation and to enhance the ideal of ourselves as one-caring.

$\sim$ Nel Noddings

\section{Caring}

Caring begins as an emotion that becomes activated as a display of compassion to others (Nieto, 2006). It is an embodied disposition, rich with associated emotions (Noddings, 2002). In the ethics of care literature, "care" is most often defined as a practice, value, or disposition and is usually related to feminist ethics in relation to motherhood. As a theory affixed in practices of care, care ethics developed in large part from analyses of the reasoning and activities associated with mothering (Noddings, 2002). 
Noddings attributed to feminine ethics a preference for face-to-face deliberation that occurs in real time, and an appreciation of the uniqueness of each caring relationship, including motherhood. Carol Gilligan (1982) laid out her own stage theory of moral development for women and concluded that women developed in a way that focused on connections among people (rather than separation) and on responsibility among people. These theories indicated that women are likely involved in dialogue and exchange with others and also hold themselves accountable to some specific responsibilities due to their oppressed gender role in their coming of age experiences, which may justify the assumption of care relations in motherhood.

According to Noddings, the definition of caring was best looked at relationally. She defined a caring relation as, "a connection or encounter between two human beings" (1984, p. 15). Given the above, Noddings placed a special emphasis on the home as a site for educational encounters. She viewed the home as the primary school and as the place to contribute to the development of children.

Usually, the mother is the family figure most associated with the act of caring (Noddings, 1984). She expresses caring in ways transmitted by culture and expectations and influences her children's lives positively through caring acts (Noddings, 2002). 
Noddings viewed education as a way to cultivate caring in society. She described education as "a constellation of encounters, both planned and unplanned, that promote growth through the acquisition of knowledge, skills, understanding, and appreciation" (Noddings 2002, p. 283). In education settings, care is an important element in good teaching, and it highlights the fact that even in difficult situations, teachers' relationships with their students make a difference (Nieto, 2006). Caring for students is a series of actions and attitudes that respects their individual differences as well as holds higher expectations (Flores-Gonzalez, 2002).

The following portrait of caring reflects the life of Zoe, a former homeschooling mother of six children, who lived in rural West Virginia. While this research took place months after Zoe stopped homeschooling, generally speaking, her mothering practices are important to note, because they show who Zoe was as a person; they provide glimpses of her essence as someone rooted in the ethic of care. Mothers who have homeschooled often exhibit particular dispositions, and engage in certain mothering practices that they themselves see as extensions of homeschooling (Lois, 2013). Indeed, homeschooling may be seen as much more than academic instruction in the home, but rather a form of mothering (Lois, 2013). In the story that follows, we see care embodied in a mother through her interactions with her children 
and the choices that she makes. This caring essence, I argue, was deepened by practicing homeschooling, and again exhibited by ceasing to homeschool. This is a story that also shows the complex nature of social class in contemporary society, as it is entangled with ideas about caring.

\section{Zoe}

I first visited Zoe's house with my two-year-old son, Aristotle, on a warm Saturday afternoon. I noticed that Zoe's appearance reflected her activity level: She sported a mousey-brown ponytail and sweat suit. Zoe and I were the same age, which made it easier for me to relate to her. But she was also the mother of a teenager, which is something I had not yet experienced. She and her husband, Aaron, were married immediately after they graduated from college. Their children were Iris (age 12), Wyatt (9), Kaylie (8), Erica (7), Ella (5), and Gavin (2).

At the time of this first visit, Aaron was not home, because he was preparing evaluations at the rural public high school, where he worked as a social studies teacher. The three youngest children had awoken from their naps, and the house was bursting with energy, as her six children clamored up and down the stairs, chatting and bickering. 
As Zoe attended to small chores, we talked about motherhood and

homeschooling. She paused now and then to interact with her children. "Do you need help?" she softly asked her two-year-old, Gavin, at one point. She watched her youngest son take off his shoes, and said, “Great job!” after he successfully placed both of them in the family shoe rack.

A few moments later, my son noticed two dogs outside. Zoe gave her older daughters, Iris and Kaily, a cue, and they proceeded outside to hold the dogs up to the window so my son could see them up close. Zoe spoke gently to Aristotle. "I am sorry the dogs can't go inside the house, because they are very stinky. I promise that you can pet them next time, after I give them a bath. Ok?" Zoe talked to my son using gentle tones. Zoe embodied caring for her children and for her "neighbors."

\section{Nature as Teacher}

Ella sometimes struggled with her speech, and her siblings were not consistently gracious teachers. This was a time when Zoe intervened in the moments that allowed natural and authentic opportunities for teaching. She told Erica, who had been teasing her sister, "Ok, you need to be patient with your sister and brother, like your older sister, Iris, is!” Turning to Ella, Zoe intervened, "Ella, say festival, -val again." "Festi-ball..." Ella tried to imitate the correct pronunciation, but failed again. 
"Festival, -val, -val." Zoe repeated the word again with a loving lilt in her voice. Then, she turned back to our conversation, "Yeah, she will get it someday! I was looking back at some blogs I had written while I was homeschooling. I've always wanted to be a teacher. And it's just interesting how it's manifested. You know, though I'm not in a classroom but I've actually been with the kids and teach them if I have the chance." As she revealed her approach to authentic engagement with her children, Zoe giggled, perhaps in light of the different views of "teaching" that exist, and the intense labor involved in being the active stay-at-home mother of six young children. Zoe turned her attention to Gavin, who was sitting on the floor and pulling his toy basket under the table. He grabbed a toy gun from the basket and asked Zoe to pull the lever back for him so that he could "shoot." "We didn't have a gun at home, and then Wyatt's friend gave him this one. Gavin really loves it," Zoe explained. Gavin aimed the gun at me and pulled the trigger. I played dead. He laughed at this, and asked his mom to pull back the lever again. "Don't shoot people, shoot the animals!” Zoe explained firmly. "Gavin, look, here is the kangaroo. Shoot it!” Zoe placed the stuffed kangaroo on the table and guided him. Zoe pushed the kangaroo down to the floor and made sounds when Gavin shot it. Gavin was laughing and repeated this shooting play. Gavin asked Zoe to pull the lever again and again so he 
could shoot. "See, you have to pull it back like that. I want you to learn!" Zoe demonstrated the action to Gavin again. With another trial, and then a gradual release of her support, taking fire "clicked.” At this, Zoe cooed, "You learn quickly!" while beaming at her toddler.

\section{Acts of Care}

"I don't like doing everything in a rush. Rushing to eat supper... or rushing to go to sports clubs...” Zoe complained before going on to tick off the family's harried schedule. Iris was on the volleyball team, Wyatt and Kaylie played on a soccer team that Aaron was coaching, and Erica and Ella took gymnastics lessons.

One clear way that Zoe cared for her children was to encourage them to take time to be whole. She called, "Wyatt, stop doing homework, go outside and play!" just before turning to me to explain. "I don't want them to get themselves exhausted and do homework immediately after school." “That's all right, I want to do it!" Wyatt said. "My teacher told me that my story doesn't look like a story, because the characters talk a lot!" he explained. Zoe asked, "You mean too many dialogues?" "Yes, dialogues!" Wyatt responded. I told Wyatt that he could write a chapter book if he had a lot of dialogue in his story. "You know what, yes, your story can be a chapter book, and it must be an interesting one. I would love to read it when you are done!” 
Zoe said. Her remark seemed to inspire Wyatt, as he delightedly refocused on his paper.

Zoe's attention moved to Gavin, who was waving his wooden blocks in the air. "You should put the blocks down on the floor," Zoe told him. So, Gavin added the blocks to a structure he was building, but it started to collapse. "Sorry, Mommy is not a good helper!" Zoe apologized. Zoe pointed to some blocks near Gavin. "There is more!" Gavin kept building while Zoe praised him. She didn't help, but stayed by his side and offered compliments such as, "You did it, Yay! Give me five!"

Then, Zoe spotted Kaylie riding her bike along the road in front of their house. Zoe rushed outside and angrily called, "Kayyyylieee!” Kaylie rode back home quickly and seemed to know what would happen next. "I have told you many times that if you want to ride your bike, you have to let me know, so that I can watch you outside. The cars on this road are very fast!" Zoe stared at Kaylie, who looked wounded. "You know, looking at you riding on the road made me worry. I was scared.” Kaylie responded, "I am sorry. I made you worry. I will remember next time.” Then, both of them entered the house.

"We didn't have babysitters, and my children never went to day care. And now that's important to me. Being here for my kids is important." Zoe's words struck 
a chord as I revisited them in my head on my way home. That also has been the way I have raised my two sons.

Zoe's caring acts show her expectations about her children's education. Caring is the critical theme supporting her motivations of homeschooling and also for discontinuing homeschooling. Zoe's actions are situated within a particular context of rural culture and the West Virginia public school system.

\section{Caring and Motivation}

Zoe's motivation for homeschooling developed over time. In fact, she initially did not see herself as a homeschooler:

I almost knew every homeschooling family in my neighborhood back in Minnesota. Their kids were well adjusted and smart. So I never had a negative perspective of homeschooling, I just didn't want to do it. So I always said I would never homeschool.

She went on to explain how her public schooling was a good fit for her family in the beginning:

Prior to homeschooling my children, I had two [Iris and Wyatt] attend public school — the same elementary school that I attended as a child. Iris completed kindergarten, first and second grade there; Wyatt completed 
preschool and kindergarten; and Kaylie completed preschool. They all excelled academically and socially and loved school. Having grown up here, I knew all of their teachers, and Iris's first grade teacher, Mrs. Smith, had been my kindergarten teacher many years before. I was less familiar with the administrative staff and had very little reason to interact with them, as Iris and Wyatt had no disciplinary or academic issues that required administrative involvement. In first grade, the school psychologist tested Iris for a Special Education [gifted] program. Also, because I grew up here, I knew many of the parents of Iris, Wyatt, and Kaylie's friends. Some, I attended high school with, and others had siblings that I knew.

Because it was such a small community, a lot of people knew each other. Mothers became friends with one another through their school relationships, and they knew the teachers well.

During the fall of Iris's second grade year (Wyatt was in kindergarten, and Kaylie was in preschool), Zoe noticed that their lives had become dictated by the school schedule. It was difficult to participate in extracurricular activities and church activities and still make sure that the children had adequate rest and time for 
homework. Iris and Wyatt had basketball and soccer clubs, and Kaylie played T-ball. And they had church activities every Wednesday evening. Zoe recounted how hard it was that their time was dominated by the school schedule:

We were constantly torn between staying home, getting homework done, and letting the kids rest. Or letting them do these other things. And we just didn't want to tell them no, "You can't do sports, because you've been at school all day." We felt rushed and pulled in many different directions, and the kids always seemed tired. If they had a game or a practice, we can't eat supper together. And, you know, eating supper together as a family is important to us, because we can talk and know everyone's day. We just didn't want to have to rush through those things. I began to consider homeschooling, though I said I would never homeschool.

Also that year, she visited Iris and Wyatt's classrooms on parent observation day. Zoe was disturbed by what she witnessed in Wyatt's classroom: When I was in Wyatt's kindergarten class, there was one boy in the class that was very disruptive. And I obviously don't know all the issues, but they had a teacher and an aide, and even though, like, you know, there 
were fifteen [students] plus this boy, they had isolated this boy. They had taken him somewhere else to sit, and he was just loud and unruly. So both the teacher and the aide focused on that boy. I sat there for two hours thinking, "What are they doing?" We spent a lot of time in line for the bathroom. We spent a lot of time, you know, dealing with kids falling out of chairs. I just think those situations are typical for kindergarteners and second graders. Just typical young child distractions. Zoe observed many such distractions and interruptions during the school hours. She understood that much of the teacher's focus had to go to the students who were struggling. However, because the teacher had to pay attention to the disruptive students, Zoe believed that she/he ignored the rest of students, who also needed attention.

Meanwhile, she also noticed the fact that so much time was wasted in school - time in lines for the bathroom, time to deal with distractions, time at lunch, etc. Zoe started thinking that she could provide focused academic instruction at home in a much shorter period of time, much more efficiently, and the children would then have the rest of the time to pursue other interests without getting exhausted between school and family activities. 
Additionally, Iris was having a hard time with math that year. Though the school had tested her for the gifted program, and her grades were all very high A's, the school started pulling her out of the classroom to deliver math intervention:

That's new to me. When I was in school, you had to have parental permission to receive special services through the reading specialist or the math specialist. Well, now you don't. They can pull your kids, and they miss classroom time to get this extra help. Iris was missing classroom time three days a week to receive extra help in math, even though she was still making A's in other subjects.

Zoe understood that it was the teacher's job to identify weaknesses in students and then to refer them the proper specialist for intervention. But, Iris also had great strengths in English, reading and creative writing. While Iris was pulled out for intervention, she was not yet labeled "gifted," and she was not pulled out to develop her specific strengths. This, in Zoe's eyes, was a deficient model of seeing her daughter. Zoe explained the alternative ways in which she developed Iris's strengths in homeschooling practice:

I just started thinking about these things... at home, not that I wouldn't work on her math. Not that we wouldn't take more time if she needs 
more time. But that I could also take time to work on these strengths to teach her things about creative writing. Like one of the first things we did when she was homeschooled in third grade was that I gave her an email account. And gave her the email addresses of friends and family. Two or three times a week I would have her construct emails, and I would say, "I want you to email your grandma and tell her about your plans for this weekend."

Zoe saw the importance of differentiation instruction done well, though she did not call it that. She saw that we all have strengths and weaknesses and recognized that we should help children to focus on their strengths more so than on their weaknesses. She saw that she could teach what they were learning at school in a much more individualized and efficient way.

Like most homeschooling families, her Christian faith connected to her desire to homeschool (Ray, 2004; Stevens, 2001):

Another reason I decided to home school was that I knew there were certain issues concerning morality and faith that I would like to instill in my children at a young age. I knew that a strong foundation of good character and faith in God would put them at an advantage in terms of self-confidence, empathy, 
good citizenship and love for life. When I homeschooled, it was not out of fear of my kids being polluted by outside influences, nor was it solely for religious reasons. It's not that I think the public school should do that [cultivate morality]. I'm not saying they're not doing their job. It's just that if the kids were at home, I could do my job. Aaron and I thought: We're gonna look at this every year. We're going to take it year by year-not reject the public school system — and we're going to try this and see how it goes.

Zoe's family was highly involved in athletics and church activities. Iris, Wyatt, Kaylie, Erica and Ella all participated in various sports year round. A good amount of family/free time was spent at sporting events and practices. Also, the children attended youth classes on Sundays and Wednesdays. When they were in public school, her children usually slept on the school bus due to their busy extracurricular schedules mixed with school. Zoe knew how much her children enjoyed participating in sports and didn't want to strip their privileges due to their fatigue after school. She wanted to develop her children's interests in sports; she also cared about their physical development. But she worried about their fatigue.

Meanwhile, the lack of family time concerned her, since everyone in the family would have less time to talk with each other, to hear about daily experiences, 
and to discuss life at school. Family life is of importance especially when children are young, because parents can understand or even nurture children's personalities (Noddings, 1984). Zoe emphasized that family was an important place for individual development and in her religious beliefs.

Zoe understood that schoolteachers could not focus on individual teaching and further reinforce the children's strengths due to schooling structures. Even if teachers wanted to care for each child, the conditions of classroom settings did not allow them to develop the deeper understandings of children (Noddings, 2003). Developing a rigorous curriculum that builds up students' strengths or interests is a challenging task for teachers who will need extra time and commitment to engage (Nieto, 2000; Valenzuela, 1999).

Zoe believed she was in a better position to cultivate her children's unique gifts in a homeschooling environment compared to the public school setting. She could better use time to develop each child's strength, to nurture healthy individuals, and to strengthen family ties.

These combined factors were the reasons that Zoe first considered and then decided on homeschooling her children. Zoe's homeschooling motivations included: having more time as a family, being able to commit to extracurricular activities 
without exhausting the children, providing a means of developing both strengths and weaknesses in her children's academics, personalities and relationships, and laying a Christian foundation of faith and ethics.

\section{Limited School Choices}

Public school and homeschooling were the only choices Zoe had as she considered options for her children's education, in part because of the very rural environs and homogenous community. School choice programs did not exist in West Virginia and were impractical given the very low population density and significant driving distances between towns, often over treacherous roads that could become impassable in winter. Zoe was unfamiliar with private and parochial schools, as there were none in her county. For Zoe, even homeschooling was barely on the map in her county, as it was done so rarely. She explained her feelings about the local homeschooling context:

There is literally no choice in my county... People don't even realize, I would say the majority of people do not even realize that homeschooling is a choice. I would say that homeschooling is so foreign here. It could be different for our neighboring county; it has a larger homeschooling 
population and even has a homeschooling organization. It also has

schools, which are affiliated with various religions.

There were some innovative, fledgling schools nearby, outfitted with intensive resources, but Zoe believed that they were for the poorest of the poor-other people's children:

I have a friend who just started working for a school; you could call it charter school-ish, maybe. But it's like the poorest of the poor. It's like the kids who have no parental involvement whatsoever. Each classroom has three teachers, because it takes that many to teach... there's only 15 kids in her class. But it's a new school, and it's supposed to be outfitted with top-notch technology, so that these kids can have opportunities that they wouldn't have had otherwise. So she's been telling me about that. It seems to work.

Her husband, Aaron, was an advocate of school choice programs. He gave Zoe books and articles so that she could learn more about them. He did not like the fact that the local public school system had what he sees as, "a monopoly." He was all for choice, including the availability of Christian schools and charter schools with high standards. Zoe explained how Aaron connected 
with other school choice advocates given the limited educational choices in their area:

[Aaron] is very pro-charter schools, which is contrary to a lot of public school teachers and the teachers union. But he's not involved with the teachers union; he's kind of always out on his own. And he's also been in communication with a guy who works as a legislator in our neighboring state, whose main area of focus is school choice. So they communicate back and forth a lot.

Aaron connected to the school choice advocates through the homeschooling fieldtrips. After looking over the activities of the homeschooling fieldtrip in the state capitol, he thought the activities were generic and decided to contact the offices of state legislators, so that the next fieldtrip would be more meaningful and educational for children. Since legislators' offices responded to his plan and were willing to meet with children, he indirectly developed a connection to school choice advocates through legislative networks. Aaron also chose not to be a part of a union or teachers' organization because of his view on the government's role in education. He believed that the teachers unions unfairly influence government education policy. He did not 
want to advance objectives that were politicized in the name of education. Aaron thought students and parents should be the main focus in education.

Zoe continued, "There's even been people that have talked about starting a Christian school in our area. And they automatically assume that I would want my kids there. And I can't say that I would want my kids there.” The local church leaders had heard from parents that they would like a Christian school, and so they wished to offer another educational option in the county. Zoe couldn't say for sure what she would choose if she had a variety of options, but she would have been pleased to see more educational choices available in her area.

Zoe's opinions about choice and expanding options were in flux. Although she may have been heavily influenced by her husband's opinions on choice, she explained that he was not her sole source of information and that her views were not solely a result of his influence. The more she became interested in homeschooling, the more she read. She definitely considered his perspective and read the books he recommended, but she had an independent mind on the issue. However, they were a team. Zoe was currently pro school choice. She and Aaron believed that education was not a one-size-fits-all issue. In their shared opinion, the government should not solely promote traditional public education, but should encourage communities to 
provide a variety of educational opportunities even within the public system to promote variety and diversity of options and not to discriminate.

Since school choice programs and private schools were absent in Zoe's area, their wishes to see more choices and to allow parents to pick the suitable school for children actually contradicted the education conditions in their county. They realized that limited educational choices would eventually rule some children out of schooling, which would disadvantage some families who might need other options.

The issue of one-size-fits-all was the core theme that Zoe and Aaron challenged in their local context, and one that was central to their children's schooling experiences. Raymond Williams' (1977) structures of feeling provide a way to understand Zoe and Aaron's thoughts as shifting and changing responses shaped by lived experiences and social context. Williams proposed that experiences within a space and place contribute to memory and interactions. Zoe and Aaron's consciousness about educational choices sparked their reflections of their local context and their engagement in pro school choice campaigns in their area. 


\section{The Role of Class in Caring}

\section{A Low Income Family}

As Aaron was a public school teacher in West Virginia - a state with one of the very lowest teacher pay grades in the nation (National Education Association, 2011) — he did not make a lot of money. Therefore, the family was considered low income given their large family size, according to federal poverty guidelines. Aaron taught school and coached full time and also worked a number of part-time jobs: at McDonalds, the post office, and as a youth pastor at their church. Zoe did not work, because she was the one designated to stay home with the children. Interestingly, Zoe felt little financial stress while homeschooling, even though they were a low-income family by federal standards. Zoe purchased supplies, such as pencils, notebooks, crayons, and folders, from Wal-Mart if she could get a bargain. She also used a lot of free online sites. For example, the children did math drills and spelling games she found online:

Usually my budget for homeschooling materials was about six hundred dollars a year. And a lot of times my budget came in under that. If something cost money, it did not deter me. I paid for a curriculum and looked for the best deals. I printed out worksheets online so they can practice. 
According to Zoe, the family used "money wisdom." If they wanted to buy something, they saved the money for their purchase, and they taught this value to their children. She saw this as a form of caring and responsibility: "We're good stewards of our money, good stewards of our time...We do the best we can with what we have." Zoe saw her own family's financial health in contrast to that of a homeschooling friend, whose debt was oppressive, even though they took in more money than Zoe and Aaron.

Zoe described the way they lived as simply and minimally. They focused on the quality of the things in their life more than the quantity. "With a limited income, we evaluate each purchase decision thoroughly, because we cannot afford not to. Caring for the kids' needs and interests is a top priority in our finances." They would be more likely to put money towards sports equipment, music lessons, local entertainment/sightseeing, and dinners with friends and family than they would to spend money on things like a trip to Disney World or going to the latest movie in the theatre.

Noddings proposed that care begins in the home and moves outward. She described care as: "Learning first what it means to be cared for, then to care for intimate others, and finally to care about those we cannot care for directly" (2002, p. 31). Zoe 
and Aaron modeled this kind of care for their children, spending money on others as they were led to do so. For instance, they sponsored a girl from Mexico through World Vision and also gave money to international medical organizations, orphanages, and the less fortunate in their community. They spent time as a family volunteering locally and would have been more likely to send their child on a trip to work in an orphanage than they would to a three-day concert event, they said.

Caring not only consists of the attitudes and actions parents have for their children, but also helping the children learn to develop care with others and the environment around them, including the learning environment (Noddings, 2002). Zoe and Aaron demonstrated caring in their relations with others, as comports with Nodding's work. By demonstrating caring acts and respect for others' ideas and feelings, Zoe nurtured her children's caring attitudes inside and outside her home.

\section{Reasons to Discontinue Homeschooling}

Zoe stopped homeschooling not because of economic reasons but because of her older children's requests to go back to school, and because of her own desire to spend more time with her youngest children. However, there were a host of contextual factors that facilitated a smooth return to brick-and-mortar schools. In the beginning, Zoe approached homeschooling year-by-year, but she believed that she would 
homeschool all the way through elementary school. When Iris finished fifth grade at home and was ready to go to brick-and-mortar middle school, Kaylie started saying, "I want to go to school!" So, Zoe and Aaron talked about this with the children and also evaluated the potential impact of resuming public school three years after their original homeschooling project began:

Well, we're not anti-public school. As Kaylie proposed, Aaron and I guessed we could try it. And Kaylie, she'd been a different student all along. So I thought maybe she'll do really well, and she got a good foundation as I homeschooled her.

After Kaylie's request, Zoe evaluated each child's attitude toward public school. Iris and Kaylie attended public school for sixth grade and third grade, respectively, while Wyatt and Erica remained at home. After the first six weeks, Wyatt also expressed his desire to attend public school, so Wyatt entered in October. Iris, Wyatt and Kaylie became very excited about what they were doing with their friends and the teachers when they attended public school. Erica started kindergarten second semester, after Zoe took her in for an evaluation, where Erica found she loved being in school like her older siblings. 
It was not difficult to act on her children's desires to enter school, because homeschooling, for Zoe, was so strenuous. The main challenge that Zoe faced while homeschooling was that she was only one mother with six children spanning in age from baby to preteen. It was very difficult to teach multiple grade levels with excellence, while having a newborn, toddler, and preschooler who also needed so much care. She believed that those infant/toddler years were just as important (if not more important) in the big picture of a child's development as were the school years, and so she pragmatically balanced her practice in regard to all of her children's needs:

Having Iris, Wyatt, and Kaylie home as much as I did, I had time with them. And so it seemed like the more involved I got in their education, the less involved I became with Erica, Ella and Gavin...And so it was like Gavin was all of a sudden a year old, and it's like I hardly knew him.

The concept of individual differences is the core theme for understanding how people differ and how they come to develop their distinctive characteristics (Murray, 1996; Bandura, 1977). In the social sciences, there has been an ongoing and well-known debate between nature (referring to genetics) and nurture (referring to the 
the environment) (Grych \& Fincham, 2001; Harter, 1990). A large base of literature has shown that the environment parents provide for their children makes a difference in the children's lives. Most parents invest tremendous effort in supporting their children's personalities and intellectual development. Modern psychologists have suggested that both nature and nurture influence how children develop (Harter, 1990; Jenkins \& Astington, 1996; Wigfield \& Eccles, 2000).

Zoe did not emphasize the nature role in her children's development but paid careful attention to the family. She believed the family environment shapes children's personalities and habits, and that the mother is in the primary position to influence who children become. She believed that the mother serves as the person who takes responsibility for the children's lives, who cultivates growth in their capacities, and who socializes the children. Providing childcare was a part of her "job," but knowing her children was even more significant, and it was a privilege for Zoe as a mother. Zoe believed that a child's personality and disposition are formed before the child is five years old. Though she saw the older children's educations as important, she believed that it was more important to place fuller attention on the younger children. She could not balance teaching her older children with being with the baby, 
toddler and preschooler. Therefore, she and Aaron were receptive when the older children wished to return to public school.

\section{Caring in the Local Context}

\section{Between Homeschooling and Public School}

Zoe acquired resources about children's learning styles, testing and evaluation from the local public school. Schoolteachers and administrators generously offered assistance in providing resources to Zoe. The following two examples demonstrate how Zoe obtained resources through the public school system.

Zoe thought that there was something not quite right with Kaylie's learning after the first several months of homeschooling. She was so different from her brother and sister, and it seemed like no matter what Zoe did, Kaylie still struggled to understand concepts. So, Zoe contacted the local elementary school principal and asked to schedule a meeting with the school psychologist. The school psychologist tested Kaylie, and then Zoe met with the principal, the school psychologist, the reading and math specialists, and the school counselor to discuss what would best help Kaylie learn at home. Zoe reflected on the experience:

Maybe it was an issue of her learning style. So I called the school, and I just asked if we could meet with, like, the guidance counselor or the 
school psychologist. And was there any testing they could do with her...

So we went through all this testing. It turned out that [Kaylie] did not have a learning disability and scored very high on the IQ testing in all areas but one. The area in which she scored very low was "working memory." The school psychologist told me that is often indicative of ADD [Attention Deficit Disorder].

The school psychologist, and the reading and math specialists helped Zoe develop a plan for Kaylie and recommended several books and exercises. Zoe found that the exercises made a world of difference in Kaylie's learning.

Before Zoe contacted the school, she mentioned this idea to her homeschooling friend, and her friend was very against her plan. Her friend responded, “Oh no, no, no. They're just going to tell you, you need to put her in school." So Aaron and Zoe talked about it. Aaron said, “We've always said whatever is best for each kid. And if there is something we can't handle at home why would we be opposed to school?" That's why they sought assistance from public school, and it turned out to be a constructive solution. Zoe implemented their suggestions, and Kaylie excelled the rest of the year and continued to excel once she was placed in public school. 
Moreover, Zoe believed that even "good" homeschoolers needed to be evaluated. In West Virginia, families may choose between standardized tests and portfolio examinations as their yearly evaluation requirement. Iris opted to take standardized tests at the public school, but Zoe opted for a licensed public school teacher/evaluator to examine Wyatt's and Kaylie's portfolios. When Zoe contacted her county Board of Education, the administrators there were unfamiliar with the regulations for homeschoolers, perhaps because homeschooling was so uncommon in the region.

Eventually, Zoe's homeschooling friend recommended a licensed portfolio evaluator, living in a college town 100 miles away. The evaluation fee was $\$ 100$. Zoe said:

She [the evaluator in the college town] is a homeschooling parent who also has her teaching certification. You just take the stack of books, this is what my friend told me. She said you don't have to do anything. You just take the stack of books, she looks at them and says, "OK, you passed." Because it's easy there. Her evaluation consists of going like this and signing the paper. And I don't think that's very thorough. 
Zoe did not want that type of easy-pass evaluation. She really wanted her children to be evaluated fairly, and she wished to evaluate her own homeschooling practices. Zoe held herself accountable for her children's learning performance, since she was their primary teacher. The results of her children's annual academic performance reflected her teaching efficacy. Zoe's attitude toward her children's learning and her teaching evaluations reflected the concept of responsibility from Gilligan's (1995) theory of moral development for women (p. 121). Zoe sought assistance with educating her children based on caring for her children's learning and on her responsibility for teaching.

For example, Zoe called the principal of the local public school again to ask for assistance in evaluation. The principal connected Zoe to an experienced teacher who had taught first through third grades for 30 years. The principal exhibited an act of caring in a way Zoe's homeschooling peers had not. Receptive attention is an essential characteristic of a caring encounter (Noddings, 2002). Zoe received a helpful response from school administrators. She was pleased because this evaluator would have a good idea of where the children each needed to be academically: 
I kind of wanted [the evaluator] to go through some of the benchmark testing that they do with students. I said, "Don't go easy on them. Print out the CSOs, see if they know what they're supposed to know." So that's what they ended up doing, like the same way they evaluated the public school students in language and in math. And it basically just puts them at what level they're at. [The school] had [Wyatt and Kaylie] complete the exercises, and then they went over the basic report card, like you have to know your letters. And so they did that report card with them just as if they were in school. So I liked that.

Therefore, the local public school was an important resource for Zoe's homeschooling practices. School administrators and teachers offered necessary assistance when Zoe wanted standards-based evaluations of academic performance.

\section{Local Resources for Low Income Families}

In Zoe's county, residents often existed on incomes far below the federal poverty guidelines. Because of their large, single wage-earner family, Zoe's children have always qualified for free lunch and for Head Start. But the family has resisted Head Start, because they are wary of government involvement in their children's lives at such a young age. 
Overall, Zoe thought that the school system and social services did a good job serving low-income families. The school system worked closely with local churches and the Family Resource Network sponsored by Catholic Charities to provide childcare support. Church leaders came to the local Board of Education meetings and offered their ideas about how to serve the low-income population in her local area. Whether organizations had at their root religious or nonreligious purposes, the school system made sure that low-income children were provided for.

Interestingly, when Zoe discussed the targets of community charity, she did not see herself and her family in that lower-income group. As she explained:

Different groups come in and do after-school activities, like with tutoring. The backpacks [church groups place snacks and sandwiches in the packs of identified children who may not receive evening meals]...they do a lot of programs for parents... One example is gun safety. But their target audience is those who are really low income.

Zoe believed that those who are lower income than she are those for whom government attention and support should be designed. Meanwhile, Zoe was continually called to participate in these targeted activities, because her children were on the free lunch list. 


\section{Roles of Social Networks in Constructing Care}

In fact, when I studied the homeschooling application process in Zoe's county, the availability of online resources was meager, with links to just a couple of homeschooling websites. As Zoe explained:

When I started thinking about [homeschooling], I would think back to my friends in Minnesota, and I basically just read a lot of articles on the computer.

Because we don't have a lot of homeschooling resources here [in the local area], there aren't a lot of people that I know that homeschool.

When preparing to homeschool, Zoe called the Board of Education and asked to speak to the curriculum director who oversees all homeschooling in her county. She shared the following:

I had a list of questions. Basically, "What do I have to do?" [The curriculum director] didn't know the answers to any of it. She's not there now or that's not her job anymore. There's another girl, and she seems a little more with it. This year she sent me a letter saying that they did not get Wyatt's homeschooling evaluation. I said he is in public school now. 
Zoe did not think that the BOE was anti-homeschooling, but rather that she was ignorant of homeschooling regulations, because homeschooling was so uncommon in her area.

Zoe searched out homeschooling information online and read an online

Catholic homeschooling women's forum. She read relevant homeschooling blogs and websites to obtain basic information. And, Zoe talked with her nearby homeschooling friend who was, in fact, her only fellow homeschooling friend.

Zoe joined two homeschooling organizations to gain access to more online information. One was a non-religious association (West Virginia Home Educator's Association-WVHEA) and the other one was religiously affiliated (Christian Home Educators of WV-CHEWV). She got newsletters in the mail and read their websites periodically to obtain information. Iris submitted her story to an essay contest held by WVHEA, because Zoe read about it in one of their newsletters. As mentioned, her children participated in homeschool day at the capitol, which was organized through CHEWV. Zoe learned of this activity on the CHEWV website. She learned about the state's testing system for homeschooling students through WVHEA. While there were not satellite groups nearby, there was a children's activity cooperative 75 minutes from her home. 
Faced with isolation, Zoe tried to form a small homeschooling cohort in her area, so that she, her friend from the county mentioned previously, and another friend in a neighboring state could meet regularly for fun. But, her homeschooling friends were ultimately not interested. She and the other two homeschooling families, however, did hold their Valentine's Day, Halloween, and Christmas parties together.

\section{Caring Through Teaching}

\section{Homeschooling Environments}

The learning environment Zoe built for homeschooling was highly structured, with classes running from 8 a.m. to noon almost every day. She did not use popular DVD curricula, but instead had a variety of textbooks and workbooks for each child. She chose standardized testing as an evaluation method for Iris and the portfolio as an evaluation for Wyatt and Kaylie, while most other homeschoolers opted for a portfolio evaluation.

Zoe described her parenting style as "parent directed." As a parent, she believed it was her responsibility to teach and to train children in many different areas of life. This meant that she had to take the time to know each child individually, so that she could best train them according to each of their unique gifts and their personalities. She believed that it was also her responsibility to set limits, boundaries, 
and to give responsibilities and freedoms, all with the ultimate goal of training children to grow in independence from her and to learn how to think. Zoe related her parenting style to her homeschooling practice:

My parenting style influences the ways I teach my children...It causes me to establish boundaries and guidelines through which I will produce the best environment for teaching. For example, I would not allow my children to do school work while watching TV. They might want to do that, but because my parenting style is parent-directed and not child-directed, I decide that we will not watch TV while doing school work and expect that the children will follow the guideline.

Zoe's Christian beliefs did come to play out in her conviction that parent-directed instruction and education were best in most areas of child rearing. As a mother who was with them all the time, she knew every child's learning style, strengths and weaknesses, which gave her the advantage of fostering her children's capacities. She valued individualism and helped each of them develop their uniqueness. Though she was currently not home schooling, she still was the parent who was directing the children's education. She was highly involved and knowledgeable about what her children did on a day-to-day basis. She communicated 
regularly with teachers via phone, email, and face-to-face meetings, because she did believe it was her job to assume responsibility and leadership in her children's education, whether it was in the home or in the public school. Her motherhood gave her both the privilege and responsibility to train her children in responsibility and social decorum within the family environment.

However, learning is not always interesting. During my observations, the children sometimes became bored. Given the homeschooling context, I had assumed coming into this research that the children would have had much more flexibility. The rigidity did not always work well for the children. For example, Zoe explained that Iris usually complained a little if she was not in the mood to learn, but then came back to learning soon after. As for Wyatt, Zoe had to justify and cajole in order to persuade Wyatt to return to learning after he had left. Although I did not often observe Zoe use an authoritarian stance, I assumed that she would do so if she used up all of the softer means to spur her children's motivations. For Zoe, learning was that important. Zoe described herself as an organized person; everything must proceed in an "appropriate" manner to develop the children's proper discipline for when they must integrate into the outside the world. She modeled those attitudes and also explained to her children the reasons why those social attitudes were important and polite. When it 
came to social decorum, Zoe insisted the children follow her standards and meet her expectations. She learned that most homeschooling families among her local peers did not have an organized learning environment due to the flexible time, which was something she disparaged.

Zoe's homeschooling practice was similar to a teacher in a traditional classroom. The teacher outlined the rules of the class, and the students were expected to follow. Her children sat in chairs and worked on their studies individually. Then, she directed each of them equally, so that each obtained what they needed from her in their unique situation, whether it was to learn multiplication or to read a book. Zoe wanted them to be able to have enough discipline that they could sit down, sit straight, and read texts with the proper learning attitude:

I'm thinking, if they were in public school you can't say, 'I'm going to go lay down and get out of my desk and lay on the floor and..." I mean, for some families that works and their parenting style is different than mine and that's what they do.

As she thought about her practice, Zoe would always reflect back on what one could do and what one couldn't do in public school. She told me that she also 
prepared them for the day that they would go to public school. It was all with the goal in mind of producing an environment most conducive for learning.

In addition to academic study, Zoe wanted her children to learn relationship skills (socialization). She believed that the best place for a young child to be socialized is within the family unit. Also, she believed that the home is a great place to teach responsibility. Zoe believed that chores helped to develop a work ethic in children. She expected her kids to help out around the house with age-appropriate chores such as putting dirty laundry in baskets, carrying dirty plates to the sink, picking up toys, helping with pets, etc.

\section{Racial Others}

Zoe's homeschooling friend, who is White, married the only Black man in the county. The racial context of this family affected how they experienced homeschooling. This is best evidenced by an anecdote shared by Zoe. "Oh, I bet you're going to be our star player on the basketball team this year. Well, you're tall and you're Black!" That was what the school resource officer told her friend's daughter as she registered for half-time public school in order to take part in extracurricular activities. Zoe believed that this officer wasn't trying to offend her friend's daughter, but that he was rude in making a stereotypical assumption. 
Zoe thinks that race is one reason her friend has continued to homeschool. It is not that her friend necessarily had a bad public school experience herself, because she went to public school in Zoe's county. She felt, sometimes, that her children have been targeted as "the Black kids." She was concerned that her bi-racial children would experience unnecessary discrimination within the public school system.

Homeschooling was her first choice when her children came of school age.

According to Zoe, her friend's curriculum and teaching methods were centered on an education that was both Biblical and attentive to the racial identities of her children. She had ten children from ages one to 18 , which made it difficult to have all her children in homeschool at once. Several years ago, she was very sick and was unable to homeschool her children, so they attended public school for one year. Though she was reluctant to send her children to public school, she did not want her health condition to impact her children's learning. After she was well, she continued homeschooling and was doing the best that she could.

Regardless of the challenge, Zoe's friend cared more about her children's capacity to receive an education free of the damage of racial discrimination than about the level of difficulty associated with homeschooling children across such a wide age spectrum. It was difficult to be a minority in a nearly all-White area with a history of 
racial violence. Zoe said, "I mean, we're White rednecks, a bunch of hillbillies. Sadly, often times we just say ignorant things, do ignorant things. So anyway, that's the only experience I know of how the system here has dealt with anything color-related." It appeared that Zoe served as a confidant and support to this particular friend. The isolation she felt both because she had married a Black man and was the mother of bi-racial children and because she seemed solely responsible for their education meant that Zoe was a critical part of her support system. Zoe's caring therefore extended beyond her own children to this friend and her children as well.

\section{Culturally Relevant and Responsive Teaching in Individualism}

Early on in this chapter, we saw how Zoe, as a mother, saw each of her children as individuals. This ideal of caring as tailoring to each child was a crucial theme in Zoe's homeschool teaching as well. Zoe related how homeschooling practices foster a child's individual academic and subject strengths:

I wanted my children to learn all of the subjects they would learn at public school: reading, math, social studies, language, science, handwriting, typing, art, music, physical education, etc. Additionally, I wanted them to develop specific areas of interest. For example, Iris was very interested in reading and writing. We often did special creative 
writing projects and took many trips to the library to explore different kinds of reading material. Wyatt is a year and half ahead in Mathematics and Science and loves challenging topics. Aaron and I tried to give him more challenging content in Math and Science, because he loves them and he is doing very well.

Zoe and the children walked to the library one mile away from their house every Wednesday, so that they could check out books that were interesting to them. Zoe described herself as a reader who read everything that drew her attention and enjoyed learning something new. She also wanted her children to like reading as much as she did, and the reading motivation contributed to their trip to the library every Wednesday.

She recognized that the habit of loving reading needed to be nurtured instead of forced. Reading was not a task, but a joy, which was why Zoe used a child-centered approach instead of a parent-directed approach in this particular instance. It also allowed her to discover her children's interests, and learning new knowledge with them with pleasure. Learning something new together added to the family bond. The relationship they built reflects Noddings' theory of caring and reciprocity. Zoe did not assign the children books to read; she let them choose. Moreover, Zoe had a clear 
philosophy of the power of words: "I think that people can teach themselves just about anything if they can read. I have loved teaching them to read and seeing them come alive while reading a book."

Developing specific areas of interest and focusing on the children's strengths were two major goals for Zoe as she homeschooled her children:

Iris is still not good in math. And, I just didn’t fret over it. You know, it was maybe a problem at times. She and Wyatt were working at the same level, but I knew there wasn't a learning disability, her brain is not wired that way, and I would work more on functional math. We'd learned on paper and apply it to everyday life.

Zoe realized that children can potentially thrive in any healthy setting. She believed that if a child had a major learning problem, they could get proper attention for that specific problem at school. But, she also believed that she could help each child in a way that would set them up to be successful if she homeschooled. Zoe illustrated her commitment to her individual children's strengths as she compared the learning styles of two of her children:

Wyatt is self-taught and learns the concepts quickly. So he could work more independently than the girls. But, Kaylie has a different learning 
style. I have to sit with her for one-and-a-half hours to work on her learning. If I do not sit by her, she will forget what she is supposed to do and will shred an eraser into fifty pieces. I had a hard time getting Kaylie to focus on learning to write her name. So, I remember that I had her use a finger in a pan of rice. Because it was something different and probably the most creative thing I did.

If there was something that the children were really struggling with, and Zoe felt like she had explained that concept in every way possible, they would just take a "time out." They would walk away from it, since she believed that it was not worth getting upset about. They would work through the idea again after coming back, without feeling so frustrated.

Zoe helped her children learn by building on her children's own individual learning styles. Not only did Zoe strive to instruct based on her children's abilities, but also to teach relative to her children's learning styles. Accordingly, homeschooling cultivated each child's individuality. Zoe told me that the children could accomplish a great deal of work in a short period of time when homeschooling. Also, teaching her children at home gave her the opportunity to know each of them better and to have a better understanding of who they were as people. She believed 
that she could respond to the children's learning needs, while a conventional classroom was unable to fit the children's individuality.

In the school setting, teachers are encouraged to reflect on and consider the relationship between culture and learning (Nieto, 2005). Culturally relevant and responsive teaching involves a sincere respect for students and belief in their potential as learners (Gay, 2002). This perspective can be expanded to any educational setting, including homeschooling. In Zoe's homeschooling practice, she believed that she was able to connect to her children's experiences and to explore how to create culturally responsive and caring environments.

\section{No Child Left Behind: Anti-Individualism and Anti-Caring}

When Zoe's children attended public school for the first time, NCLB had already taken effect. She knew that different learning practices had unfolded at the elementary school level in response to NCLB. One of the learning practices that occurred frequently at the local elementary school was timed reading. Aaron told her that, in the name of NCLB, a local reading specialist was given a grant by the federal government to formulate a program to improve academic performance in her county. This program was implemented in reading and math when Iris was in first grade: 
Everything was timed, everything. So it started out really slow, and all the kids had to master that time before they would move on as a group. Teachers might set the time at 60 seconds to have students finish the task, but it would take forever to move up as a group.

Zoe also observed students timing each other:

In second grade, [students] broke up into groups a lot. There are twenty kids in the class; they may have had five groups of four. They would go through and give each other math flash cards, or they would give each other reading flash cards. You have to read so many words in a certain period of time.

Zoe observed that this timed instruction seemed chaotic, and that many interruptions went on during the timed program. Meanwhile, Zoe thought that peer teaching was not necessarily negative, but she felt that the timed practices had steered away from the purpose of reading and other issues. She would rather that her children read slowly and understand, than read quickly to meet a certain score. Zoe valued reading comprehension. She found out that children usually have no idea what they read when rushed: 
It was night after night we were doing these timed readings, and the kids always did well at home. They've never struggled with it.... Iris is like flying through stuff [at home], but [at school] she could not move on because the other kids can't achieve the certain scores.

In Dynamic Indicators of Basic Early Literacy Skills (DIBELS), the program she was witnessing, timed reading is built on the premise that one must read fluently in order to comprehend - that there is a connection between speed and comprehension (Riedel, 2007). Zoe was not aware of the research behind this program and misunderstood the purpose of timed reading. That she made decisions based on that understanding without receiving a clear explanation from the teachers suggests that she did not ask questions about the program, nor did the school staff take the time to make sure parents understood the approach.

She understood that school helped some children who were falling behind, and these policies were enabling them to keep up. Zoe did not blame the teachers for spending extra time teaching the students who needed more time in learning. She recognized that it was an inevitable consequence of trying to teach large groups of students in different academic level with a small number of adults. However, attention to individual growth and development is difficult if not impossible in the typical 
public schooling setting; and this structure of schooling was unable to meet the particular needs of her children.

She believed that her children needed to be challenged and to move on at their own faster pace, instead of being held back by the performance of the lowest group member. She looked at the quantity and quality of work that came home from school in relation to the hours spent there, and she had a hard time reconciling how this program benefitted Iris. The problems of public school instruction could be remediated at home. Zoe's focus was on what was best for her children. She believed that homeschooling was a solution for her children to develop to their full potentials.

The NCLB practices at the school promoted a collective movement and what Zoe felt was an uncaring approach that did not attend to the individual capacities and needs of her children. NCLB as a federal policy focused on systemic movement and group performance, which appeared to translate into group treatments. Zoe's interest was in her children and their learning. Her choices to use state assessments indicated that she was not opposed to state standards; she was opposed to the school-based practices she observed. The law did not care about her children, she believed. Instead, she believed that NCLB cared only for preserving institutions, and perhaps for the children who were weighing most heavily on state assessment outcomes. 


\section{Child Agency}

Zoe was highly involved with her children, whether they were at home or at public school. She enjoyed listening to them and having conversations about their interests. Zoe explained that she didn't micromanage her children's lives when something came up, but instead encouraged or offered different perspectives. "I have to know my kids. And to know my kids, I have to hear from them. So it's not the type of parent-directed where [the children] sit down, shut up, don't say anything."

This relationship was evidenced in her children's words and enthusiasm about homeschooling. As Wyatt relayed, "I really love homeschooling! I have all this free time. I can play video games and build Legos and play outside after I finish school works in the morning. There is no way I'd want to go to school!" Before homeschooling, Wyatt went to preschool and kindergarten at the public school. And, he loved his time at home. So, when Wyatt asked to follow his sisters and return to the public school, Zoe was surprised.

In response, Zoe explained to Wyatt, "Now, you know, if you go in, we're going to do the whole year. We're going to finish the year in public school, and we will reevaluate over the summer." Zoe knew a homeschooling mother who pulled her children in and out of school constantly, based on whether or not her children felt like 
going to school. By being clear on the commitment required, Zoe believed that she showed Wyatt the attitude and responsibility he should have regarding decision-making.

Unfortunately, the transition back to public school was rocky for Wyatt. He got into trouble and struggled in his initial months at school. Wyatt left his seat and went to the restroom without the teacher's permission. He sometimes did not know what to do during class, could not find the art classroom, or could not follow the routine of the PE class. Wyatt missed many breaks due to his behaviors.

Zoe had routines and rules in her home school, for example, "Don't interrupt me for something silly. Go sharpen your pencil. Go to the bathroom. Get a drink. But then come back." Zoe explained how Wyatt tried to transfer homeschooling rules to the public school. Unfortunately, this made for a difficult transition, as did the fact that he missed the critical beginning of the year, because it was October when he decided that he wished to follow his sisters to school. He did not know how the system worked. So, Zoe eventually met with Wyatt's teachers, explained how his difficulties stemmed from her homeschooling rules, and asked the teachers to try to take the time to explain as much as possible to Wyatt, a big question-asker. 
At the time of his troubles, Wyatt made this statement to his mother: "Mom, I just want to come home and be homeschooled again, but I know you wouldn't let me. I know we talked about the decision before I went to school. But, you say you will look at it [homeschooling or public school] again in the summer, right?" Wyatt was aware of his responsibility to keep the promise. He knew he had to commit to his decision, and he finished the year.

But, as he acclimated to the routines and rules of the public school, Wyatt changed his mind about wanting to return home. "I wanna go back to school. I love my teachers and friends at school. I don't think I will choose homeschool." Wyatt confirmed his decision after Zoe and Aaron reevaluated his learning in public school. Once Wyatt caught on to how the system worked, he loved it and began to thrive. Wyatt's decision to remain in public school surprised Zoe, since she thought that Wyatt would choose to come back to homeschooling. However, Zoe was glad that her son could so thoughtfully express his needs and opinions.

Zoe, Aaron, the schoolteachers, and Wyatt communicated with each other, listened to each side, and, importantly, gained trust with each other. They engaged in dialogue and learned about Wyatt's needs and their mutual expectations, so that they could identify and confront issues together. They were able to construct a type of caring 
that allowed Wyatt to feel he could be successful in school. He had experienced the very caring environment of his homeschool and still opted for a public school environment. Wyatt's experience suggests that the caring and support Zoe sought and did not find previously in public school, was, in fact, available.

\section{The Father's Role}

Compared to most homeschooling fathers, Aaron had a significant role in his children's academic instruction (Lois, 2013; Stevens, 2001). Aaron taught Iris, Wyatt and Kaylie social studies and science at home, using West Virginia's teaching standards as a guide. He taught all three children together, following the curriculum for the middle child's (Wyatt's) grade level. He also taught Iris logic, using a commercially prepared instructional sequence.

Regarding Aaron's role, Zoe explained, “I remember one time we went to the zoo, and Aaron gave the children things to look for, and questions before we ever went. So they had to think about those questions." When it came to homeschooling, Aaron tried to work with the children to construct knowledge through their activities.

During field trips, he would ask the children questions instead of just sightseeing. He also studied with his children and helped them understand content as needed. 
Aaron took the eldest three children to Homeschool Day at the state capitol two years in a row. Zoe never went to Homeschool Day, because she needed to care for the youngest children at home. Aaron tailored the trip to his eldest children's needs and connected the content learned to the state standards. He made appointments with state senators and a county representative. In the first year, Aaron wrote out questions for the children to ask the politicians about their jobs, and the children took notes in their individual notebooks. During the second year of the event, Aaron even scheduled lunch for his family with a pro-homeschooling state senator. Zoe added, "And then the second year, some people were meeting with their representatives, because they like Aaron's idea." Aaron's ideas sparked changes in subsequent state Homeschool Days. Eventually, he started bringing his high school civics classes to the capitol to meet the contacts he made through Homeschool Days.

Aaron filled a caring role within his family by providing a holistic education to his children. He stated that he is a student himself-always reading and seeking to learn and understand more about many different topics. Even though the children were no longer homeschooled, Zoe and Aaron were equally responsible for teaching them to be critical thinkers and to reflect on their actions and behavior. Aaron specifically provided spiritual leadership and was interested in all details of his 
children's lives. His role could be labeled atypical, in that he believed it was his job to provide Biblical instruction outside of a church setting. Although Zoe filled a fairly traditional role as a mother, Zoe and Aaron saw each other as a team—they functioned as a unit in loving, caring and educating their children.

Aaron participated very little in the daily tasks of homeschooling, compared to Zoe's full involvement, and yet provided most of the family's income that made homeschooling possible. Even though Zoe shared her philosophy of gender equality and expressed how she demonstrated it in children's chore responsibilities (e.g., it is not always a woman's job to clean the house.), Zoe was still the one who stayed at home while Aaron managed external activities - working, taking children to meet the state senators, or pushing the political movement for school choice. Her role still fell within traditional gender roles, where women remain in the position to nurture children in the marriage. Aaron believed that being a teacher was more than a career or an occupation, but rather a gift or a calling that first should be displayed at home and in the lives of his children:

Aaron has been gone from home a lot, because he teaches during the day and then has other various jobs in the evening. But for the time he was home, he 
was always doing something to help, or to just see how it's going, or to take the kids somewhere on the weekend.

I could see how Aaron cared with many small and thoughtful actions done for his family.

\section{Discussion}

Zoe does not fit into any of the boxes defined by the literature or frameworks on which I rely, nor does she fit easily into my own framework. Zoe is a hybrid ideologue-pedagogue. She rejected the factory model of education but was not fully committed to the idea that public education was fundamental to democracy, so reform was not part of her discourse. As a White, Christian woman, she was part of the dominant culture, but she seemed slightly uncomfortable explaining how her religion influenced her homeschooling practices. Zoe did not fully acknowledge her economic and social positions, but she did not appear to distance herself from poorer families because of any sense of disdain for low-income people or those who must rely on government assistance. She is a puzzle.

\section{Zoe and Public Schools}

Although Zoe claimed to be parent-directed in her approach to parenting and homeschooling, she clearly demonstrated both parent-directed and child-centered 
practices in homeschooling and in her homeschooling practice. Zoe's criticism of the collective approach to schooling she witnessed in public schools and her concern for her children's individual needs points to a child-centered approach. Her rejection of the idea that children must be seen and not heard and her desire to listen to her children to determine what their interests were and how to nurture them, is also evidence of child-centeredness.

At the same time, Zoe's day-to-day practices mirrored the authoritative parent-directed approaches similar to traditional teacher-centered schooling practices. But even those practices reflected a child-centeredness, which came to light when Wyatt returned to public schools. Zoe's practice taught self-regulation and responsibility, which conflicted with traditional schooling practices that in many cases constantly monitor student behavior, leaving almost no decisions to the children-not even the most basic decisions, like going to the bathroom.

Zoe's pedagogical disagreement with public schools fell within the social realm. She had few problems with the current economic goals of schooling that produced the standards and assessment environment. She embraced those goals and sought to ensure that her children were adhering to the objectives that existed to serve those goals. What did not interest her was the way in which schools tended to treat all 
children the same and kept them from becoming fully developed individuals. There was nothing in the ways in which Zoe talked about homeschooling that suggested that she was concerned with democratic education, but her husband had an interest in that area and contributed to their children's learning in that arena in particular ways, specifically around politics and citizenship.

\section{Zoe and Dominant Culture}

Zoe knew she was a White, Christian, female person. She was aware of identity and hierarchy. But she was not fully comfortable claiming the dominant group's position. She pointed out racism in her community. She pushed back against the idea that she might have been a typical Christian homeschooler. And she resisted the notion of strict gender roles even while filling one.

Zoe's homeschooling practices were not primarily religious in nature. She was not inclined to be a Christian homeschooler. She sought secular materials, and her practices did not reflect strict adherence to any particular tenet. But Zoe was a practicing Christian, and her religion was a part of her parenting and teaching practices. Again, her claim of parent-direction in both her parenting and teaching was resonant of a particular aspect of Judeo-Christian parenting, where parents have been tasked by God to point their children in the right direction. Likewise, her focus on 
character was also informed by her religious beliefs. Specifically, her use of "money wisdom" and modeling "good stewardship" were examples of the kinds of teachings to which her family would be exposed during their multiple church classes - three - throughout the week, not including regular Sunday worship.

Compared to Zoe's homeschooling friend, Zoe's White culture did not directly influence her decision-making in homeschooling, but it did indirectly shape her homeschooling practices. Zoe had a wonderful school experience as a child and had no complaints about teachers and administrators in her public school experiences. Besides, Zoe received assistance from the public school system, and the school administrators and teachers cooperated with Zoe to facilitate her homeschooling practices. White culture was the dominant one in her local area, and she understood how the racial context could influence her friend's homeschooling motivation. Together Zoe and her friend, along with their respective families, formed a definition of culture within a whole way of life. This definition was embedded in their experiences and practices in the local context. The experiences that Zoe's friend confronted could explain the cultural experiences among the different races. The concepts of dominant culture and oppressed culture demonstrated how cultures and race come into view and were unique in Zoe's area. 
Zoe expressed that she and Aaron were a team in family affairs, but, in my observation, it seemed that Aaron mostly took the lead to influence the direction of family. As a public school teacher, Aaron might have obtained more information and influences about the educational choices and might have had the resources and means to connect to the political party in comparison to his stay-at-home wife. Typically, mothers initiate, execute, and manage homeschooling practices and are also credited for doing much of the political labor of homeschooling (Gaither, 2008; Stevens, 2001; Wilcox, \& Robin, 2011). Aaron's role is atypical in pushing the influences in politics in homeschooling. Zoe still fulfills the traditional women's role of staying home with children all the time before and after the homeschooling period.

\section{Zoe and Neoliberal Ideology}

Zoe embraced the philosophy of neoliberalism and supported the educational choices provided that they offered her and her family more options. Though Aaron and Zoe were situated in the rural area of West Virginia, where educational choices have not been as accessible as those in the city, they upheld the free market in education, which ought to expand the individual choices and competition among schools. Since Zoe was an informed parent capable of doing the information research, 
she was able to exert her self-determination to decide either to homeschool or to stay in public school.

When Zoe's children attended the public school three years prior, NCLB had already taken affect. NCLB has promoted the idea that competition leads to better schools, the improvement of educational opportunities for all students, and parental empowerment through choice in education. Though NCLB has promoted competition among public schools, Zoe did not have many choices in her rural area.

Moreover, individualism was the primary approach that Zoe emphasized in her children's education. Zoe resisted the concept of a factory model of education when her two children attended school. School as a factory, children as products, and standardized testing are three main perspectives of factory education (Serafini, 2002). In Zoe's observations of Iris and Wyatt's learning in school, students were like products on the conveyor belt, and sometimes progressed slowly or quickly forward, based on the whole learning setting instead of an individual's need. Schools operated more like assembly lines, sorting students as they passed through each stage of the curriculum, and measured the quality of "student product" through standardized tests (Gatto, 2002; Arce et al., 2005). 
Zoe resisted the notion that her children's abilities could be determined in the standardized environment, and she supported individualism in education. Her philosophy on individualism and school choice contributed to the family's motivation for homeschooling.

\section{Zoe's Capital and Its Use}

The literature shows that parents with higher educational attainment know how the schooling system works. They understand the academic standards and teachers' expectations for students. Bourdieu (1990) understood human action to be embedded within culturally constructed "fields" or arenas of interaction. He used the term "habitus" to capture everyday practices tied to subjectivities (e. g., class) and life experiences. Habitus is an internalized code or learned ability to associate certain meanings with certain symbolic forms or goods that are distributed and reproduced through "familial strategies" and educational institutions (Bourdieu, 1998).

Zoe's homeschooling practices justify Bourdieu's process of habitus. Zoe's educational background bestowed upon her the ability to negotiate with schoolteachers and administrators, either when she sought help in her children's evaluations or when she requested the meeting with teachers to clarity Wyatt's situation. Her ability to use the Internet to research and obtain homeschooling 
information and to seek a network to make homeschooling activities diverse reflects her cultural capital, which facilitates homeschooling practices.

\section{Zoe and Social Class}

The homeschooling literature does not account for Zoe and her family. While she is categorized as very low income, her income level does not appear to have much influence on her homeschooling practices. Zoe identified herself as "working class", but she does not fit into the sociological definitions of working class either because her husband is a white collar worker and she and her husband are highly educated. Income and class are not the same thing, but it is difficult to determine how to explain Zoe's social class given her income level, her use of cultural capital, and her schooling practices. This is particularly true if I rely on the literature describing social class and parent-school relations, or social class and school choice.

Zoe was a very low-income woman possessed of a middle-class sense of authority when engaging with public institutions. She used a middle-class sense of pity when discussing those in need of government assistance. And she used a middle-class approach to parenting, specifically when it came to balancing a respect for authority with independence, self-regulation and questioning. 


\section{Zoe's Theories}

Because Zoe is a hybrid ideologue-pedagogue homeschooler, it is challenging to characterize her working theories in any way that is consistent. What can be said is: She tightly aligned her understanding of the problem with her vision of the outcome and her ultimate decisions. Her action of giving her children the freedom to choose public school, and her recognition that where homeschooling once met her need to focus on her children and then did not, clearly moved her away from the ideologue and into the pedagogue category.

Zoe's Christianity also played a central ideological role in her practice. Unlike Christian parents who homeschool for religious reasons, Zoe's choice to homeschool stemmed mostly from pedagogical concerns. But both her approach to parenting and her use of the Bible as an instructional tool point to the importance of religious belief. It is worth noting that among the things that were weighing down her children's schedules, it was public schooling and all of it demands, and not church-related activities, that had to be set aside.

\section{Summary}

Helping her three older children to reach their maximum potentials was the motivation that drove Zoe to homeschool. She applied different teaching approaches 
to customize each child's learning and wielded her cultural resources to enrich homeschooling practices. Three years after first beginning her homeschooling project, nurturing her younger children ironically became the key factor that encouraged her to stop homeschooling.

Caring for each of her children in their different stages of life contributed to a pragmatic and fluid form of care that interrelated with Zoe's shifting, complex stance on educational choice. Her project was personalized and oriented toward the local. It included care for the children, the church, and the community. It was about making do in the moment.

Even though the father in this family was a public school civics teacher, a true conception of democratic education as outlined in the second chapter of this dissertation was not part of his educational project in the home school because he saw democracy as choice and privatization more so than thick relationships between the state, parents, and children promoting education for all children. It could be said that this family used the local school like wealthy executives would use consultants. The real motivation for homeschooling was the family's religious beliefs, not a concern for building stronger communities through democratic schools or advocating for reform that can change structural inequalities and reconceptualize troubling race 
relations. But even so, the mere fact that dialogue could occur among the parents, the children, and the school in this case does point to the possibility of working toward democratic education in the future, given a change in the community toward shifting purposes and commitments. Zoe did express a level of commitment to her children pursuing intellectual inquiry. It is not completely clear, however, the degree to which they would be encouraged to grapple with outside ideas and a vast range of perspectives as they matured. But again, the lines of communication between the home and the school were open. Given this, I suggest that there could be hope in the community - eventually - for a more democratic educational future. 


\section{CHAPTER FIVE: RENELL'S STORY}

"Do not spoil what you have by desiring what you have not; remember that what you now have was once among the things you only hoped for."

Epicurus

\section{Desire}

Desire means a passion for something (Deleuze \& Guattari, 1972: Anscombe, 2000; Schroeder, 2004). Passion is a state of mind that is expressed through actions (Deleuze \& Guattari, 1972; Price, 1989). Desire is associated with differing individual actions. For example, one individual may have the desire to learn through reading, while another may desire to fulfill a dream through making a plan a reality; and yet another individual may desire to express passion through teaching. Without actions, we cannot interpret the ideas behind the desire (Deleuze \& Guattari, 1972; Oddie, 2005).

Deleuze and Guattari proposed that desire is not to be identified with lack but rather with a real productive force. They used the term "desiring" as synonymous with "production"- - to describe the nature of desire as a machine, functioning as a circuit breaker in a larger "circuit" of several machines. The desiring-machine produces a flow of desire from itself. Deleuze and Guattari (1972) pictured a multi-functional 
universe composed of such machines all connected to each other. "There are no desiring-machines that exist outside the social machines that they form on a large scale; and no social machines without the desiring machines that inhabit them on a small scale" (p. 51). Desire produces reality in the social field.

Intrinsic desires are valuable in and of themselves. Pleasure, the welfare of one's children, and justice are all intrinsic desires. These desires often prove to be motivating, because achieving these things is considered good. Subsequently, the actions that are taken to achieve these desires may also be judged as good. Therefore, desire motivates action. One seeks satisfaction through the fulfillment of desires.

Desire produces a type of consciousness. Hegel (2011) proposed that desire moves consciousness outside to form a relation with the world, which reflects the limits of the subject in turn: "I know who I am through the connection with others."

Renell's homeschooling practices and her schooling experiences can be described as motivated by desire. She came from a background of struggle and continued to struggle in her quest to accrue economic, social, and cultural capital within her local context. I felt Renell's sense of desire after spending a week in Memphis with her. Her homeschooling story is bound up with her schooling 
experiences, her hometown and her race. The desires that drove her actions were both conscious and unconscious.

My husband, my two sons, and I spent three days driving from Morgantown, West Virginia to Memphis, Tennessee, and we were excited and also curious about this area, since this was our first time visiting the city. Renell was very responsive to my emails before we met in person. Renell, a talkative stay-at-home mother, was born and went through all her education, including the first years of college, in her hometown, Memphis. Jace, her husband, who was earning a Master's degree in English, and working as a server in a restaurant, was born in Michigan, grew up in San Diego, California, and had completed his postsecondary education in Memphis. Their only son, Kevin, was a nine-year-old, well-behaved boy with a reserved personality. He has never left Memphis. Renell has homeschooled Kevin since he was four after she finished a temporary job assignment, and she has served as the co-leader in her homeschooling support group.

Thirty-five-year-old Renell greeted me at her front door wearing a head wrap, an African-style blouse, jeans, and a beautiful bracelet made of glass and metal beads. I could see her light eye makeup behind her round red glasses as she introduced her husband, Kevin, and herself. Renell's neighborhood was adjacent to a popular city park 
and near grand homes with beautiful lawns and pristine apartment buildings. The neighborhood was filled with joggers and dog-walkers. I found it surprising that the family could afford to rent in this district. The parking lot of their apartment complex was pitted with potholes, which indicated why it might be more affordable. Renell provided a detailed introduction to her building regarding its history, architectural style and owner. As she explained, "This apartment is over 100 years old...I did some research." Renell, I soon found out, was the kind of person who read the historical markers no matter where she went. She was fascinated by historical homes and events. "I am really into history, but not like the History Channel!" she explained laughingly. I saw, as my time with her unfolded, her desire to know and understand the past. What is more, I saw her taste for fine things. As it turned out, homeschooling was strongly connected to these desires.

\section{Activism}

Kevin's room was brightly lit. There were two windows on one of his walls. A small television stood next to his "little library" on a small bookshelf that spilled over onto the floor. Toys and DVDs were neatly stacked on a second shelf. I spotted some books that seemed to be about girls and/or have female protagonists. Kevin caught me 
checking out his selection and commented, "I like this book. It talked about a girl who rescued her family from a forest fire."

Curious about Renell's curriculum and knowing that she was a Christian, like Zoe, I asked her whether or not she taught her son about the women of the Bible, as well as about the men. She responded:

Yeah, I try to make people and things of all sorts of backgrounds just naturally part of the fabric of his learning experience, where it's not focused on any one group of people. It's also not male-centric. I do consider myself a feminist.

In expressing this logic, Renell proudly claimed who she is. Renell kept things grounded as she taught Kevin her faith and ideals:

You know, we're not in this bubble in this world where everybody believes the same thing. And that's ok, because that's part of his learning experience - how to navigate, tolerate, and be amicable with people of all types of faiths.

Renell's curriculum centered on cultural studies. She wanted Kevin to be proud of who he was, to know his history, and to help his community. She shared passionately about many issues of race and culture, her voice rising and her tone deepening as she did so. She explained, "I focus on the Afrocentric part a little bit out 
of my own militancy, but also out of my respect, love, and adoration for my culture as well as other cultures." I would replace "militancy" with "activism" to explain her attitude, and the philosophy behind her desire to act.

\section{A Passion for Learning}

It was a cool Tuesday afternoon. Kevin was back from his lunch break. Renell gave Kevin a geography worksheet and said, "You need to give me more information about Pennsylvania." Renell set her laptop up in front of Kevin, and Kevin typed "Pennsylvania's motto" into the Google search bar. Then, a list of websites appeared on the screen. Meanwhile, Renell was reading a library book about slavery. She explained, "This book interests me because it offers a different historical version as far as I know. I think I will look for more books to see if this version was unique, or something I just don't know!" I noticed her eyes shining, and it was like she had discovered a new treasure. Then Kevin called out, “Mom, I can't find the motto of Pennsylvania!" Renell set down her book and came to sit by Kevin's side. Renell prompted after clicking to a Pennsylvania website, "What do you think? Which statement is its motto?" “That would be 'virtue, liberty, and independence,' I think!” Kevin said, while pointing to the text on the screen. 
Kevin looked for information online and referred to his geography books on the table as he finished his Pennsylvania worksheet. "Do you remember where Pennsylvania is?" Renell asked suddenly in the middle of her own reading. "It's in the east or west?" she asked. "East," Kevin responded. "North or south?" "North," he answered. "Right, so we say it's in the northeast," Renell reminded him. "You need to find the population of Pennsylvania and its square miles," Renell said after checking his worksheet. Then, she resumed her reading. "Really? I need to check this...interesting statement..." Renell murmured to herself regarding her text, while Kevin quietly searched for the answers necessary to complete the worksheet. "I can't find the population of Pennsylvania!" Kevin told his mother. She put down her book again and said, "I need to show you the US Census website and then you can find the latest demographics of each state!" After entering that website, Renell guided him to find the information, explaining the features of the website along the way. They found the number of square miles in Pennsylvania, and they also spotted the interesting facts about racial/ethnic groups. I could see that these facts fascinated Renell as she pointed her finger at the screen and said excitedly, "Wow, look at those figures. We should take a look and learn more!" Renell looked at the report, explained to Kevin how the data were collected, and then opened another 
window. She and Kevin ended up spending 30 minutes learning new information together. Their inquiry was provoked by Kevin's roadblock.

This mother-son exchange did not surprise me, as Renell had already shared how much she loved to dig deep for knowledge and was always reading:

My favorite day at school was the last day of school, because teachers usually gave away textbooks that they weren't going to use anymore. I wanted as many books as I could get my hands on, so that I could play school and read all summer. And most of the books that I got were for grades higher, which I really loved. So I had a milk crate full to the brim, and a full backpack.... I'm tottering out the door, and the teachers are laughing, but they loved seeing a kid so studious.

A deep desire to learn, and a passion for knowledge were important facets of Renell's essence. Her homeschooling practices reflected her values, and provided time and space to develop her intellect. In this quest, books and the Internet were her partners, and her disposition was continually modeled for Kevin. She implemented what she believed by teaching and demonstrated her passion for learning by sharing it with her son. But, desire is complex, which was reflected in Renell's homeschooling journey. 


\section{The Context of Educational Choice in Memphis}

Four educational choices were available for parents in Memphis. These were private schools, public schools, school choice programs (which may have included public and private options), and homeschooling. This section outlines the educational forms available to Renell.

\section{Private School}

Private schools in Memphis were not available to everyone because of their high cost. In order to appear more welcoming (as Renell interpreted it), the local private schools represented themselves as economically and racially diverse. But according to Renell, in reality, it was the White children who were able to patronize what were considered high-quality schools. While private schools offered scholarships and financial aid, acceptance was extremely competitive and often required an entrance examination. Unfortunately, Renell had missed the deadline to apply, because she was unfamiliar with the process and did not have the kind of support network that would give her regular access to good information about private schooling options.

\section{Traditional Public School}


Renell explained that there was a "great" public school in close proximity to her apartment. However, she would not consider having Kevin attend. This was because homeschooling worked for Kevin. Renell explained:

It's a great public school. I thought about it. I have a friend who taught there for several years. We went to college together is how I know her. And we talked last year, and she invited me to come and sit in on her class.... But now we're comfortable with [homeschooling] and our final plan was that we were open to homeschooling him all the way through high school.... Otherwise, public school was never really... once we started [homeschooling], it kind of was out of the question.

Another issue within public schools was the "merging war" between the city and the county schools. Renell explained the historical feud between Whites and Blacks in her city, a battle that had continued into the present. Whites, who tended to live in the suburbs, wanted to form their own school districts in order to further segregate the public school system in Memphis. This has resulted in heated disputes and even chaos. Renell did not want Kevin to be educated in such a segregated climate. As she exclaimed indignantly: 
Some of the municipalities want to break off and form their own school district, that's how desperate they are to keep their precious White children away from the Black kids in the city schools. And to not have them in their schools and to just keep their worlds whitewashed...the climate right now here with this merger foolishness, and it just nixed any serious thought of him going...I don't care how good it is. I just don't want us to be stuck in the middle of that, because it's so much about the adults right now.

Renell believed that this merger war was not about what was best for the kids, and this troubling context of overt racism bolstered her choice to homeschool. In effect, turning away from the public schools was, to Renell, an anti-racist act. Renell believed that bureaucracy in the public schools was a huge problem, and that the administration was not concerned about students in the city school system. She believed that city schools did not receive adequate funds to help students perform at high levels. And, there was frequent turnover of teachers and administrators, who were sometimes fired and replaced by individuals whom she regarded as unqualified to work in the city schools. She explained:

Yeah, they get a lot of teachers through those different programs, like Teach for America and stuff that aren't from here, which a lot of parents 
have a problem with. I'm one. And you can't just come here from Florida,

New York, Chicago, California, and think with your grand ideas that might

be great, but you know, this is the South. And the majority of this city is

Black.

Dissatisfaction with hiring new teachers and administrators from outside the area was another concern to her. She believed that schoolteachers and administrators needed to be raised in Memphis, know the history of this city, understand why there were two separate school systems, and hold ties to the city. Renell argued that there were also so many structural and racial issues present outside of the scope of education, and the needs of teachers or administrators needed to be addressed first. She believed that outsiders could not realize the whole ecological system in this city. She complained:

There are people who are from here or lived here many years who want to teach and can't get in to teach. And that's something that's seen in many areas, not even just education. This city gives a lot of contracts to people outside of it. We don't take care of our own, which is a big reason why economically we aren't where we could be, and why so many people are poor here, is because we won't pay for services and goods that are available 
locally, we will go outside to get it. We go outside to get supposedly qualified teachers, but we won't hire people who are qualified and who have a sincere interest to educate children, because they understand this city.

Renell put her direct attention toward the facts of hiring schoolteachers from outside of the city when talking about the ecological system in her hometown. The effect of desire is to direct attention toward reasons to fulfill the desire and has notable effects on other forms of attention. Renell's desire for improved public schools in her context has played an important role in directing her attention to the needs of and for teachers and administrators and their bonds to this city.

Renell's desire for changes in the local school context has been reflected in the notion of the structure of feeling. Structure of feeling is a term Raymond Williams (1977) defined as "the continuity of experience from a particular work, through its particular form, to its recognition as a general form, and then the relation of this general form to a period." Raymond Williams adopted the concept of structures of feeling to understand culture and cultural change at a particular time and place. $\mathrm{He}$ described that emotional or cultural experience is conditioned by the structures of the world we live in, though the structures can be perceived in several ways. It suggests 
that a common set of perceptions and values shared by a particular generation can be articulated in particular forms and conventions.

Therefore, each group lives and produces its own structure of feeling. Particular groups might express this most forcibly and extend unevenly through the culture as a whole. Renell emphasized the racial issues in her city. Structures of feeling were shaped and interpreted differently by Black and White people. Her structures of feeling could mirror her desire for changes in the local school context.

\section{Public School Choice Programs}

There were a variety of school choice programs in Renell's city: charter schools, vouchers for private school, optional programs and magnet schools. Optional programs were a type of advanced programming within schools - a higher track. She did not claim to be familiar with the full menu of public school choice programs in the city, but she doubted them because they were structured within the public school system. Renell explained:

I'm not real familiar [with school choice programs], and I do have an acquaintance who is a teacher at a charter school. I know in general what charter schools are. I've learned a little bit from some of the documentaries, like Waiting for Superman...It was all about the lotteries that some schools 
have because they have so many applicants trying to get into those charter schools, which is really disturbing to me.

The school choice context was yet another variation on the public school theme, and one that presented for Renell more concerns about equity. For Renell, exploring this program was simply not reasonable.

\section{Homeschooling}

Homeschooling in Memphis has been growing by leaps and bounds. But according to Renell's account, by far the richest educational opportunities were organized in the suburban areas in which predominantly White, middle-class families resided, where many families could afford to homeschool. A wide range of co-op activities and classes, and supports for homeschooling families were offered in the suburbs. Unfortunately for Renell, these opportunities were over 30 minutes away by car, and so she could not participate regularly. She explained, "And that is where you can see how homeschooling here can perpetuate social class differences, in where you can find the co-op classes and extra things like that."

There were multiple ways in which parents could register to homeschool in the state of Tennessee. The state supported a website that explained homeschooling policies and procedures to families. Parents were directed to register for 
homeschooling through their local Boards of Education or through homeschooling organizations. Renell paid $\$ 80.00$ for her membership, and the agency took care of her registration paperwork.

Renell explained that, unless some miracle happened and Kevin got a full scholarship to a private school, homeschooling was a perfect fit. For Renell, given the very constrained choices of schooling available to her in Memphis, homeschooling was sensible even though it did not erase social inequality completely. As we shall see, there were many elements of homeschooling that answered Renell's questions about what made for a successful and meaningful life for both herself and her son.

Considering what homeschooling offered, she simply could not pass up the opportunity.

\section{Homeschooling Desire}

\section{Desiring Private School}

Renell's initial reason for homeschooling Kevin was that she could not afford the private school that she wanted to send him to. The private, religious boy's school posted an annual tuition of $\$ 16,000$, which was unthinkable for Renell and Jace.

As a child, Renell had excelled academically, but at the same time, she was often bored in school. She always believed that she would have achieved more if she 
could have attended a private school. This desire for something more drove her to consider private education first as an educational choice for Kevin:

I knew I probably wanted to send my kid to private school, because that did stem from my own experience. The whole strong desire of wanting him to go to a private school, that definitely came from my experience, because I wanted to go to a private school. Because I always felt like, I would get what I need, what I keep asking these teachers to give me and they won't. I would get that at a private school. Because I knew a couple kids here and there growing up who went to private school. And they would tell me about it, and I was like, "You're doing that at your school?" And I would be so sad and sometimes jealous.

Renell believed that private schools were much better than the public schools, based on the curricula and the nature of the two types of schooling. However, Renell did believe that there were some not-so-good private schools. In her philosophy, a "good" private school was a "for-profit" school. Actually, Renell misunderstood something fundamental about private schools: There have been very few for-profit K-12 schools that are private. For-profit schools have tended to be public. I think she referred to better customer service as a reality of schools that rely on tuitions, such as 
tuition-reliant or tuition-based schools. Renell believed that a private school would respond to what customers (parents) ask for, such as a challenging curriculum and services. For example, a greater percentage of private school faculty, in her mind, has graduate-level degrees than do public school faculty. She also believed that private schools offer a broader range of foreign languages and sports activities than do public schools. She also believed that private schools offer a better world-view and more cultural experiences and exposure than do public schools. She believed that all private schools were college preparatory and were more successful for college preparation than were the highest tracks in the public schools.

Renell illustrated the difference in foreign language availability between public schools and private schools in her area:

Because you're paying for it, you get what you pay for. You get what you pay for and what you don't pay for in free public education. It's like sending your kid to a pre-university kind of thing [at the private schools]. It's not just teachers with bachelor's degrees; [private schools] have high percentage of masters and doctorate degree teachers. There are a lot of [public] schools that don't even have the option of French, they only have Spanish, and they don't have a teacher qualified enough to teach more than 
two years of that. But you have private schools that are offering Spanish,

French, Chinese, Japanese, Russian, German, Latin, Italian.

\section{Healing the Pain of Public School Memories}

Again, Renell's motivation for homeschooling was deeply rooted in her desire to be challenged intellectually and to achieve more than she felt was possible in her own public schooling. She was always in the "high" group and always outperformed others, even in that accelerated group. However, her teachers did not want her to go ahead of the other kids in the group, so she was usually assigned to help teachers to do other things after she finished her work. So, she got bored in class due to the unchallenging content and had some behavioral issues such as humming songs during class. I can see Renell's eyes shining when talking about her high achievement: ...I was seven, eight years old, and asking the teacher myself: "Can you give me something harder to do?" They were like, "She's probably going to be just like this in third grade." They're like, "So she needs a challenge." And back then, the way to challenge a kid was to just let them skip a grade and go to the fourth grade. Because they were like, "She's going to be like this in the third grade, she's going to be bored, she's going to be harassing us to give her more work." 
Therefore, her teachers had considered skipping her ahead when Renell was in second grade. But, skipping didn't happen due to the school system, and her mother's decision. Nearly three decades later, Renell still looked crestfallen as she spoke about this disappointment:

I wished my teachers would have let me [skip grades]. But, they were part of the school system, and apparently it didn't allow them to. They wanted me to skip third grade. And all the third grade teachers were in an uproar, because they all had been so excited to find out which third grade class I was going to be in. They were so anxious to have a student like me in their class. And they were literally upset at the idea that there was talk of me skipping third grade and going to fourth grade. Going from second to fourth grade. Which didn't happen, and I was disappointed.

Renell's mother was also against the idea of skipping grades. Her mother was worried about her social and emotional maturity, because she had heard about some bad experiences with skipping from a friend's daughter. Renell's mother was also worried that she could not handle the world if she finished school at 16, especially given the limited job options for young Black women in the South. It sounded to me like Renell still held a grudge about her mom's decision: 
I wish I had been smart enough back then to argue back, "Well I am skipping a grade in elementary school. By the time I get to high school, my maturity will have caught up!” Because I would have been a year ahead for so many years, unlike my mother's friend's daughter. They didn't skip her grade until she was already in high school, which is really rare. But I didn't have the brains or the audacity then to keep arguing with my mom. So it didn't happen.

Eventually, Renell lost her love for school, because she could not find a challenge anywhere. She believed deeply that she should have had the opportunity to skip grades. Even though in high school she still took honors and AP classes, it was too late. She had already become an average student.

Consequently, Renell wanted to teach Kevin the way she would have liked to have been taught in schools. She believed that homeschooling provided the opportunity to nurture and customize for a child's strengths and weaknesses. She believed that homeschooling could improve weaknesses, because there was the space to address them instead of rushing to brush them over. Renell knows her son's learning strengths and weaknesses, and shared: 
We're not rushing any of that either, and if ever he's in a place where he's progressing at a rapid pace and maybe even getting bored with something, then we may just go ahead and move forward to another grade level in that subject, because we can.

Renell spoke of the public school system as a threat to her child's education and identity. In contrast, Renell tailored education to fit Kevin where he was in every subject. He was not pigeon-holed into anything. If he was ahead with a concept, she gave him more challenging content. She customized her teaching to Kevin's learning style, in order to help him blossom into the unique person that she believed he was meant to be. Renell believed that homeschooling her son was a way to relive her own desire for appropriate curriculum and pedagogy.

Renell's not skipping a grade was a devastating memory for her; she deeply believed that she would have had a "different" life and more accomplishments if she had been allowed to skip a grade. Although she may be right that skipping a grade might have created different opportunities, Renell would have still been in the same school. The amount of weight she placed on the decision to keep her with her peer group suggested that Renell felt very deeply that she was cheated by her public schooling experience. She wanted something more for her son. 
Epicurus believed that desire was for the purpose of happiness and fulfillment, and relieving pain. Renell's desire to homeschool her son was directly tied to the pain resulting from her not getting what she wanted. Epicurus proposed two strategies for pursuing any given desire: you can either strive to fulfill the desire, or you can try to eliminate the desire. For the most part, paring the desire down to a minimum core, which is easily satisfied, was what Epicurus advocated. But, Renell chose the first strategy to carry out her desire, and it seemed to be opening up new possibilities for her to pursue her desires on Kevin's behalf.

Renell's school problems had not only been about academics; they also had been tied up in the racial dynamics of the community. The rift between the two systems came to a head for Renell when she switched from a Black city school to a White county school for secondary school. "I was living a nightmare...Even my intelligence was challenged at first by the teachers, because we've always had city schools and county schools." Renell was in the "gifted" class in the city and assumed that she would still be "gifted" when she shifted to the county system. She reminisced:

I kept asking my 5th grade teacher, "When am I going to be put into Apex [the gifted class]?" It was probably almost through the first semester of 5th 
grade when she finally decided to tell me that I wasn't going to be in Apex until basically I proved myself. Because I had come from city school, and their curriculum was not at the same level as county schools.

Renell was really disappointed and hurt by her teacher's response, but she came to recognize the disadvantage written into the unequal curricula.

The context of gross inequality reared its ugly head quite strongly as it came time for Renell to apply for college. Since her parents didn't go to college and did not know how to apply, she had to navigate the whole process on her own. She believed she was treated unfairly by the school system that made positive assumptions about White, middle-class students and held back students like her, who were Black and/or from working class or poor families. Eventually, Renell figured out how to apply for college by asking her friends, and she looked for resources on her own. For her own son, Renell was determined to build a support system that replaced what she feared the public system would not provide.

\section{Desiring Opportunity for a Black Male Student}

Her son's gender and race fueled Renell's passion for homeschooling. She had read research reports demonstrating how racial and gender stereotypes in public school oppressed Black male students' mental and academic development. She 
believed that raising a Black male in the US was a huge undertaking on many fronts.

Moreover, she knew that providing an excellent education now would contribute to

Kevin's future success and happiness. Renell did not want to expose Kevin to the racial bias that was running rampant in the public schools. And, she did not want her son to be labeled, treated disparagingly, or stereotyped at public school:

Many Black boys were diagnosed with ADHD after going to school and have to take medication, which was RIDICULOUS. They are boys just doing their natural behaviors and having them sit in the seat for 7 hours a day was nonsense... They're put on that track where they're just churning out more worker bees. I felt that — to my core — that that's what would happen to him. So I know my Black son, when it comes to success, yeah...we're at the bottom of the ladder. And I really, truly believe that's why I was like, [we need to] homeschool.

Renell believed that homeschooling would provide the chance at fairness that Kevin deserved, although private school preparation, she believed, would be even better.

Homeschooling promised to fulfill a number of Renell's desires. If she could not afford the best, which she defined as private schooling, at least she could create a 
close second through homeschooling. By homeschooling her son, she could fulfill her unfinished dream of customized education and also could carve out space for the continued development of her own intellect. And perhaps most significantly, she believed that homeschooling would protect Kevin from the ravages of a racist society.

\section{Desiring Cultural and Economic Capital}

Although her family income level was just above the federal poverty level guidelines, Renell had the latest technology to support her in homeschooling. The reason that Jace and Renell were low income was that she stayed out of the workforce in order to homeschool Kevin. Renell was well educated and could be well employed.

Over the years, she had purchased a new laptop, an iPad, and a quality all-in-one printer. With the savvy use of her tax return and help from her family, Renell also set a nice budget for the annual homeschool convention and for her curriculum. She had designed a curriculum to fit Kevin's needs, and used free resources online and free activities in museums, so her budget was lower than it would have been had she purchased pre-packaged curricula. She shared:

I was comfortable with creating the curriculum myself. I moved more and more away from using store-bought curriculums. I like the idea of coming up with it on my own, to me that is really teaching...the zoo, all the 
museums and places, all the cultural centers around the city have a free day.

Every day of the week just about one of these places has a free day.

Renell cleverly used her free local resources. She created her own

homeschooling curriculum, obtained many of the materials from the local public

library, and shared resources with other homeschooling families. These practices

made homeschooling affordable. Still, Renell wished to cultivate Kevin even more,

and wished that she could afford to travel more extensively with him, to enroll him in

music classes, and to take him to more organized homeschooling activities in the

suburbs. Because of her tight budget, not everything was possible.

Renell deeply valued the experience that she had gained from her own travels,

and she longed to take Kevin around the US and to other countries. She believed that

exposure to a variety of people and different places broadens people's worldviews.

Renell would have liked to incorporate travel experiences into her son's learning, and learning into their travels. However, the expense of travel had made these dreams impossible at the moment.

Regardless of the economic limitations, Renell still believed she could develop a well-rounded young man. In her philosophy, mastery in the three areas of music, sports, and languages would contribute to well-rounded personhood, and 
accomplishment in these areas would contribute to future career success. Renell wished that she had accomplished more in her childhood, and that is why she hoped to provide Kevin with these opportunities. Resources for extras like music, sports, and languages were not readily available. Renell appreciated it when her parents asked to pay for Kevin's swimming lessons, but her parents could only contribute so much. The family could not experience and explore foreign languages, nor could Renell find affordable music lessons for Kevin. She said disappointedly:

I hope one day we'll be able to afford to travel again like before we had a child... We have not been able to take him anywhere outside of this city. And that was such a huge thing for me when it came to saying, "Yes, we're definitely going to homeschool. I wanted to be able to pack up and us take him to DC and explore DC. But that's the only area that I feel like [our income level] has negatively impacted us, and music lessons is the other area.

Renell told me that homeschooling is a financially friendly option if the mother knows how to search out free resources (assuming that they are available, which they may not be in rural areas). 
Renell wished to provide a more diverse learning environment for Kevin's education, which she had not obtained in her childhood. Music, sports, and languages were three main areas that Renell valued, since they not only lead to a well-round person, but also contribute to career preparation. She believed these mastery in these areas could bring future economic capital. To accomplish this goal, she explored and sought every budget-friendly resource to supplement Kevin's homeschooling.

Bourdieu's concepts of cultural capital and habitus are reflected in Renell's homeschooling practices. Bourdieu (1998) stated, "Embedded within familial and communal practices, habitus guides the cultivation of dispositions that are internalized by the individual" (p. 17). Bourdieu argued that parents use the different forms of capital in myriad ways in their engagement with their children's education. Renell with the "proper" cultural capital had easier access to social networks and resources for educational knowledge than one might expect of someone at her income level. She was better able to locate, read, and interpret knowledge and had the capacity to take advantage of educational resources for her son's education. In Renell's homeschooling environment, Kevin had been exposed to this cultural capital through his home life, interactions with his parents, and the various activities that were encouraged or organized by his parents. Kevin was exposed to the cultural capital 
Renell possessed; theirs was a habitus of navigating knowledge and engaging in critical thought. Renell took little in texts at face value, and she was raising a child who did the same.

\section{Networking Desire}

Renell initially found homeschooling information on her own using the Internet, because she didn't know any homeschooling families. She looked at her state website to learn information about registration, legal concerns and resources. She found that, unlike Zoe's situation in West Virginia, she simply needed to turn in her attendance sheet and Kevin's grades to the homeschooling agency with which she registered each year.

Renell joined the largest homeschooling organization available, the Memphis Home Education Association (MHEA). This organization put out a monthly newsletter about social activities and events, application dates for the different homeschool sports teams, science fair opportunities and other educational events: They [MHEA] provide a lot of the extracurricular activities through their organization. And they leave the rest, the logistics of homeschooling, they leave that to the [smaller, local] support groups. They want you to join a 
support group and get with some people that you can learn that kind of stuff from. And to support you. They feel that that's what the support groups are for, to help you learn how to homeschool, or change something you're doing in your home school.

Renell left her original support group because the children were older than Kevin, and Renell did not see much diversity in the group. It consisted mostly of Black families, and she wanted to expose Kevin to a diverse group of families that reflected the real world. Therefore, she and another friend from that original support group formed a new group last year. There were three Black families and four White families in her new homeschooling support group, called Shelby Homeschoolers. She was one of the two leaders in her support group. Renell explained:

When two Black women start a support group, naturally, especially in this city where racism is still so very prominent, there are going to be Black homeschoolers who are going to just naturally gravitate to us. But that's part of why we named the group the way we did. I came up with the name. We were both trying to think of something very generic that was not overly descriptive in defining us in any kind of way. Because we wanted to make sure that people understood our group was open to everyone. 
Renell maintained a website for her group, so that families in her group could communicate and share information. Her support group followed the traditional brick-and-mortar school-year calendar. They had their first monthly meeting in August 2011 to disseminate the activities for the upcoming school year. Those educational activities focused on core academic areas, such as reading and math. Everybody in her group contributed ideas about activities, either at the group meeting or on the website:

Actually we don't really communicate on [the website]. It's just like an informational website, but it's also where we decided last year to take advantage of all the technology we have access to and to try to be as paperless a group as possible. So we disseminated the one hand out in the August meeting, but then everything else, it's all put online on our website. There's a space where you can see which activity or field trip is coming up next, and then there's a page with all of them listed. We have our membership application on there; we don't charge. We don't have dues that members have to pay. Our group is one of the few that is free.

However, the children in her group were so young, they just wanted to play every time they met. It was hard for parents to talk over them, so they decided their 
second year in operation, to be a "field trip group." In 2012, they gave out a handout with the calendar of activities and already had some fieldtrips and holiday celebrations planned. "Sometimes we would have more structured play for them. I think it was around Valentine's Day, and it turned out really fun... some of the parents came up with different games for [the kids] to play, and win little prizes." Renell was the person who sent a welcome letter by email for new members. The group also had a Scholastic Book Club, and Renell ran that too. Renell could log in as the teacher to complete the order, and took charge of receiving and delivering the books. They also had a 4-H club connected to their group. They kept the membership list in their cell phones so that they could send out text messages to the group at a moment's notice. And, they held a curriculum exchange meeting in the springtime to swap curricula, workbooks, books and games. Renell's support group had developed a well-functioning structure, and had gradually expanded their support to homeschooling families.

Renell hoped to make a connection with other homeschooling families and to make friendships both for her and Kevin. Sharing the experiences and making friendships with people on the same journey was Renell's primary desire for homeschooling network support. 
The support group played an emotional supportive role among those families.

During a fieldtrip, for example, they talked about how "terrible" the public schools are in Memphis and they also shared their dream: how wonderful all of the public school students would be if they were homeschooled. Overall, the group's cultural and emotional connections seemed more important than the academic purposes of the group.

\section{Culturally Responsive and Relevant Teaching}

I guess I was surprised that [Kevin] wasn't as studious as I thought. Again, I used myself as the point of reference, and he is my offspring. Though I know every child is different, not exactly like their parents, because I was...I thought he was just going to very easily gravitate to learning and embrace it. And that he would very easily just grasp concepts, and that I would have this natural born genius on my hands. And I had a very rude awakening that that was, um, not the case.

Kevin struggled in math, and he was one year behind where he was supposed to be for his age. However, he excelled in languages. Renell tailored Kevin's learning based on his strengths and weaknesses and applied the approach of culturally relevant and responsive teaching to Kevin's math. As a teacher, Renell created a bridge 
between Kevin's ability and his learning styles and simultaneously used his experiences and knowledge to inform her teaching approach.

In order to improve his mathematical understanding, Renell has tried different math curricula, such as workbooks and CDs, and has employed an array of activities, such as whiteboard work and hands-on experiences. Renell spent $\$ 120$ this year for Kevin's math materials, including CDs and a textbook. Each CD presented instruction and practice for every concept. Kevin was familiar with the math routines and knew how to load the CDs, taking control of his own learning. If he was consistently not scoring up to Renell's standards on his online math lessons, she stepped in. She would intervene once, and then, if he continued to struggle, she would move onto the next topic. She has learned that Kevin's brain takes longer to process some concepts, and she has found that eventually he caught up to his peers. She knew that pushing and pushing did not help him, but frustrated him instead.

Renell was aware of her control over what Kevin learned, but Kevin also had some control over his learning. For instance, Renell allowed Kevin to pick the state or county of study in geography. She gave Kevin the space to explore different areas of interest; for example, when they went to the library, Kevin checked out animal books, which he loved. Also, they visited the zoo, and Kevin took pictures of his favorite 
animals and scenes with his camera. And, Renell encouraged and helped him to make his very own book of animal profiles.

Renell generally tried to be "hands off." She wanted Kevin to be an independent learner. Renell usually taught one new concept in math and one in etymology and then let him do the work independently. Kevin studied a wide range of language arts subjects, like grammar and analogies, on his own. There was a reason that Renell stressed independence with Kevin. Renell knew Kevin's personality. He was capable of becoming clingy and acting like "a momma's boy." And so Renell sought to counteract this tendency through her teaching style.

Creating rich learning experiences for Kevin was a goal of homeschooling that Renell believed he would not receive in the public schools. She provided as broad of an education as she possibly could to fill the gap that she believed she had in her own schooling experiences. Renell taught etymology and analogy, which she did not study until high school. She thought that younger children could learn this in elementary school. She believed learning etymology and practicing analogies at an early age has helped Kevin to develop his critical thinking.

Renell introduced Kevin to foreign languages at a young age because of the research base that promotes such practices. Kevin loved languages and wanted to 
learn as many languages as he could. Kevin first studied French, because Renell had a foundation in the French language. Kevin has also studied Chinese and Spanish. She encouraged Kevin to listen to podcasts in different languages to immerse him in the sounds. She would have loved to bring together native speakers of these languages to do some round-table discussion with Kevin, to sit with him and do more one-on-one conversational stuff, because she knew that that was really how he would master languages.

\section{Cultural and Heritage Studies}

Renell incorporated cultural studies into her daily routines. She wove her cultural identity into the fabric of every subject, every topic, and every concept in Kevin's learning. She believed that Black people have been —and still were - marginalized, but in a homeschooling environment, that did not need to happen. Black people are not an extraneous group, and so Renell did not portray her culture as such:

[We explored three biographies] and all three were Black. We did Dr.

[Benjamin] Hooks, a major civil rights activist. We also studied Wilma Rudolph, a famous track and field sprinter who overcame polio, and Nikki Giovanni who is a well-known poet and essayist... 
Renell kept her homeschooling curriculum Afrocentric all year long and purposefully shaped her curriculum using a number of other cultures as well. She believed that students should be introduced to multiple cultures throughout the school calendar instead of focusing on a certain culture during a certain period. She used the example of Black History Month to illustrate the Eurocentric curriculum in the public school. Renell explained proudly:

We are a family of color, not only in actual physical images, pictures, but also in texts. The images are created through our words and the words of other people of color - these need to be just a normal everyday part of his learning experience. We don't appear to [Kevin] as these marginalized characters, but that we have always been part of humanity, and it wasn't all of a sudden that one day White people allowed us as people of color to be part of humanity and to exist.

Renell expected that Kevin would become a productive citizen, and with a foundation in cultural and heritage-type studies, he would not have a jaded view of his community. He would have high expectations of everyone in the community and would know how to help them get to that place — rather than belittling those people who can't or aren't able to do their best due to the environment. That was why Kevin 
read the "Black Child's Pledge" every day before his homeschooling learning, so that he could be confident, could know who he was, and have a sense of community. The pledge was written by Shirley Williams and published by the Black Panther Party in 1968:

He won't have this Eurocentric view of everybody else... That has for a while been lacking in the Black community. It's everyone kind of being out for themselves... But also teaching him that you don't have to hate anyone to love yourself and to love the people of the community you identify with, and you also need to make sure you are helping your community be the best it can be.

\section{Black Child's Pledge}

I pledge allegiance to my Black People.

I pledge to develop my mind and body to the greatest extent possible.

I will learn all that I can in order to give my best to my

People in their struggle for liberation.

I will keep myself physically fit, building a strong body

free from drugs and other substances which weaken me 
and make me less capable of protecting myself, my

family and my Black brothers and sisters.

I will unselfishly share my knowledge and

understanding with them in order to bring about change

more quickly.

I will discipline myself to direct my energies

thoughtfully and constructively rather than wasting

them in idle hatred.

I will train myself never to hurt or allow others to harm

my Black brothers and sisters for I recognize that we

need every Black Man, Woman, and Child to be

physically, mentally and psychologically strong.

These principles I pledge to practice daily and to teach

them to others in order to unite my People.

With these values at the forefront, Renell integrated her own cultural identity with rich, in-depth exploration of other cultures and ethnicities in her homeschooling practices. 
Renell believed that the information and the curriculum presented in the public school has underplayed slavery, the Civil War, and the Civil Rights Movement. She told me that those historical events have been presented in a Eurocentric perspective and were not accurate, but distorted. Renell offered a broader and more in-depth picture of those events, and generally a richer understanding of her people, as well as the additional races/ethnicities that often have been glossed over and marginalized in the public schools and in society. She underlined her view:

How many kids learn about slavery outside of a very scripted Eurocentric textbook, that still, even though it mentions [slavery], it glosses over it? Not saying that slaves were always just depressed and downtrodden...[History texts] want to talk about how great White people are, and we're very ashamed of our history and our part in American slavery. They don't really get into the why and how of slavery. And really how horrible it was, and the repercussions of it, but I can. To really give [Kevin] a good view of the expansive culture, and all the ethnicities in this country, and incorporate that into his everyday education.

Below is a partial scene, taken from research field notes, depicting how Renell talked about slavery with Kevin as part of homeschooling instruction: 
Renell and Kevin both sat down on the couch with a book about slavery. "I will read with you. We will read the introduction, and then half of the first book section," Renell said. Surprised, Kevin asked, "We will read the whole book?" Renell clarified, "We will finish the book eventually, but we will read the introduction and some part of the book today." When they finished the introduction, Renell aked, "Do you understand what it said?" Renell explained slavery in ancient times according to the information in the book, and said, "But in our country, slavery is completely a case of race."

Renell explained which regions used slavery and how they transported the slaves to other countries. "Would you like it if somebody did that to you? You would have shackles on your feet and your hands tied behind your back if you were a slave." Kevin shook his head in the negative. "Do you want there to be slavery? You would work and not make money," prodded Renell, but Kevin hesitated. Renell seemed to know what her son was thinking, and so she started talking about the activities that they did a couple months ago when they provided food for senior citizens. "When we helped without being paid, it's called volunteering. You choose to work without making money, and you want to do it. 
Slavery is somebody forcing you to do something!" Renell connected their activities to these concepts. "I don't want to be the slave!" Kevin responded then. "Right. You have questions?” Renell asked. Then, she read a section about how kids were sold into slavery by their parents if the parents did not have money. Kevin was surprised when learning this from the book. "It's like we have the student loan now and then we sell you to pay back the money. Of course, we will never do that to you." Renell giggled and hugged Kevin. He looked relieved. Then Renell continued the inquiry: "How are slaves traded? So, I would trade you for a bag of groceries? Does that sound a fair game to you?" And, she explained how Europeans brought Africans to America..."Mom... what happens to you if you are slave?" Kevin asked. "We are not slaves anymore. It's illegal. We have not been enslaved for a long time,” Renell explained. “Oh...I know that slavery’s sad,” Kevin said and hugged Renell again.

Soon, Renell explained, they would read a children's biography version of Harriet Tubman's story. There was a cotton museum in the city, and they would do a tour of the cotton museum, since it was a major hub for the cotton industry during the years of slavery. And, as she explained, this would be the first time that Renell would connect a field trip so closely to content. 


\section{The Husband's Role in Homeschooling}

Jace was a waiter. He was well educated, having nearly completed his

Master's degree in English. Even though Jace was home during the day, Renell was the primary teacher in charge of homeschooling. Jace stepped in to provide alternative explanations when Renell had exhausted all of her ways to teach Kevin. Jace and Kevin usually took a stroll to the nearby park or to a store three days per week. Jace and Renell shared the responsibility for disciplining Kevin during my stay with them.

When Renell was elsewhere, Jace put all of his attention into Kevin. At the homeschooling fieldtrip I attended, Jace was the only father who accompanied his family. During the fieldtrip, Jace took care of Kevin. He watched him play with other kids as Renell socialized with the homeschooling mothers. Renell explained that Jace participated in every homeschooling fieldtrip and family activities, such as museum trips and grocery shopping. I noticed that Jace took many photos and also videotaped Kevin when he swam alone for the first time at swimming lessons.

Jace was not from Memphis. He grew up the child of two middle-class parents—a doctor and a nurse — in California. So, his experiences were different socioeconomically and geographically than Renell's. He only had second-hand knowledge of the public school systems, compared to Renell's first-hand knowledge. 
But, the information about school systems in Memphis did not shape his decision about homeschooling.

At first Jace was against the concept of homeschooling for stereotypical reasons. He was concerned about socialization. Renell did a lot of research on homeschooling and presented a great argument for it and changed his perception of homeschooling. Renell made the decision to homeschool Kevin, and Jace, after many discussions, agreed. His priority was to give his son the best opportunity to have a well-rounded education.

Jace also believed that being a part of a homeschooling group increased how much he supported homeschooling, since members were like-minded individuals. Jace told me he did support public schooling, even though he has very critical of the people on the school board, who, in his opinion, find ways to hinder the education of the students.

At the time of data collection, Jace was seeking teaching position in a public school. Jace and Renell expressed that they hadn't given up on the public school system. If that were the case, Jace wouldn't be pursuing public school teaching as a career. For Jace, this was about taking the experience of being a homeschool parent 
and applying that to the public school system to be a more well-rounded educator.

\section{Preparing for Child Agency}

As explained earlier in this chapter, Renell wanted to include Kevin in the educational decision-making process and not to dictate everything to him. She wanted Kevin to know that his opinion mattered and she wanted him to learn to be responsible for himself.

Renell was preparing for the day Kevin would attend school either in high school or college. Ideally, it would be a private school. But that conversation would include Kevin; he would have a say. To develop his abilities in critical thinking, and for him to be able to make his own informed decisions, Renell focused on grammar, etymology, analogies, and other language arts. With this knowledge, she believed that Kevin would be able to articulate arguments:

We are big language arts people. My husband is about to finish his Master's in English. So that's our strong suit, which is why I just think that it is so important to master language and critical thinking skills. And I want those to be well cultivated by the time he gets to high school, not by the time he finishes high school. I want this when he gets to 9th grade. He should be very articulate. That's something else that's part of my goals, to 
educate a child who will be able to have that kind of conversation, and participate in the conversation on whether or not he goes to high school [or continues to homeschool].

If Kevin felt like it was good for him to attend school, he would have to present a case to Jace and her about why he should go. Then, the three of them would discuss it and make the decision together.

Lately, Kevin has been growing in independence, but for this mother, his growth is bittersweet:

He won't even ask to come sleep with us. I just want, I'm still trying to hold onto these last few minutes of him being really young because soon he'll be in the double digits. I've asked him, "You want to come sleep with us?" "No.... I'm a big boy. I need to sleep on my own bed." And I'll be devastated, but at the same time, I'll be proud of him for speaking up and for him being able to, for him being independent and for recognizing, even though mom is having a "moment," you know, he doesn't succumb to it. He knows that $I$ have to grow up. 


\section{Discussion}

Renell homeschooled for both pedagogical and ideological reasons. She defied categorization and held beliefs that may seem contradictory. Ideologically she was Afrocentric and adhered to a neoliberal belief in the principles of the market. She believed that the markets applied pressure on some schools and parents and could affect school quality. She wanted to raise her child with pride in his racial identity, but aspired to place him in majority White private schools, which undoubtedly would have been Eurocentric. Private schools were, in her opinion, the absolute best schools, because they were tuition-based and therefore would (she assumed) have to be responsive to the parents who attended in order to keep the tuition rolling in.

Pedagogically, Renell preferred child-centered approaches that built on her son's strengths, and she engaged in practices that were intended to help him advocate for himself both inside and outside the home.

\section{Renell and Afrocentrism}

"Negroes who have been so long inconvenienced and denied opportunities for development are naturally afraid of anything that sounds like discrimination."-Carter G. Woodson 
Renell's implementation of an Afrocentric curriculum resonates with Carter

Woodson's commentary. Dr. Woodson noted that African-American contributions

"were overlooked, ignored, and even suppressed by the writers of history textbooks and the teachers who use them" (p. 142). He also expressed, "If a race has no history, if it has no worthwhile tradition, it becomes a negligible factor in the thought of the world, and it stands in danger of being exterminated" (p. 143).

Renell's Afrocentric curriculum is a good example of Freire's consciousness in a culture of silence. Renell understood that her own people in American history have been ignored and suppressed in public school. She felt the need to design an Afrocentric curriculum, and taught it all year. She believed that the detached and marginalized approach to Kevin's cultural heritage would have defined the public school curricular experience.

Renell's dissatisfaction with how school curricula emphasized the dominant culture is also demonstrated the theory of hegemony. Gramsci's (1971) insights about how power is established in the realm of ideas and knowledge through consent rather than force have inspired the use of explicit strategies to contest hegemonic standards of legitimacy. Therefore, the dominant group implements its educational influences in schooling to disseminate the dominant culture and to justify social, political, and 
economic status quo (Apple, 2007). US public schools have played an influential role in assimilating diverse students from different cultures (Banks, 1996; Larson \& Ovando, 2001). Freire (1974) proposed that the educational process is never neutral. School systems have mostly valued Eurocentric middle-class culture and oppressed non-dominant cultures (Apple, 2000; Freire, Macedo, \& Giroux, 1985; Oliva, 2009). Therefore, educational practices in public school have led to the marginalization of students who are minority and from low income and working class (Delpit, 1997; Nieto,1999; Valenzuela, 1999).

Renell believed that she was the best teacher for Kevin, in the absence of a private schooling experience, especially in Afrocentric curriculum. Sharing the same cultural knowledge and knowing Kevin's prior experiences, Renell used culturally relevant and responsive teaching to make learning effective and teach to and through Kevin's strengths. Gay (2000) described how teaching instruction is culturally mediated when it integrates various aspects of understanding and representing information. In Renell's homeschooling practices, Kevin was allowed to share his perspectives in their own cultural and social experiences and was an active participant in his learning. Learning relationships between Renell and Kevin in homeschooling were congruent because they shared a Black culture. 
Homeschooling itself is a culturally relevant and responsive educational form.

Because culture is a key to learning, it plays a role not only in communicating and receiving information, but also in shaping the thinking process of groups and individuals. When students' knowledge and skills are connected to their lived experiences and their frames of reference, their learning is more meaningful. Homeschooling practices can link the cultural background and experiences to the contents through a mother's or father's instructions. Parents are well situated to demonstrate culturally sensitive caring and to build culturally relevant and responsive learning communities.

An interesting point regarding culturally relevant and responsive teaching is that many researchers have proposed various ways for teachers to connect academic content to students' cultural and experiential background in school settings (Gay, 2000, 2002; Hollins, 1996; Ladson-Billings, 1994, 1995; Moll, Amanti \& Gonzalez, 2005; Neito, 2006; Rothstein, 2004; Valenzuela, 1999). Renell's story reflects the gap between teachers and at least some portion of the African American community community in her hometown. She criticized the outsider teachers and the superintendent of schools for not knowing the real needs and ecological system in Memphis. Indeed, she painted them as fundamentally unable to listen and respond to 
what the community needed. In her view, there was currently no line of real communication between homes and the public schools. In her view, there was a major breach between the state on one hand, and parents and children on the other. In the present moment, she saw that democratic education was not a possibility for local low-income children. She saw homeschooling as a (limited) answer to achieving culturally relevant and responsive education. This was a form of education that she used to mold a critical, knowledgeable young man (her son) who could in the future attain higher education and economic capital. While Renell's stated educational purposes were not wholly democratic, she cared about more than only Kevin. Indeed, she had a dream that all African American kids in the community who could not access rigorous, child-centered and Afro-centric education could be homeschooled so that they, too, would have the chance to move ahead. This dream did include a desire for social justice and equity, not only personal attainment.

Renell's concern of a fair chance for Black male students shed light on the social reproduction that may be inherent in the school setting. Renell was very emotional while talking about the biases against and stereotypes regarding Black males. She shared, "I was devastated when I knew I had a boy...I could envision what he would become in public school... I wanted to give him a fair chance in education." 
She had concerns about the labels for Black male students who are viewed as social problems and deficient in academic environments. School norms and structures sometimes have worked against Black children who are labeled as troublemakers, and school personnel have held low expectations of them (Alridge, 2003; Fields-Smith \& Williams, 2009; Kunjufu, 2005). Delpit (2012) argued that African-American students do not achieve to their potential in schools, because they're hindered by "society's deeply ingrained bias of equating blackness with inferiority" (p. 24).

Social reproduction continues to occur, because the education system is overlaid with legitimate knowledge and cultural legitimacy justified by the dominant group (Apple, 2006; Bourdieu, 1998; McNeil, 2000). There is evidence that supports that Black males face more negative perceptions, and that teachers' biases about behavioral issues instead of promoting higher academic standards contribute to the overrepresentation of Black students in special education services (Fields-Smith \& Williams, 2009; Kunjufu, 2005; Taylor, 1991; Klingner \& Edwards, 2006). Renell worried that Black male stereotypes would threaten Kevin's learning if he attended public school, and believed that homeschooling offered a fair chance for Black male children. "If we do not recognize the brilliance before us, we cannot help but carry on the stereotypic societal views that African-American children are somehow damaged 
goods and that they cannot be expected to succeed" (Delpit, 2012, p. 92). A similar motivation drove each of the members of her co-op group to homeschool.

\section{Renell and Neoliberalism}

Renell grew up working class and she still identified herself as working class due to her roots. Renell related to working-class concerns. Her parents never went to college and knew little about the process of attaining higher education. She believed that her parents were unable to assist her and she viewed them as disengaged from her schooling. As Renell saw it, her parents lacked the cultural capital to design and pursue an educational program for their gifted daughter (Bourdieu, 1984). Her memories of childhood reflected the "accomplishment of natural growth," wherein her parents stayed in the background and allowed her to develop as she would (Laureau, 2003). Renell's negative schooling experiences, which she attributed in part to her parents' lack of knowledge, were partially due to her social class location. It could also be said that the schools at that time seemed not to have the understandings to engage with the funds of knowledge that her family did (and still does) possess. Renell's personal desire for education influenced her educational choice for her son. The motivations shaping Renell's homeschooling practices were woven between the local context of race and her public school experiences. Memphis offered 
various educational choices for parents who could decide the best education for their children. Renell could wield her parental right to decide on Kevin's educational program. In so doing, she practiced self-determination towards acquiring a culturally relevant and responsive education that would nurture Kevin's potential for agency as he grew into an adult. She was an informed parent, and was capable of making the educational choice based on Kevin's needs. However, homeschooling seemed to be the only option Renell could really pick for her son, due to her financial strain, her distrust of the public school, and her doubts regarding the local school choice programs. She yearned to achieve her unfulfilled educational dream through homeschooling her son. Renell's determination for Kevin's education was a combination of motivations and abilities that led her to set goals and to take the initiative to reach these goals.

It seems possible that her parents' hands-off approach matched with the educational limitations that she experienced might have resulted in Renell becoming more of an advocate for more and better opportunities within the public schools. Instead, it resulted in Renell developing an appreciation for market-based schooling structures. She believed strongly that "you get what you pay for," and interpreted that as a need to gain access to systems where people pay large sums of money for 
education. This was complicated by her ongoing inability to pay elite private school tuition. Renell was not interested in what she considered to be the lower-status market of charter schools. She believed that charters in her locale were designed to appease the desire for choice among low-income and poor people, and she wanted only the best for her son.

\section{Renell's Unresolved Contradiction}

It did not appear that Renell saw the contradictions in her reasoning about the context of choice. Her desire was to ensure that her Black male child received an education that both prepared him to achieve in college and that respected and preserved his identity. While attaining these goals could be realized in her homeschool it seemed, these goals would not be as likely in her first-choice, the elite private school attended by mostly Whites. It may be that this unresolved contradiction stemmed less from Renell's beliefs about schooling her son and more from her conflation of her own personal schooling experiences with the limited options available to her. Renell had chosen to retreat from public schooling in order to treat the injury she felt that she had suffered. This had little to do with her child or his needs. 
Renell's schooling experiences seemed to drive her homeschooling

motivations. She was able to use clear and articulate arguments about identity and opportunity as well as preparation for employment and citizenship, which reflected her deep engagement with the principles of self-determination and democratic education. Her Afrocentric curriculum worked against the dominant culture and factory model. For Renell, homeschooling was an anti-racist act. But her ability to make arguments and explain the need for Afrocentrism in a racist city did not fully address how homeschooling was only a substitute for what she could have had if she were wealthy.

\section{CHAPTER SIX: CONCLUSION}

In this chapter I present an overview of this study, a cross-case discussion, and implications of the research. Identity, pedagogy, and agency emerged as themes in both cases. I return in this chapter to the key theories and literature presented in earlier chapters, examining more deeply how these cases contributed to broader understandings of homeschooling motivations and practices. Finally, I offer conclusions and final reflections. My readers will also find a postscript after this chapter, explaining how I have changed through doing this project. 


\section{Overview}

The purpose of this qualitative case study was to explore why and how two low-income families decided to homeschool children. I employed three methods of data gathering: in-depth interviews, observations, and document analysis. After explaining my study to the homeschooling parents and then obtaining their consent, I spent four months interviewing the homeschooling mothers and observing their homeschooling practices. In addition to the scheduled visits, I was invited by them to join their family activities (such as a church activity and a child's sports lesson) and to attend a relevant homeschooling event (a homeschooling fieldtrip). Six interviews with homeschooling mothers, ten observations of homeschooling practices or family interactions, document analysis from homeschooling practices, and observations of family activities and fieldtrip provided a rich data set.

The primary question was how and why low income families decide to homeschool their child(ren). I also considered several attendant questions:

1. How and why do local contexts of "choice" shape low income homeschoolers' experiences?

a. How do local public school experiences shape homeschooling experiences, motivations, and practices? 
b. How do low income homeschool experiences confirm, discredit, and complicate established theories of low income families' educational experiences, motivations, and practices?

2. How do low income homeschooling families manage homeschooling?

a. How do families network and negotiate homeschooling in local contexts?

The following summaries review what was found regarding answers to the research questions.

\section{Cross-Case Discussion}

As I have described in this dissertation, identity, pedagogy, and agency were the central themes in the cases of both of the participants, Zoe and Renell. This brief cross-case analysis compares and contrasts these homeschooling mothers' experiences engaging identity, pedagogy, and agency. In presenting the cross-case analysis, I highlight particular defining "moments" for each mother that show how identity, pedagogy, and agency came together in their processes of creating alternative spaces that promoted more relevant, responsive, and "democratic" (personalized, choice-based) education than they believed that they could secure elsewhere in their communities. 


\section{Identity, Pedagogy, and Agency}

To review, regarding the relationship between income level, parenting identities and agency, Lareau (2003/2011) proposed that poor and working class families rely on the assumption of natural growth. This means that poor and working class families (again, according to Lareau) see their primary job as taking care of their children (e.g., feeding, sheltering, and clothing them) so that they can grow and develop safely. But as I have already pointed out, Lareau's work has been criticized because it views low income and working class families as deficient. The theory does not account for the funds of knowledge that all families bring to educational contexts. This lack of recognition of family assets may be because poor and low income families are very creative and they have developed agency that is not always conventional and thus not always recognized by schools (Graue \& Sherfinski, 2011). A number of additional studies have suggested that sometimes the agency of poor and working class families is in line with school-based thinking about what parenting and parent involvement should look like but these efforts to connect go unacknowledged by school people. Many low income parents, it has been found, have very high expectations for their children's academic success and educational attainment (Fordham 1996; Stevenson, Chen, \& Uttal, 1990). And many poor and working-class 
parents do engage in practices that are aimed at developing their children's academic skills, even though they often struggle to realize their desires to cultivate their children's skills because of material constraints (Rosier, 2000, 2001; Rosier \& Corsaro, 1993). Sometimes the suggestions may seem challenging for underresourced schools. For example, low income parents may suggest that schools should contain community resource centers that offer wrap-around care for all families, and adult education and technology instruction in the evenings. All of these examples push against the idea that low income families do not see themselves as capable of making change, or that they are simply happy to comply with their present circumstances.

Pedagogy is a tool that Renell's and Zoe's families used to cultivate their children in various ways. Their practices defy current conceptions of pedagogy and language among low income families. Lareau (2003/2011) believed that for low income families, language use focuses on directives rather than dialogue. She found that low income children were encouraged to entertain themselves rather than participate in organized activities. She argued that this "poor and working class" child rearing style contributed to the social and economic constraints of low income children (Lareau, 2003/2011).

The results of this study disrupt these views of low income families' abilities 
to choose, act as agents in their children's educations, and use pedagogies that draw on rich language uses. In this research, Zoe and Renell both used logics of child rearing that contradicted Lareau's views of low income families engaging relatively low levels of self-determination.

Returning specifically to my data, I now want to consider the "moments" of identity and agency that served to crystallize the spaces in which identity, pedagogy, and agency came together in important ways. By highlighting a couple of these moments that Renell and Zoe respectively engaged, I will show how the mothers acted in ways that reflected how they saw themselves as choosers, and provided the space for them to use their desired pedagogies.

Renell. Renell was keenly aware of how race and class inequities have historically oppressed African Americans, and particularly young men. She resided in an especially segregated and racist community. For Renell, homeschooling emerged as the only choice given the state of the public schools (including the school choice program). Choice, generally speaking, was simply not good enough for the educational purposes that she viewed as non-negotiable. Ironically, she fought back against a system that disallowed equity by taking the step to opt out while taking on the responsibility to educate her child without state support. 
Reading the Black Child's Pledge every day was a central piece of Renell's curriculum. By centering this commitment to her people's future, Renell acted creatively in the space of a deferred dream of equity. While she currently saw no possibilities for change in education, she claimed her own son's future as her project and, in beginning a co-op, sought to shape a space with other mothers that could promote community. In the meantime, Renell believed that the way to move towards equity was to continue her homeschooling project of endeavoring to: "give my best to my People in their struggle for liberation... [and] unselfishly share my knowledge and understanding with them in order to bring about change more quickly." Homeschooling was a temporary and partial solution to a much bigger problem-it was a space in which to intensely cultivate her own child and to engage with other African American families so that there would be more capacity to activate broader social and educational changes in the future.

Unfortunately, homeschooling took vast amounts of Renell's time. This was time that could be potentially devoted to other forms of activism. But for now, Renell saw her son and her own intellectual cultivation as primary projects. Homeschooling was a place where Renell could draw on her cultural, racial, class, and gender identities in order to justify a project of self-determination. The Afro-centric 
curriculum bolstered this project because it provided a space for intensive cultural cultivation.

The pedagogy by which Renell carried out her project of cultivation was in direct contrast to what might be expected by social reproduction theories like Lareau's (2003/2011). This was crystallized for me as a researcher at the moment I heard Zoe explain the classical methods she used to cultivate Kevin's language learning. She was not teaching Kevin Ebonics. In fact, she was teaching him French, a high-status Romance language. Her motivation for this was multi-faceted: Kevin had a talent for language learning, French supplied capital and prepared Kevin for college, and it also honed his English skills which were important for both college admissions and success.

Zoe. Zoe, on the other hand, did not design the whole curriculum for each child, but expanded specific topics to develop each child's strong points. What surprised me the most about Zoe was the ways in which she would dialogue with a range of different sources in order to meet each child's unique needs. She did not look at it as a personal failure that she needed help from school professionals at times, and she respected the expertise that they could offer. Meanwhile, the relationship was two-way in that the public school was willing to support her children no matter where 
they were "housed" for their education — at the school or at home. The lines of separation blurred.

"I want to go to school!" -Kaylie's request—was not so shocking to me.

Rather, I marveled that this homeschooling family would listen to such a profound request from such a young child. Surprising to me was the role that child agency played in this family since the stereotype of many religious families is that the parents direct the children's lives and that the children do not have very many choices. This was not the case in this family, however. The children's voices were heard when, as in Kaylie's case, the parents believed that they carried a good bit of pragmatism.

The openness of this family to working among the state, the parents, and the children to best meet all of the children's needs was clear. This indicated a democratic disposition in some respects. There were other elements of homeschooling that were not so oriented toward democratic engagement, however. For example, I did not see lessons that analyzed historical causes of current social inequities - the kinds of lessons that were the building blocks of Renell's curriculum. Even though the father in this family was a public school civics teacher, some of the most important "civics" lessons for this family focused on the thin form of democracy (Apple \& Beane, 2007). That is, they were about personalization, individual choice, and charity toward others. 
Ironically, the lessons were not often about possibilities for self-determination and there was little if any discussion of how things could change through democratic processes. Instead, the focus was on personal and group morality. This was especially surprising and not a little disturbing given that the family lived in one of the poorest areas in the US, in which differences in opportunities by social class were striking and the stereotyping of poor families was rampant.

Both mothers exhibited dispositions that supported thin democracy and neoliberal reform efforts. They could give any middle class family a run for their money in terms of cultivation, even though they did not have the same kinds of economic resources.

Pedagogy, language, and cultivation. While the mothers were very different, they were also the same in many ways. Although they expressed distinct themes of care and desire, they both cared and they both desired. These identities led both mothers to their projects of cultivation as self-determination. Renell and Zoe possessed different cultural reference points based on their different racial and cultural backgrounds and schooling experiences. But for both women, their cultural experiences served to sharpen curricular decision-making. Language use in Zoe's and Renell's families showed low income mothers and children mostly engaging in a 
communicative model instead of the directive speech forms, something that would not usually be expected in families that were not middle class or upper-middle class. The children in both families, as I have showed in their portraits, learned to listen to others' opinions, communicate with people in and outside the family, and even exchange arguments. The rich development of language in both of these homeschools convinced me that Renell's and Zoe's children would be prepared to interpret issues and events in ways that should position them to be civic participants in society.

Both mothers acted as curriculum developers and navigation agents. They had active dispositions towards inquiry and finding out new information that belies commonplace expectations of low-income mothers as being passive recipients of curricula and knowledge. Their voracious reading habits assisted them in seeking out new information and knowledge regarding their children's learning. Moreover, both mothers used technology and deliberately located learning programs from media sources and the internet to complement their children's learning.

Renell and Zoe were both adept choosers. They actively and skillfully reached out towards public resources and organizations to enhance their children's learning opportunities in ways that would not typically be predicted in the literature based on their income levels. 
Both mothers saw the utility of creating and using homeschooling networks.

They tailored their networks based on their opportunities in their local communities.

They set up opportunities for engagement with others in many ways.

\section{A Test of Democratic Capabilities}

Exit rights are the opportunities that youth have to recognize the ideologies of their groups and to think and act in self-determined ways that may be different from their group's ideas. Macedo (2000) believed that exit rights do not usually exist in (Ideologue) homeschool settings due to generally non-tolerant environments that do not expose children to diverse ways of life and provide them to a multitude of ideas and concepts. He argued that children may become trapped in their closed culture and thus become incapable of exercising exit rights.

The children in this study were not educated in entirely isolated, homogenous environments. The presence of diverse educational activities is contrary to claims that homeschooled children are absent from the democratic public production of values (Apple, 2002; Lubienski, 2001). Even Zoe, who is quite religious, does not run a completely ideologically or socially isolated homeschool. In fact, some engagement with children and adults outside of the family was important, and indeed was a form of cultivation. 
The mothers realized gendered and cultural identities in their settings. At the same time, both families were astutely aware of the individuality of each child, and the diversity outside of the home. They deliberately developed their children's rationalities, encouraging them to listen to others' opinions, exchange thoughts, and argue thoughtfully. These techniques echoed those used in democratic education. Again, Zoe's efforts in this regard did not represent the ideal, but her awareness and discussions of difference suggested that her children were exposed to the perspectives available in her community. And, Zoe's young daughter did engage her exit rights. She decided that she wanted to leave homeschooling. Furthermore, her parents supported this request.

Family identity, agency, and pedagogy likely affect how youth engage their rights to exit. How families present diversity and foster their children's abilities to think critically may be a prerequisite of exit rights. Generally speaking, the children in this study were not at the age threshold when exerting independence is perhaps most common (later adolescence). But, the little indication that this study provides suggests that the children do have opportunities to think flexibly. There was not a reason to believe that the children were under the influence of repressive fundamentalist thinking, although determining this was not the thrust of this study and I must say that 
both families had particular ideologies that they took very seriously. I do believe, however, that these families' activities have progressively paved multiple directions in which the children should flourish and exhibit their autonomy whether or not they choose to exert their exit rights.

A cautionary note to this analysis is that the very child-centered, tailored, personalized education that I have described in these families may have disadvantages, just as I have indicated advantages. While producing strong and self-determined individuals is certainly important in the democratic project, the context of neoliberalism in which these mothers were deeply enmeshed makes me question whether or not their time spent away from the public sphere in homeschooling will ultimately result in community shifts toward figuring out more democratic ways of educating, or whether the private homeschooling spaces that they have claimed will fuel further neoliberal tendencies and the kinds of reforms that are increasingly present in public education. While I hope that more movement toward thick democracy is the answer to this question, I cannot predict the future of homeschooling.

\section{Conclusions and Final Reflections}


This study offers insights into how and why two low income families decided to homeschool their children. Zoe and Renell's stories do not lead to predictable conclusions or final destinations. However, each story represents the journey (to this point) of each low income mother. This study sought to deepen our understanding of two low income mothers' motivations and experiences in homeschooling. The themes that emerged from this study reveal the significance of how changing class dynamics intersect with parenting logics and local contexts to support homeschooling. I suggested that homeschooling may be seen as a space that may be necessary in some contexts as a "time out" away from troubling local public school contexts. I have argued that with time and great effort, it may be possible for the (partial) democratic tendencies of homeschooling practices to inspire local public school communities to become more richly democratic in the deliberative sense.

Both mothers used the rich resources that they acquired through their life experiences, including their educations in the public schools and their backgrounds growing up in working class homes, as funds of knowledge that allowed them to create educations for their children that they believed were improvements over what their children could presently acquire in their local public schools.

While Renell's homeschooling project was in many ways focused on social 
justice not only for her son but for African Americans more generally, she did not see how the public schools in Memphis could become democratic schools given the current socio-political and economic conditions.

Zoe's project was not oriented toward democratic education even though her husband felt that a particular knowledge of politics and civics was important to learn. However, she lived in a community in which she felt that she could share resources and agency for education amongst local school personnel, her, and her children. There was open dialogue and communication that facilitated her children's education at home and allowed for a fairly easy transition back to public education. While there was little that could be termed democratic education in either the home or the local school, the structure of state-parents-children was intact in this case, providing the community with a base from which more democratic education could eventually be constructed given new conditions in the future.

In some limited ways, both mothers engaged practices that could be seen as models for more democratic futures. These were Zoe's disposition towards active and mutual communication among the state, parents, and children and Renell's passion for critical multicultural teaching. Again, I say this with caution as their practices also could reinforce the neoliberal tendencies that they also (more strongly) reflect. 
This study is important for seeing how low income mothers are clearly positioned as agents of consumption within contemporary society. They embraced a philosophy of neoliberalism that emphasizes individual choice in education. Ideas about the virtues of competition and choice permeated their perspectives. And given local contexts lacking in their desired education, both mothers exerted their self-determination to choose homeschooling.

This study shows how two low income mothers thought about educational choice. The participants showed that as the economic situation in the US has shifted and as the gap between rich and poor has expanded as well, patterns of parents' agency by income level may also have shifted. It may also be the case that Zoe and Renell are indications of how difficult it is to move into the middle class. Even with college degrees and continual agency in the forms of caring and striving, they were in economic positions that qualified them for federal aid. The idea that people in poverty are universally lacking in the various kinds of capital may need to be revisited. 


\section{POSTSCRIPT}

"You have to ask specifically to use the restroom and there is no scheduled break time in many public schools in the US.” These are facts that I learned after my arrival in the US. Because students in Taiwan have 10-minute breaks during every 40minute class and can use the restroom, play at the playground, or eat snacks when they wish to, learning about the various controls imposed on children in the US was a surprise for me to say the least, and a difficult pill to swallow. As I read stacks of articles on how hegemony permeates US public schools in my graduate programs, I began to believe that US teachers and students must be exhausted. I realized that I myself would have many tensions with my students if I became a teacher in the US. As I read more and more, talked with friends, teachers, community members, and other students at West Virginia University, the context of teaching became more understandable and I could empathize more and more with teachers and schools, even though my own family's experience with public schooling in the US has been disappointing. And as I began to meet with my participants and listen to their stories, I could identify with both the local teachers and with my participants (who were both mothers and teachers). "Did I do that in school as a teacher?" is the question I asked myself most frequently when the participants relayed an insight or experience, 
because I recognized and respected the positions of the teachers and the public schools.

After learning more about school choice through this dissertation project, frankly I am now totally against it. I see that if we look at the big picture of education, school choice sets up an unfair game that advantages the families who have the best opportunities to obtain information. Instead of saying the words "school choice", we should tell the truth. Really, this is about choices for whom?

As a public school teacher, I believe that school is for the public good and it should be improved on many fronts. We do not need to invent another solution like homeschooling or new-fangled private schools and encourage people to jump to the other boat. Together as teachers and parents, we should work together to make schools more welcoming for everyone. Thick democracy in schools reflects my educational philosophy when I call myself a teacher and when I call myself a doctoral student.

My original intention for this project was to consider how we can work together to improve public schools for all students and families by learning the reasons behind how and why low income and working class families left their local public schools. I assumed that low income families had very few choices and that 
middle class families had lots of choices, because that is how the literature paints social class relations.

At the same time, as a mother, thick democracy does not reflect my orientation because I pulled my son out of public school and put him in private school. I have stewed emotionally over this, engaging in a self-examination about why I could never solve Hercules' issues in school based on my educational background as a teacher and as a low income but middle class mother. My own perceptions regarding the possibilities of ever achieving anything close to thick democracy through public education were shaken by the emotions I experienced as I watched my own son struggle, and as we experienced undeniable racism and xenophobia. A good friend's son faced problems in the local public schools at about the same time that Hercules was struggling. But her only choice was to keep her son in public school. I see my privilege and acknowledge that I was very lucky to have educational alternatives for Hercules. I am scared to imagine how Hercules' life would have been different if he was forced to remain at his local public school. In fact, I related strongly to Renell when she described how racism impacted her choices.

Although I hate to look in the mother mirror, I can see my own contradiction when I both decry and embrace with my life the "thin democracy" of neoliberalism as 
a mother who chose the best that she could for her son. I have to admit that social inequality was still perpetuated in my study as Renell and Zoe used their cultural capital and chose homeschooling. As a mother, I assume that mothers would never neglect their own children's needs and would strive for their good to the greatest extent possible. Mothers, indeed, are in a difficult double-bind when their own children's welfare is at odds with conceptions of the common good.

My ideas regarding low income families, homeschooling, and democratic education have changed through the course of this study when my identities have shifted back and forth between mother, Taiwanese, doctoral student, and former public school teacher. The shifts and contradictions that I experienced in designing this study, collecting data, writing up and defending this project may lay the foundation for future work examining the relationships between homeschooling, brick-and-mortar schools, and low income family empowerment. Although I do not expand in detail here, that work could be enriched by exploring the differentiated gender roles activated by homeschooling mothers versus fathers, and the reasons for these discrepancies. 


\section{REFERENCES}

Abrams, L. S., \& Gibbs, J. T. (2002). Disrupting the logic of home-school relations:

Parent involvement strategies and practices of inclusion and exclusion. Urban

Education, 37(3), 384-407.

Acemoglu, D., Robinson, J. (2005). Political origins of dictatorship and democracy.

Cambridge, MA: Cambridge University Press.

Alarcon, P. A. (2010). Recognizing and regulating home schooling in California:

Balancing parental and state interests in education. Chapman Law Review 13, 391-416.

Alridge, D. (2003). The dilemmas, challenges, and duality of an African-American educational historian. Educational Researcher, 32, 25-34.

Anderson, B. C. (2003). Children who are home schooled succeed academically.

In edited by C. Mur, Home Schooling (pp. 43-54). San Diego: Greenhaven Press.

Andre-Bechely, L. (2005). Could it be otherwise? Parents and the inequities of public school choice. New York: Routledge.

Angelis, K. L. (1998). The evolving relationship between homeschoolers and their local public schools. ERIC Reports, ED417483, U.S. Department of Education, 
Office of Educational Research and Improvement, Washington, D.C

Angrosino, M., \& Mays de Perez, K. (2000). Rethinking observation: From methods

to context. In N. Denzin and E. Lincoln (Eds.), Handbook of qualitative research (2nd ed.) (pp. 637- 707). Thousand Oaks, CA: Sage.

Anscombe, E. (2000). Intention ( $2^{\text {nd }}$ Edition). Cambridge, MA: Harvard University Press.

Anthony, K. V., \& Burroughs, S. (2010). Making the transition from traditional to Homeschooling. Current Issues in Education, 13(4), 1-33.

Anyon, J. (1980). Social class and hidden curriculum of work. Journal of Education, 162, 67-92.

Arce, J., Luna, D., Borjian, A., \& Conrad, M. (2005). No Child Left Behind: Who Wins? Who Loses? Social Justice, 32(3), 56-62.

Arons, S. (1986). Compelling Belief: The Culture of American Schooling ( $1^{\text {st }}$ ed.). Amherst, MA: University of Massachusetts Press.

Apple, M. W. (1995). Education and power (2nd Ed.). New York: Routledge. Apple, M. W. (2000). Official knowledge: Democratic education in a conservative age (2nd Ed.). New York: Routledge.

Apple, M. W. (2002). Does education have independent power? British Journal of 
Sociology of Education, 23, 607-616.

Apple, M. W. (2006). Educating the "right" way: Markets, standards, God, and inequality (2nd Ed.). New York: Routledge.

Apple, M. W., \& Beane, J. A. (Eds.). (2007). Democratic Schools: Lessons for a powerful education (2nd Ed.). Portsmouth, NH: Heinemann.

Aries, P. (1962). Centuries of childhood: a social history of family life. Trans. Robert Baldick. New York: Vintage.

Ascher, C. (2006). NCLB's supplemental educational services: Is this what our students need? Phi Delta Kappan, 88(2), 136-141.

Banks, J. A. (1996). Multicultural education, transformative knowledge, and action: Historical and contemporary perspectives. New York: Teachers College Press.

Bandura, A. (1977). Social learning theory. Englewood Cliffs, N.J.: Prentice-Hall.

Ballantine, J. H. \& Hammack, F. M. (2009). The sociology of education: a systemic analysis (6th ed.). Upper Saddle River, NJ: Pearson.

Bannier, B. J. (2007). Home schooling and developmental education: Learning from each other. Research \& Teaching in Developmental Education 23 (2), 62-68.

Bartels, L. M. (2008). Unequal Democracy: The Political Economy of the New Gilded 
Age. Princeton: Princeton University Press.

Basham, P. (2001). Home schooling: From the extreme to the mainstream.Vancouver, BC: Fraser Institute.

Basham, P., Merrifield, J., \& Hepburn, C.R. (2007). Home schooling:

from the extreme to the mainstream. Vancouver, BC: The Fraser Institute.

Bates, V. L. (1991). Lobbying for the Lord: The new Christian right home-schooling movement and grassroots lobbying. Review of Religious Research 33, 3-17.

Bauman, K.J. (2005). One million homeschooled students. Teacher's College Record. Retrieved August 13, 2012 from http://www.tcrecord.org

Beane, J.A. (1993). A middle school curriculum. Columbus, OH: National Middle School Association.

Beck, C. W. (2010). Home education: The social motivation. International Electronic Journal of Elementary Education 3(1), 71-81.

Bee, A. (February 2012). Household Income Inequality within U.S. counties: 2006-2010. Census Bureau, U.S. Department of Commerce.

Behar, R. (1996).The vulnerable observer: Anthropology that breaks your heart. Boston, MA: Beacon Press. 
Bierlein, L. A. (1995). Charter schools: A new approach to public education. NASSP Bulletin, 2-20.

Birkland, T. A. (2001). An introduction to the policy process: Theories, concepts, and models of public policy making. Armonk, NY: M.E. Sharpe.

Blumer, H. G. (Ed.). (1969). Symbolic interactionism: Perspective and method. Englewood Cliffs, NJ: Prentice Hall.

Bourdieu, P. (1973). Cultural Reproduction and Social Reproduction. IN R. Brown (ed.) Knowledge, Education and Cultural Change: Papers in the Sociology of Education (pp. 71-112). London: Tavistock.

Bourdieu, P., \& Passeron, C. (1977). Reproduction in education, society, culture. Beverly Hills, CA: Sage

Bourdieu, P. (1984). Distinction: A social critique of the judgment of taste. Translated by Richard Nice. Cambridge, MA: Harvard University Press.

Bourdieu, P. (1998). Practical reason. Stanford, CA: Stanford University Press.

Bowles, S, \& Gintis, H. (1976). Schooling in capitalist America: Educational reform and the contradictions of economic life. New York: Basic Books.

Brantlinger, E. (2003). Dividing classes: How the middle class negotiates and rationalizes school advantage. New York: Routledge/ Falmer. 
Bracey, G. (2004). The 14th Bracey report on the condition of public education. Phi Delta Kappan, 86(2), 149-167.

Byfield, J. (2001). Home is where the smarts are. The Report, 43-44.

Butler, J. (1987). Subjects of Desire: Hegelian Reflections in Twentieth-Century France, Columbia University Press.

Carey, K. (2004). The funding gap 2004: many states still shortchange low-income and minority students. Washington, DC: Education Trust.

Carper, J. C. (2000). Pluralism to establishment to dissent: The religious and educational context of home schooling. Peabody Journal of Education, 75(1/2), 8-19.

Cawelti, G. (2006). The side effects of NCLB. Educational Leadership, 64(3), 64-68.

Chatham-Carpenter, A. (1994). Home versus public schools: Differing social opportunities. Home School Research, 10(1), 15-24.

Chubb, J. E., \& Moe, T. M. (1990). Politics, markets and America's schools. Washington, DC: Brookings Institution.

Cogan, M. F. (2010). Exploring academic outcomes of homeschooled students, Journal of College Admission, 208, 18-25.

Collins, R. (1977). Functional and conflict theories of educational stratification. In 
J. Karabeland and A.H. Halsey (Eds.), Power and Ideology in Education (pp.

118-136). New York: Oxford University Press.

Collins, R. (1979). The credential society. Orlando, FL: Academic Press.

Cooper, C.W. (2003). The detrimental impact of teacher bias: Lessons learned from

African American mothers. Teacher Education Quarterly, 30(2), 101-116.

Cooper, C. W. (2007). School choice as "motherwork": Valuing African American women's educational advocacy and resistance. International Journal of Qualitative Studies in Education, 20(5), 491-512.

Cortes, C.E. (1991). Empowerment through media literacy: a multicultural approach. C.E. Sleeter (Ed.). Albany, NY: State University of New York Press.

Cremin, L. A. (1978). The free school maneuver: A perspective. In T.E. Deal and R. R. Nolan (Eds.) Alternative schools: Ideologies, realities, guidelines (pp.32-45). Chicago, IL: Nelson-Hall.

Cremin, L.A. (1980). American education: The national experience, 1783-1876. New York, NY: Harper \& Row.

Creswell, J. (1994). Research design: Qualitative and quantitative approaches.

London: Sage. 
Creswell, J. W. (1998). Qualitative inquiry and research design: Choosing among five traditions. Thousand Oaks, CA: Sage.

Cummins, J. (1997). Cultural and Linguistic Diversity in Education: A mainstream issue? Educational Review, 49 (2), 105-14.

Dahl, R. A. (1989). Democracy and its critics. New Haven, CT: Yale University Press.

Davis, R. H. (2012). Homeschooling a personal choice not a movement. Teachers College Record. Retrieved July, 12, 2012 from http:// www.tererecord.org

De Gaetano, Y. (2007). The role of culture in engineering Latino parents' involvement in school. Urban Education, 42(2), 145-162.

Deleuze, G. \& Guattari, F. (1972). L'Anti-Oedipe. Paris: Minuit. Translated as Anti-Oedipus by Robert Hurley, Mark Seem and Helen R. Lane. London: Athlone, 1984.

Delpit, L. (1997). What should teacher do? Responsive and culturally responsive instruction, rethinking Schools. An Urban Educational Journal 12(1), 6-7.

Delpit, L. (2012). Multiplication is for White people: Raising expectations for other people's children. New York: New Press.

Dewan, S. \& Gebeloff, R. (January, 14, 2012). Among the wealthiest 1 percent, many 
variations. The New York Times.

Dewey, J. (1916). Democracy and Education: An Introduction to the Philosophy of

Diamond, J. B., \& Gomez, K. (2004). African American parents' educational orientations: The importance of social class and parents' perceptions of schools. Education and Urban Society, 36(4), 383-427.

Duncan, G. J., \& Murnane, R. (2011). Whither opportunity? Rising inequality, schools, and children's life chances. New York: Russell Sage Foundation.

Dunk, E. V., \& Dickman, A.M. (2003). School choice and the question of accountability. New Haven, CT: Yale University Press.

Edelson, D. C., Gordin, D. N., \& Pea, R. D. (1999). Addressing the challenges of inquiry-based learning through technology and curriculum design. Journal of the Learning Sciences, 8(4), 391-450.

Eisner, E. W. (1991). The enlightened eye: Qualitative inquiry and the enhancement of educational practice. New York: Macmillan Publishing Company.

Emerson, R. M., Fretz, R. I., \& Shaw, L. L. (1995). Writing ethnographic fieldnotes. Chicago, IL: The University of Chicago Press.

Ensminger, M. E. \& Fothergill, K. E. (2003). A Decade of measuring SES: What it 
tells us and where to go from here. In Bornstein \& Bradley (Eds.).

Socioeconomic status, parenting, and child development (p.13-27). Mahwah, NJ:

Lawrence Erlbaum Associates.

Espeland, W. N., \& Sauder, M. (2007). Rankings and reactivity: How public numbers recreate the social world. American Journal of Sociology, 113, 1-40.

Feinberg, W., \& Soltis, J. F. (2009). School and society (5th Ed.). New York:

Teachers College Press.

Feinstein, L., Duckworth, K., \& Sabates, R. (2008). Education and the family: passing success across generation. NewYork: Routledge.

Fields-Smith, C., \& Williams M. (2009). Motivations, sacrifices, and challenges: black parents' decisions to home school. Urban Review, 41, 369-389.

Flores-González, N. (2002). School Kids/Street Kids: Identity development in Latino students. New York and London: Teachers College Press.

Fordham, S. (1996). Blacked Out: Dilemmas of race, identity, and success at Capital High. Chicago: University of Chicago Press.

Foucault, M. (1986). Discipline and punish: The birth of the prison. Harmondsworth: Peregrine.

Freire, P., Macedo, D., \& Giroux, H.A. (1985). The politics of education: Culture, 
power and liberation. Westport, CT: Bergin \& Garvey.

Freire, P. (2005). Education for critical consciousness. New York, NY: Continuum.

Freire, P. (2006). Pedagogy of the oppressed (30th Anniversary Ed.) New York:

\section{Continuum.}

Friedman, M. (2001). Martin Buber and Mikhail Bakhtin: The dialogue of voices and the word that is spoken. Religion \& Literature, 33(3), 25-36.

Fuller, B. (2000). The public square, big or small? Charter schools in political context. Cambridge, MA: Harvard University Press.

Kunjufu, J. (2005). Keeping black boys out of special education. Chicago, Il: African American Images.

Gaither, M. (2008). Homeschool: An American History. New York: Palgrave Macmillan.

Galston, W. (1995). Two Concepts of Liberalism, Ethics, 105, 516-534.

Gandin, L.A., \& Apple, M.W. (2002). Thin versus thick democracy in education: Porto alegre and the creation of alternatives to neo-liberalism, International Studies in Sociology of Education, 12(2), 99-116.

Gatto, J.T. (2002). Dumbing us down: The hidden curriculum of compulsory schooling ( $2^{\text {nd }}$ ed.). Gabriola Island, B.C.: New Society. 
Gay, G. (2000). Culturally Responsive Teaching: Theory, Research, \& Practice. New York: Teachers College Press.

Gay, G. (2002). Preparing for culturally responsive teaching. Journal of Teacher Education, 53(2), 106-116.

Gerlach, L., \& Hine, V. (1970). People, power, change: Movements of social transformation. Indianapolis: Bobbs-Merrill.

Glaser B.G. (1978). Theoretical sensitivity. Mill Valley, CA: Sociology Press.

Glenn, C. (1988). The myth of the common school. Amherst, MA: University of Massachusetts Press.

Goldstein, L. (1999). The relational zone: The role of caring relationships in the co-construction of mind. American Educational Research Journal, 36(3), 647-673.

González, N., Moll, L., Tenery, M. F., Rivera, A., Rendón, P., Gonzales, R. (2005). Funds of knowledge for teaching in Latino households. In N. Gonzalez, L. C. Moll, \& C. Amanti (Eds.), Funds of knowledge: Theorizing practices in households, communities, and classrooms (pp. 89-112). Mahwah, NJ: Erlbaum.

Green, C. L., \& Hoover-Dempsey, K.V. (2007). Why do parents homeschool? A systematic examination of parental involvement. Education and Urban Society 
39 (2): 264-285.

Grinde, D.A. (1999). Thomas Jefferson's perceptions of Native Americans. Gilrath (ed.), Thomas Jefferson and the education of a citizens, Library of Congress, p193-208.

Grych, J. H., \& Fincham, F. D. (2001). Interparental conflict and child development: Theory, research, and application. Cambridge, England: Cambridge University Press.

Gutmann, A. (1999). Democratic education. Princeton, NJ: Princeton University Press.

Harter, S. (1990). Causes, correlates and the functional role of global self-worth: A life-span perspective. In J. Kolligian \& R. Sternberg (Eds.), Perceptions of competence and incompetence across the life-span (pp.67-98). New Haven, CT: Yale Univ. Press.

Harvey, D. (2005). A brief history of neoliberalism. Oxford, UK: Oxford University Press.

Hannerz, U. (1992). Cultural Complexity: Studies in the Social Organization of Meaning. New York: Columbia University Press.

Hauser, R. M. \& Huang, M. H. (1997). Verbal ability and socioeconomic success: A 
Trend Analysis. Social Science Research, 26, 331-376.

Hellenbrand, H. (1990). The unfinished revolution: Education and politics in the thought of Thomas Jefferson. Newark, DE: University of Delaware Press. Jane, L. D. (2011). High-stakes testing narrows the curriculum. Educational Leadership, 68(6), 78-80.

Henig, J. R. (1995). Rethinking school choice: Limits of the market metaphor. Princeton, NJ: Princeton University Press.

Hollins, E. R. (1996). Culture in school learning: Revealing the deep meaning. Mahwah, NJ: Lawrence Erlbaum Associates.

Holt, J. (1982). How Children Fail (revised ed.). New York: Delacorte.

Irvine J. J. (2010). Culturally relevant pedagogy. Teaching Tolerance, 40-44.

Isenberg, E. (2006). The choice of public, private, or home schools. New York: National Center for the Study of Privatization in Education, Teachers College, Columbia University.

Jenkins, J. M., \& Astington, J. W. (1996). Cognitive factors and family structure associated with theory of mind development in young children. Developmental Psychology, 32, $70-78$.

Kaestle, C. F., \& Vinoski, M. (1980). Education and social change in nineteenth 
century Massachusetts. Cambridge, UK: Cambridge University Press.

Kaestle, C. F. (1983). Pillars of the Republic: Common Schools and American Society, 1780-1860. New York, NY: Hill \& Wang.

Katz, M. (1968). The irony of early school reform. Cambridge, MA: Harvard University Press.

Kelly, N.J. (2009). The Politics of Income Inequality in the United States. New York: Cambridge University Press.

Klicka, C. J. (2004). The Facts are in: Homeschoolers Excel. Practical Homeschooling, 57,12.

Klingner, J. K., \& Edwards, P. (2006). Cultural considerations with response-to-intervention models. Reading Research Quarterly, 41, $108-117$.

Kintz, L. (1997). Between Jesus and the market: The emotions that matter in right-wing America. Durham, NC: Duck University Press.

Kirschner, J. (1991). The shifting roles of family and school as educator: A historical perspective. In J. Van Galen and M. A. Pitman (Eds.), Home Schooling: Political, historical, and pedagogical perspectives (pp. 137-158). Norwood, NJ: Ablex Pub. 
Kiter Edwards, M. L. (2004). We're decent people: Constructing and managing family identity in Rural working-class communities. Journal of Marriage and Family, 66(2), 515-529.

Kiyama, J.M. (2011). Family lessons and funds of knowledge: College-going paths in Mexican American families. Journal of Latinos and education, 10(1), 23-42.

Knowles, J. G., Marlow, S. E., \& Muchmore, J. A. (1992). From pedagogy to ideology: Origins and phases of home education in the United States, 1970-1990. American Journal of Education, 100(2), 195-235.

Koonce, D., \& Harper, W. (2005). Engaging African American parents in schools: A community based consultation model. Journal of Educational and Psychological Consultation, 16(1), 55-74.

Kunzman, R. (2009). Write these laws on your children: Inside the world of conservative Christian homeschooling. Boston: Beacon Press.

Kunzman, R. (2012). Education, schooling, and children's rights: the complexity of Homeschooling. Educational Theory, 62(1), 75-89.

Kvale, S., \& Brinkmann, S. (2009). Interviews: Learning the craft of qualitative research interviewing. Thousand Oaks, CA: Sage Publications, Inc.

Ladson-Billings, G. (1994). The dream keepers: Successful teachers of African 
American children. San Francisco: Jossey-Bass Publishers.

Ladson-Billings, G. (1995). But that's just good teaching! The case for culturally relevant pedagogy. Theory Intro Practice, 34(3), 159-165.

Larson, C. L., \& Ovando, C. J. (2001). The color of bureaucracy: The politics of equity in multicultural school communities. Belmont, CA: Wadsworth/Thomson Learning.

Laureau, A.P. (1986). Perspective on parents: a view from the classroom. Paper presented at the annual meeting of the American Educational Research Association, San Francisco.

Lareau, A., \& Horvat, E.C. (1999). Moments of social inclusion and exclusion: race, class, and cultural capital in family-school relationships. Sociology of Education, 72(1), 37-52.

Lareau, A. (2000). Home advantage: social class and parental intervention in elementary education, $2^{\text {nd }}$ edition. Lanham, MD: Rowman \& Littlefield.

Lareau, A. (2003). Unequal Childhoods: class, race, and family life. Berkeley, CA: University of California Press.

Lareau, A., \& Weininger, E. B. (2003). Cultural capital in educational research: A 
critical assessment. Theory and Society, 32, 567-606.

Lawrence-Lightfoot, S. (2003). The essential conversation: What parents and teachers can learn from each other. New York, NY: Random House.

Leys, C. (2003). Market-driven politics: Neoliberal democracy and the public interest.

New York: Verso.

Lewis, A. E., \& Forman, T. A. (2002). Contestation or collaboration? A comparative study of home-school relations. Anthropology \& Education Quarterly, 33(1) $60-89$.

Lewin, T., \& Medina, J. (2003, July 31). To cut failure schools shed students. New York Times.

Lipman, P. (2004). High stakes education. New York, NY: Routledge.

Lipman, P., \& Hursh, D. (2007). Renaissance 2010: The reassertion of ruling-class power through neoliberal policies in Chicago. Policy Futures in Education, 5(2), 160-178.

Llewellyn, C. (1996). Freedom challenge: African American home schoolers. Eugene, OR: Lowry House.

Lois, J. (2013). Home is where school the school is. New York University Press.

Lubienski, C. (2001). Redefining Public Education: Charter schools, common 
schools, and the rhetoric of reform. Teachers College Record, 103(40), 634-666.

Lyman, I. (2000). The homeschooling revolution. Amherst. MA: Beach Press

International.

MacFarquahr, N. (2012, July, 21). Resolute or fearful, many Muslims turn to homeschooling. New York Times. Retrieved July, 21, 2012 from http://www.nytimes.com/2008/03/26/us/26muslim.html?pagewanted=all

Macedo, S. (2000). Diversity and distrust: Civic education in a multicultural democracy. Cambridge, MA: Harvard University Press.

Main, G. (2001). Peoples of a specious land: families and cultures in Colonial New England. Cambridge, MA: Harvard University Press.

Marsh, J.C. \& Willis, G. (1999). Curriculum: alternative approaches, ongoing issues. Upper Saddle River, NJ: Prentice-Hall.

Marx, K, Engels F, (1848). The Communist Manifesto. In R. Reader, R.C. Tucker $2^{\text {nd }}$ edition. New York, NY: New American Library.

Mayberry, M., Brian D. Ray, B.D., \& Knowles, J.G. (1992). Political and religious characteristics of home school parents: Results of an ongoing study in four western states. Home School Researcher, 8(1), 1-8.

Mayeroff, M. (1971). On caring. New York, NY: Harper and Row. 
McCombs, B. L., (2001). What do we know about learners and learning? The learner-centered framework: Bringing the educational system into balance, Educational Horizons, 79(4), 182-193.

McCool, D. C. (1995). Public policy theories, models, and concepts: An anthology. Englewood Cliffs, NJ: Prentice Hall.

McDermott, M. (1982). Social relations as contexts for learning in school. In E. Bredo and W. Feinberg (Eds.), Knowledge and values in social and educational research. Philadelphia, PA: Temple University Press.

McDermott, P. A. (1995). Sex, race, class, and other demographics as explanations for children's ability and adjustment: A national appraisal. Journal of School Psychology, 33(1), 75-91.

McDowell, S. A. (2000). The home schooling mother-teacher: Toward a theory of social integration. Peabody Journal of Education, 75 (2), 107-123.

McNeil, L. (2000). Contradictions of school reform: Educational costs of standardized testing. New York: Routledge.

McNeil, L., \& Valenzuela, A. (2001). The harmful impact of the TAAS system of testing in Texas: Beneath the accountability rhetoric. In G. Orfield and M.L .Kornhaber (Eds.), Raising standards or raising barriers? In equality and 
high-stakes testing in public education (pp. 127-150). New York: Century Foundation Press.

Medlin, R. G. (2010). Learning style and academic achievement in homeschooled children. Home School Researcher, 25(4), 1-9.

Merriam, S.B. (1998). Qualitative research and case study applications in education. San Francisco: Jossey -Bass Publishers.

Mill, J. S. (2001). On liberty and other essays. Oxford, UK: Oxford University Press. Nichols-White, D. E. (1996). In Grace Llewellyn (Ed.), Freedom challenge: African American Homeschoolers (pp. 60-87). Eugene, OR: Lowry House.

Moll, L., Amanti, L. C., \& Gonzalez, N. (2005) Funds of knowledge: theorizing practices in households, communities, and classrooms. Mahwah, NJ. Lawrence Erlbaum.

Moore, R., \& Moore, D. (1986). When education becomes abuse: A different look at the mental health of children. Journal of School Health, 56(2), 73-75.

Morton, R. (2010). Home Education: Constructions of Choice. International Electronic Journal of Elementary Education 3(1), 45-56.

Murray, L. (1996). The impact of postpartum depression on child development. International Review of Psychiatry, 8, 55-63. 
National Household Education Surveys Program (2007). National Center for

Education Statistics. Retrieved May 28, 2012, from

http://nces.ed.gov/nhes/homeschool/

National Education Association (2011). 2011-2012 Average Starting Teacher Salaries

by State. Retrieved December 18, 2012, from

http://www.nea.org/home/2011-2012-average-starting-teacher-salary.html

Nieto, S. (1999).The light in their eyes: Creating multicultural learning communities.

New York: Teachers College Press.

Nieto, S. (Ed.) (2005). Why we teach. New York: Teachers College Press.

Nieto, S. (2006). Go beyond niceness: Think critically about what it means to "care" for students of color. In Mica Pollock (Ed.), Everyday antiracism: Concrete ways to successfully navigate the relevance of race in school. New York: The New Press.

Nichols, S., \& Berliner, D. (2005). The inevitable corruption of indicators and educators through high-stakes testing. Retrieved June 25, 2012, from http://epsl.asu.edu.

Noddings, N. (1984). Caring: A Feminine Approach to Ethics and Moral Education.

Berkeley: University of California Press. 
Noddings, N. (2002). Starting at Home: Caring and Social Policy. Berkeley:

University of California Press.

Noddings, N. (2003). Happiness and education. Cambridge University Press, 43, 236-240.

Noguera, P. A. (2001). Transforming urban schools through investments in the social capital of parents. In S. Saegart, J. P. Thompson, \& M. Warren (Eds.), Social capital and poor communities (pp. 189-212). New York: Russell Sage Foundation.

Northeast and Islands Regional Educational Laboratory at Brown University (LAB). (2002). The diversity kit: An introductory resource for social change in education. Providence, RI: Brown University.

Oddie, G. (2005). Value, Reality, and Desire. New York: Oxford University Press.

OKIN, S. (2002). Mistresses of Their Own Destiny. In: K. Mcdonough and W. Feinberg (Eds.), Citizenship and Education in Liberal-Democratic Societies (pp. 325-340). New York: Oxford University Press.

Oliva, P. F. (2009). Developing the curriculum (7th Ed.). Boston, MA: Pearson/Allyn and Bacon., Inc. 
Patton, M. Q. (1990). Qualitative evaluation and research methods (2nd ed.).

Newbury Park, CA: Sage.

Patton, M. Q. (2002). Qualitative evaluation and research methods (3rd ed.).

Thousand Oaks, CA: Sage.

Pippin, R. B. (2011). Hegel on self-consciousness: Desire and death in the

Phenomenology of spirit. Princeton, N.J: Princeton University Press.

Price, H. (1989). Defending desire-as-belief, Mind, 98, 119-127.

Rambusch, N. M. (2010). Freedom, order, and the child. Montessori Life, 22(1), $38-43$.

Rapp, R. (1992). Family and class in contemporary America: Notes toward an understanding of ideology. In B. Thorne\& M. Yalow( Eds.), Rethinking the family (p.49-69). Boston: Northeaster University Press.

Ray, B. D. (1997). Home Education. The Homeschool Court Report, 13(3), 2-11.

Ray, B. D. (2002). Customization through homeschooling. Educational Leadership, $59(7), 50-54$.

Ray, B. D. (2004). Homeschoolers on to college: What research shows us. Journal of 
College Admission, 185, 5-11.

Rao, V. (2012, August, 4). As home-schooling moves to mainstream, stigma fades. NBC News. Retrieved August 4, 2012 from http://today.msnbc.msn.com.

Reich, R. (2002). Bridging liberalism and multiculturalism in American education. Chicago, IL: The University of Chicago Press.

Riedel, B. W. (2007). The relation between DIBELS, reading comprehension, and vocabulary in urban first-grade students. Reading Research Quarterly, 42(4), 546-567.

Robertson, S. (2004). A Class Act: changing teachers' work, the state, and globalization. London, UK: Falmer.

Rosier, K. B. (2000). Mothering Inner-city children: The Early school years. Piscataway, N J: Rutgers University Press.

Rosier, K. B. (2001). Without the parent you lose the child: Teachers' expectations and parents' (non-) involvement. Sociological Studies of Children and Youth,8, $3-42$.

Rosier, K. B., \& Corsaro, W.A. (1993). Competent parents, complex lives: Managing parenthood in poverty. Journal of Contemporary Ethnography, 22(1), 71-204.

Roschelle, A. R. (1997). No more kin: Exploring race, class, and gender in family 
networks. Thousand Oaks, CA: Sage.

Rosin, H. (2007). God's Harvard. Orlando, FL: Harcourt Inc.

Rothstein, R. (2004). Class and schools: Using social, economic, and educational reform to close the Black-White achievement gap. Washington, DC: Economic Policy Institute.

Rush, B. (1965). Essays on education in the early Republic. In Frederick Rudolph (Ed.),

Cambridge, MA: Harvard University Press.

Safran, L. (2001). Creativity as “mindful” learning: A case from learner-led home-based education. In A. Craft, B. Jeffrey, and M. Leibling, Creativity in Education (pp. 80-91). London: Continuum.

Saunders, M. K. (2009). Previously homeschooled college freshmen: Their first year experiences and persistence rates. Journal of College Student Retention, 11(1), 77-100.

Saunders, M. K. (2010). Previously homeschooled college freshmen: Their first year experiences and persistence rates. Journal of College Student Retention, 11(1), 77-100.

Sabatier, P. A. (2007). Theories of the policy process (2nd Ed.). Boulder, CO: Westview Press. 
Savery, J., \& Duffy, T. (2001). Problem based learning: An instructional model and its constructivist framework. Educational Technology, 35(5), 31-38.

Schroeder, T. (2004). Three Faces of Desire. New York: Oxford University Press.

SchvaneveldJt,. (1973).The interactional framework in the study of the family. In A.

Reinhard \&t M. Quinn (Eds.), Family-centered community nursing: A sociocultural framework (p. 119-138). S t. Louis, M O: C .V. Mosby.

Serafini, F. W. (2002). Dismantling the factory model of assessment. Reading \& Writing Quarterly, 18, 67-85.

Sexson, B. (1988). Home schooling: A socio-educational analysis of an emergent cultural shift in consciousness. Ann Arbor, MI: University of Michigan Press.

Smith, S. (2001). The democratic potential of charter schools. New York: Lang.

Smith, M. L., Miller-Kahn, L., Heinecke, W., \& Jarvis, P. (2004). Political spectacle and the fate of American schools. New York: Routledge.

Smith, M. L., Miller-Kahn, L., Heinecke, W., \& Jarvis, P. (2004). Political spectacle and the fate of American schools. New York: Routledge.

Smrekar, C., \& Goldring, E. (1999). School choice in urban America: Magnet schools and the pursuit of equity. New York: Teachers College Press. 
Spring, J. H. (2010). American education (14th Ed.). New York: McGraw-Hill.

Stake, R. (1995). The art of case study research. Thousand Oaks, CA: Sage.

Stake, R.E. (2006). Multiple case study analysis. New York: Guilford Press.

Stough, L. (1992). Social and Emotional Status of Home Schooled Children and Conventionally Schooled Children in West Virginia. M.S. Thesis, West Virginia University. [ED 353 079]

Strauss, A., \& Corbin, J. (1990). Basics of qualitative research: Grounded theory procedures and techniques. Newbury Park, CA: Sage Publications, Inc.

Stevens, M. L. (2001). Kingdom of children: Culture and controversy in the homeschooling movement. Princeton, NJ: Princeton University Press.

Stevens, M. (2008). Cultural sociology and its diversity. Annals of the American Academy of Political and Social Science, 619, 97-113.

Stevenson, H. W., Chen, C. \& Uttal, D.H.( 1990). Beliefs and achievement: A study of Black, White, and Hispanic Children. Child Development 61, 508-23.

Tabb, W. (2002). Unequal partners: A primer on globalization. New York: The New Press.

Taylor, A. R. (1991). Social competence and the early school transition: Risk and 
protective factors for African-American children. Education and Urban Society, $24,15-26$.

Tierney, W. G., \& Jun, A. (2001). A university helps prepare low income youths for college: Tracking school success. Journal of Higher Education, 72(2), 205-225.

Thompson, G. L. (2003). What African American parents want educators to know. Westport, CT: Praeger.

Tozer, S. (1999). Class. In David Gabbard (Eds), Power, knowledge, and the politics of educational meaning(pp.149-159). New York: Erlbaum.

Tozer S.E., Senese, G., \& Violas, P.C. (2009). School and society: historical and contemporary perspectives (6th Ed.). New York, NY: McGraw-Hill.

Trueba, H. (1993). The relevance of theory on language and culture with pedagogical practices. In B. Merino, H. Trueba, and F. Samaniego (Eds.), Language and culture in learning (pp.145-167). Washington, DC: Falmer.

Tsai, F. T. (2008). Family social networks: Taiwanese immigrant parents' homeschooling experiences. Doctoral dissertation, University of Oklahoma. Tyack, D. (1974). The one best system: A history of American urban education. Cambridge, MA: Harvard University Press. Tzuo, P. (2007). The tension between teacher control and children's freedom in a 
child-centered classroom: Resolving the practical dilemma through a closer look at the related theories. Early Childhood Education Journal, 35(1), 33-39.

Urban,W. J., \& Wagoner, J.L. (2004). American education: a history (3rd Ed.). New York: McGraw-Hill.

Valenzuela, A. (1999). Subtractive Schooling: U.S.-Mexican Youth and the Politics of Caring. New York: State University of New York Press.

Valenzuela, A. (2005). Leaving children behind: How "Texas-style" accountability fails Latino youth. New York: State University of New York Press.

Van Maanen, J. (1988). Tales of the field: On writing ethnography. Chicago:

University of Chicago Press.

van Manen, M. (Ed.). (2002). Writing in the dark: Phenomenological studies in interpretive inquiry. London, Ontario: Althouse Press.

Van Galen, J. (1986). Schooling in private: A study of home education. Doctoral dissertation. University of North Carolina, Chapel Hill.

Vygotsky, L. S. (1978). Mind in society: The development of higher psychological Processes. Cambridge, MA: Harvard University.

Warner, W.L., Meeker, M., Eells, K. (1949). Social class in America: A manual of 
procedure for the measurement of social status. Chicago, IL: Science Research Associates.

Walters, P. B. (2007). Betwixt and between discipline and profession: A history of the sociology of education. In Sociology in America: A history. Craig Calhoun ed., Chicago, IL: University of Chicago Press.

Wells, A.S., Slayton, J., \& Scott, J. (2002). Defining democracy in the neoliberal age: Charter school reform and educational consumption. American Educational Research Journal, 39(2), 337-361.

Wilcox, C., \& Robinson, C. (2011). Onward Christian soldiers? The religious right in American politics, $4^{\text {th }}$ edition. New York: West View Press.

Williams, R. (1977). Marxism and literature. Oxford U P, Oxford.

Wigfield, A. A. E. \& Eccles, I. S. (2000). Relations among children's ability-related beliefs, achievement values, and achievement goals. Paper presented at the annual meeting of the American Education Research Association in New Orleans.

Woodson, C. (1918). A century of Negro migration. Lancaster, PA: The new era printing company.

Yin, R. K. (2003). Case study research: Design and methods (3rd ed.). Thousand Oaks, CA: Sage Publications. 
Yin, R. K. (2009). Case study research: Design and methods (4th ed.). Thousand Oaks,CA: Sage.

Zeisler, K. (2012). The impact of resources on education: A position paper on how theories of social capital provide insight on the achievement gap in the United States education system. Retrieved Jul.4, 2012, from http://www.eric.ed.gov/contentdelivery/servlet/ERICServlet?accno=ED530 $\underline{790}$

Zweig, M. (2004). The What's Class Got To Do With It? Ithica, NY: Cornell University Press. 


\section{Appendix A}

\section{Volunteer Participants Wanted for Homeschooling}

\section{Study}

I am a doctoral student at the West Virginia University and conducting

WVU IRB approved research as part of my degree program in

Interdisciplinary Education. My dissertation topic is homeschooling families. I am looking for volunteers to take part in my research study. Volunteers have to meet the following criteria: (a) parents who homeschool currently or homeschooled in the past year, (b) families that are situated in the lower and/or working classes, and (c) parents willing and able to articulate their homeschooling experiences.

If you participate, you will be interviewed three times and asked to complete one survey. I would also like to do four to five half-day observations of homeschooling/parenting practices at your home. You can withdraw from the study at any time and for any reason without explanation.

I look forward to speaking with you if you are interested in participating in this study. Please feel free to contact me with questions, using the contact information provided below.

Thank you for your time and consideration. 
Sincerely,

\section{Cheng-Hsien Wu}

For more information and to participate in this study, please contact

Cheng-Hsien Wu (304-276-7724) at cwu1@ mix.wvu.edu 


\section{Appendix B}

\section{Survey for homeschooled parents}

Hello, my name is Cheng-Hsien $\mathrm{Wu}$ and $\mathrm{I}$ am conducting a voluntary and confidential survey about homeschooling as part of a West Virginia University IRB approved research study for my dissertation, under the direction of Dr. Adriane Williams. Your cooperation will contribute to my research regarding homeschooling in the U.S. I appreciate you taking your valuable time to answer the following questions. Thank you!

Name:

- Demographic section

1. Please indicate the number of parents living in the household
a. 1 parent
b. 2 parents
c. Non-parental guardian(s): How many?

2. Please indicate parents' occupation and \# hours worked per week. 
a. Parent/guardian 1-yourself (name, occupation, \# hours worked):

b. Parent/guardian 2 (name, occupation, \# hours worked):

3. What was the total income of all persons in your household over the past year, including salaries or other earnings, interest, retirement, etc. for all household members?
a. $\$ 25,000$ or less
b. $\$ 25,001$ to 50,000
c. $\$ 50,001$ to 75,000
d. $\$ 75,001$ or more

4. Please indicate your highest level of educational attainment

(Parent/guardian 1--yourself):
a. GED

b. High school graduate

c. College degree 
d. Master's degree

e. Doctoral degree

5. Please indicate your highest level of educational attainment (Parent/guardian 2):

\section{f. GED}

g. High school graduate

h. College degree

i. Master's degree

j. Doctoral degree

6. How many children are in your household?

7. Please indicate your children's race(s):
a. White (Caucasian)
b. Black (African-American)
c. Hispanic
d. American Indian or Alaska Native 
e. Asian or Pacific Islander

f. Other, please specify

g. NA

8. Do you currently homeschool any of your children?
a. YES
b. NO

9. Between which years have you homeschooled any of your children?

10. What grade(s) would your homeschooled child(ren) be in if they were attending a traditional school? And, if your children currently attend traditional school, which grades are they in?

a. Child 1 (name and grade/home or traditional):

b. Child 2 (name and grade/home or traditional):

c. Child 3 (name and grade/home or traditional): 
d. Child 4 (name and grade/home or traditional):

e. Child 5 (name and grade/home or traditional):

f. Additional children (name(s) and grade(s)/home or traditional):

\section{- Interest section}

11. What are your primary reasons for homeschooling? (Please check all that apply)

a. You are concerned about the school learning environment, such as safety, drugs, or negative peer pressure.

b. You are dissatisfied with the academic instruction at available schools.

c. You prefer to teach your child(ren) at home so that you can provide religious instruction.

d. You prefer to teach your child(ren) at home so that you can provide moral instruction.

e. You want to private school but cannot afford it.

f. Your employment needs force you to homeschool your child(ren). 
g. Your child(ren) could not get into the desired school.

h. Your child(ren) has/have a physical or mental health problem that has lasted six months or more.

i. Your child(ren) has/have other special needs that you feel the school can't or won't meet.

j. You have another reason for homeschooling your child(ren).

(Please specify

12. Of the reasons you just mentioned, which would you say is the most important?

(Please rank from 1-4, 1=most important, 4=least important)?

Most important reason:

Second most important:

Third most important:

Fourth most important: 


\section{Appendix C}

\section{Consent form/interview protocol}

Title of the study: Homeschooling Experiences

Investigator:

$\mathrm{Wu}$, Cheng-Hsien, doctoral student in interdisciplinary education, West Virginia University, Morgantown, W.V. Telephone: 304-276-7724

Purpose:

This study is being conducted in partial fulfillment of the requirement for the doctoral dissertation. The purpose of this project is to reveal how homeschooling families situated in lower income and/or working class manage homeschooling, difficulties encountered, and strategies used in homeschooling.

Procedures:

I will contact participants via email and/or phone, explain my study, and gain consent and signatures. A survey will be sent to participants via email in the first month of the study to be returned by email. I will arrange for convenient schedules of three interviews and four to five half-day observations with each participant. I will 
have three interviews with each participant and four to five half-day observations while visiting their hometown. I will carry out fieldwork throughout the four months of the study.

Potential Risks or Discomforts:

To my knowledge, this study involves no potential risks or discomforts. If you want to discuss these or any other discomforts you may experience, you may call the investigator listed in number 2 of this form.

Potential Benefits:

There is little research about the homeschooling practices from the lower income and/or working class. This study will render significant insights of how families situated in the lower income and/or working classes homeschool children. It will disclose experiences of lower income, homeschooling parents who deal with financial and other obstacles. In sum, this study will provide new knowledge for the educational community.

Please note the following concerning the interviews:

- Your participation is entirely voluntary. You may terminate the interview at any time and/or choose not to answer certain questions. 
- You are being audio taped during interview. These audiotapes will be destroyed after the investigator transcribes the content of the conversation.

- Your responses will remain anonymous with as much confidentiality as is legally possible. At no time will your identity be revealed either by the procedures of the study or during the reporting of the results.

- No negative consequence will result for choosing not to participate or for withdrawal from this study.

Thank you in advance for your willingness to participate in this study.

I have been fully informed of the above-described procedure with its possible benefits and risks, and I have given my permission to participate in this study.

Date 


\title{
Appendix D
}

\author{
Interview questions
}

First interview

1. Please share some of your unforgettable school memories throughout your education, including good and bad memories. Let's start when you were a child...

2. Tell me your experiences with school administrators, teachers and other families when your child/children attended public school.

3. Tell me the reasons why you decided to homeschool your child/children?

4. What are/were the goals you hope/d to reach by homeschooling your child/children?

5. In your opinion, what qualifications are needed to be a "good" homeschooler? Why?

6. In what ways does your homeschooling differ from other kinds of schools (public schools, private schools, parochial schools) and other homeschool families?

7. How has your economic position influenced how you homeschool?

8. Tell me how you obtain resources for homeschooling practices (e.g., supplies, materials, software, computer, fieldtrips, or whatever else is needed).

9. Why do you continue homeschooling? (Why did you discontinue homeschooling?)

10. What situations would force you/convinced you to discontinue homeschooling practice? (What situations will/would let you continue homeschooling practice?) 
11. Anything else that you would like to add to help me understand why you homeschool/ed your children?

Second interview

12. How would you describe your parenting style?

13. Tell me about how your parenting style influences the ways in which you teach your child/children.

14. What are the best things about teaching your children? What problems or challenges do you face in teaching your child/children?

15. What subjects/skills/knowledge do/did you want your child/children to learn at home? Why?

16. Tell me how your curricula suit/ed your child/children's needs? Your family's and community's needs?

17. How do/did you help them when he/she/they have/had learning problems?

18. How do you evaluate your teaching in relation to your child/children's learning progress?

19. Can you talk about any changes, surprises, or discoveries along the way once you started homeschooling? For you as a teacher? For your children?

20. Tell me what you believe are some strengths of homeschooling?

21. Tell me what you believe are some weaknesses of homeschooling?

22. Anything else that you would like to add to help me understand how you teach/taught your children at home?

Third interview 
23. Tell me how you first learned about homeschooling.

24. Tell me how you investigated homeschooling.

25. Tell me your experiences with registering to homeschool and with the regulation of your homeschool by your local school district and your state.

26. What are the educational activities that you are involved in outside your home? Why did you join them? What do/did you gain?

27. Do you participate in any homeschool group(s)? Why or why not? What are your activities in the group?

28. What knowledge/skill/information sets have you learned or obtained from other homeschool parents/groups/agencies? Who are your three biggest supporters?

29. Is there any other support or resources that you would like but you have not found yet? Why would that be helpful?

30. Tell me your opinions about the school choice program in your area. Are you satisfied, or are there things that you would change?

31. How do you feel that the current system serves people of this area who are poor and working class? Could you give an example? How does the system serve people of color? Could you give an example?

32. How do you relate with other homeschooling families, especially White middle class homeschoolers?

33. Anything that you would like to add to help me understand homeschooling and school choice in your community and state? 


\section{Appendix E}

\section{Observation Protocol}

All observations will be framed around the participants' practices and the

focus will be their social and cultural interactions as they relate to education. Some examples might include:

- play

- religious activities

- technology

- curriculum activities

- sports

- friendships 
- family activities

\section{Appendix F}

Worksheet 1: Analyst's Notes While Reading a Case Report

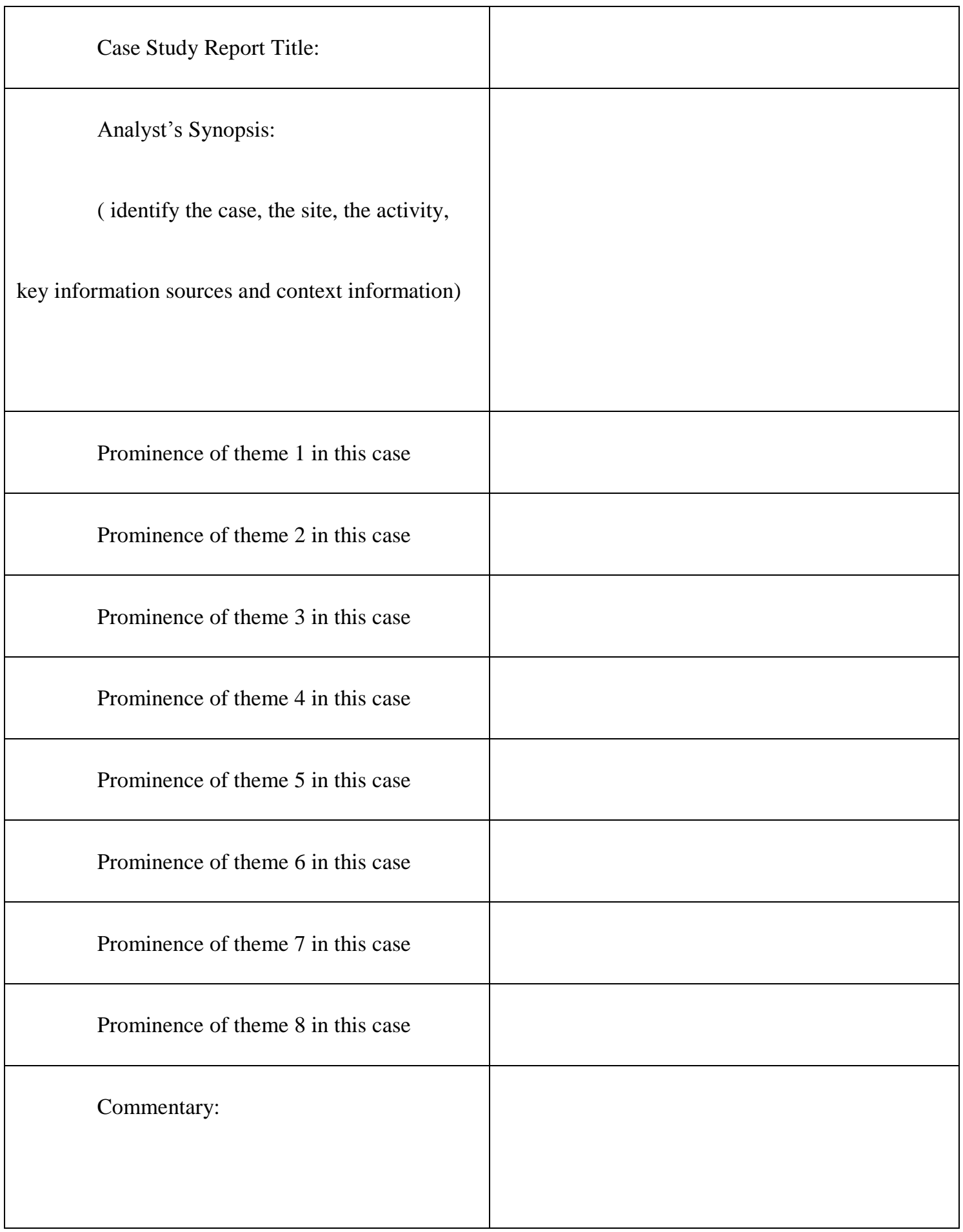


(other themes emerging from the data)

This form was modified from Multiple Case Study Analysis, by Robert E. Stake. Copyright

2006 by The Guilford Press. 


\section{Appendix G}

Worksheet 2: Ratings of Expected Utility of Each Case for Each Theme

\begin{tabular}{|c|c|c|}
\hline Utility of Cases & Case A & Case B \\
\hline Original themes from & & \\
Matrix & & \\
\hline Thailability & & \\
\hline Theme 2: Networks & & \\
with Homeschool Supports & & \\
\hline Theme 3: Relations & & \\
Themene & & \\
Homeschoolers & & \\
\hline with White Middle Class & & \\
\hline
\end{tabular}




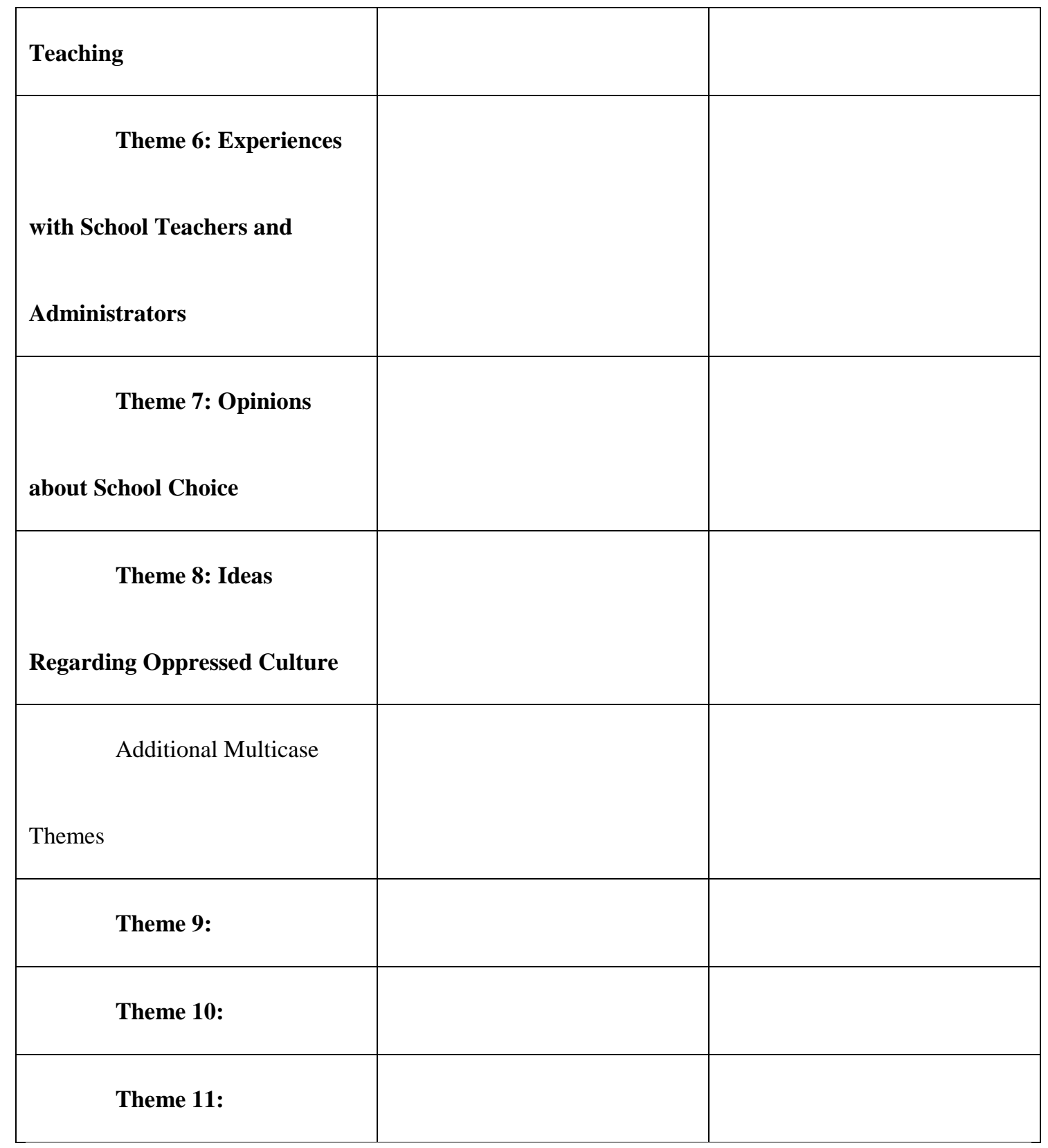

$\mathrm{H}=$ high utility; $\mathrm{M}=$ middling utility; $\mathrm{L}=$ low utility. High utility means that the case appears to be one of the most useful for developing this theme. The original themes can be augmented by additional themes after the cross-case analysis begins.

This form was modified from Multiple Case Study Analysis, by Robert E. Stake. Copyright 2006 by The Guilford Press. 


\section{Appendix H}

Worksheet 3: A Matrix for Generating Theme-Based Assertions from Case

Findings Rated Important

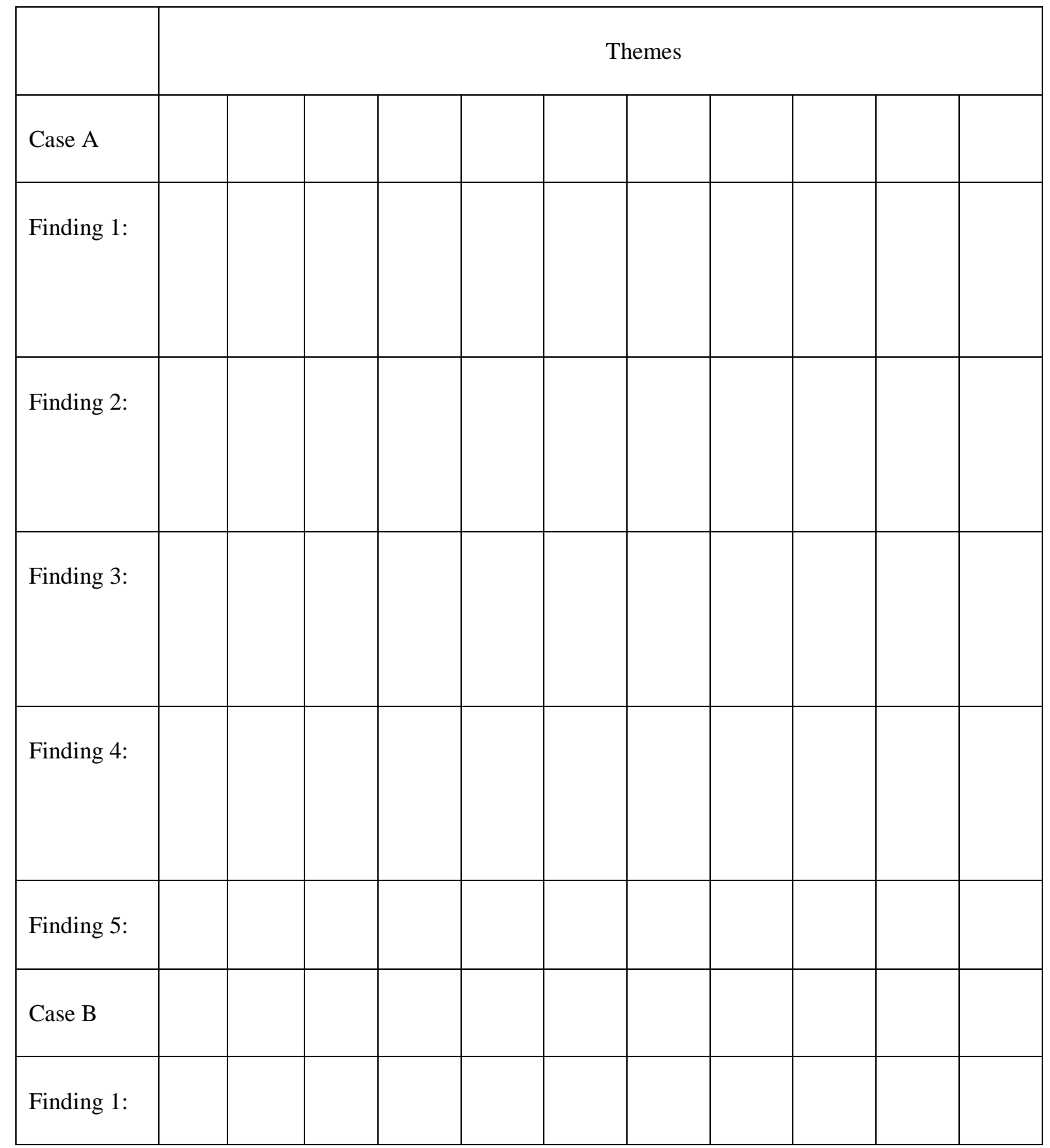




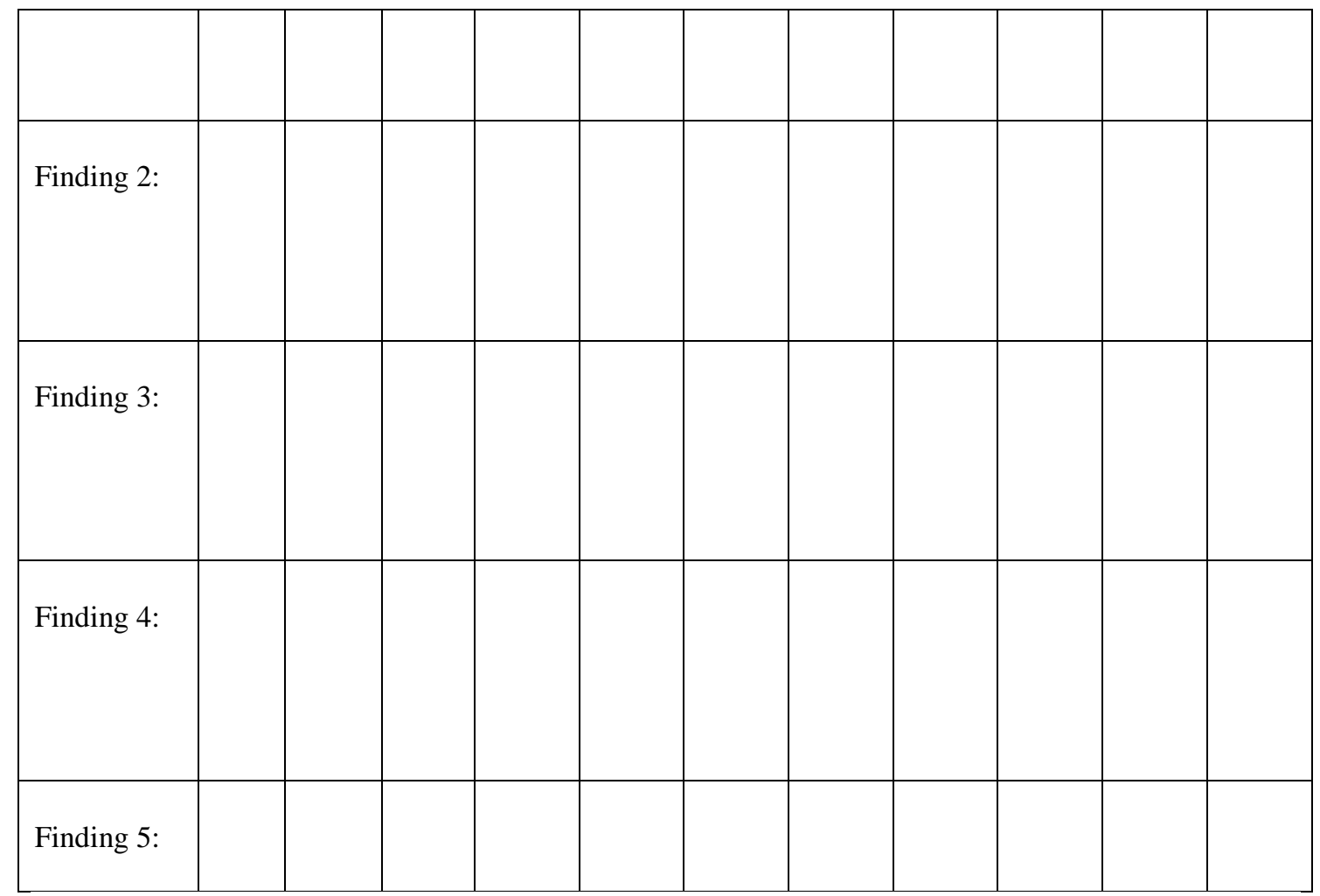

$\mathrm{H}=$ high importance; $\mathrm{M}=$ =middling importance; $\mathrm{L}=$ low importance. A high mark means that for this theme, the case finding is of high importance. This form was modified from Multiple Case Study Analysis, by Robert E. Stake. Copyright 2006 by The Guilford Press. 


\section{Appendix I}

Worksheet 4: Multicase Assertions for the Final Report

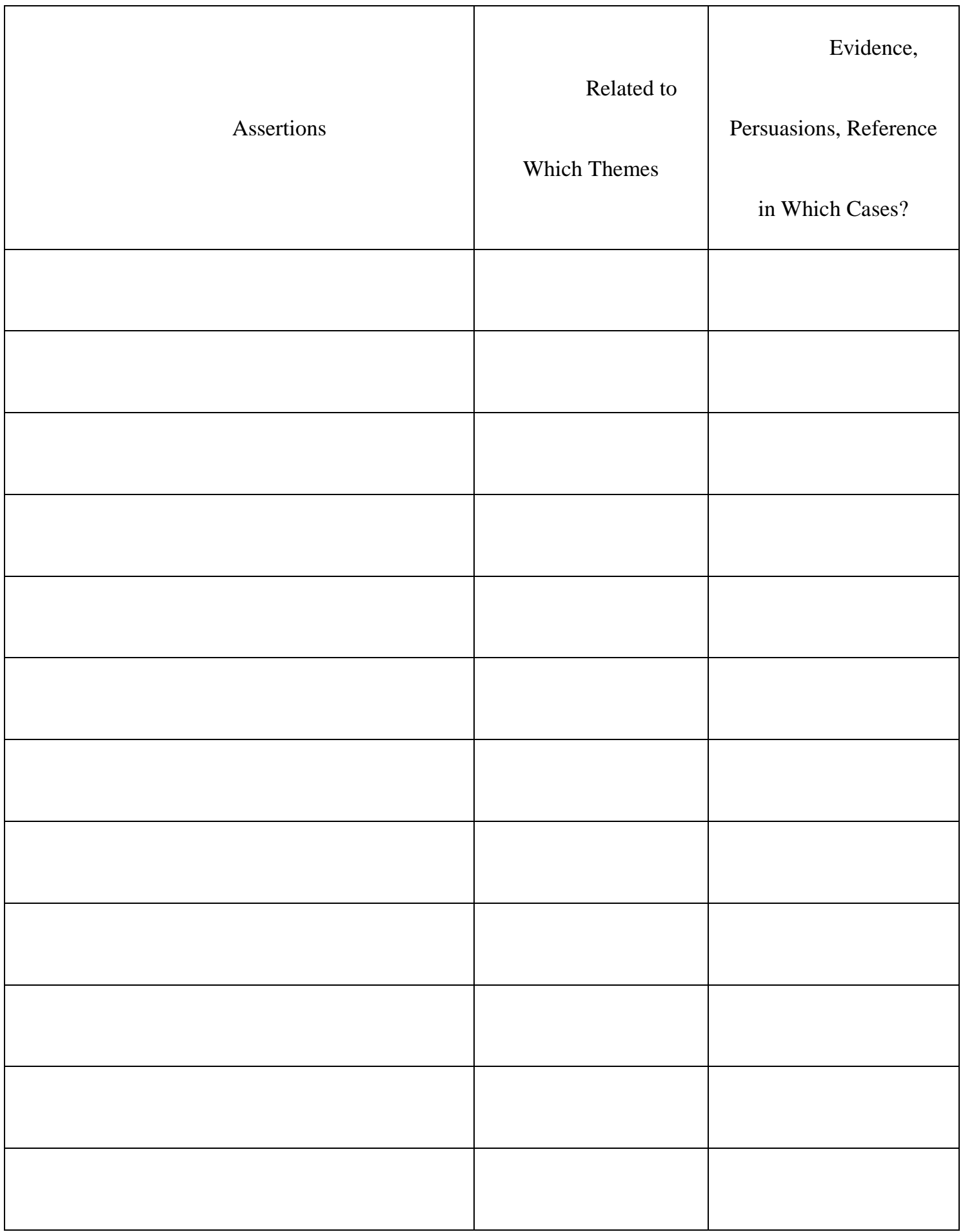




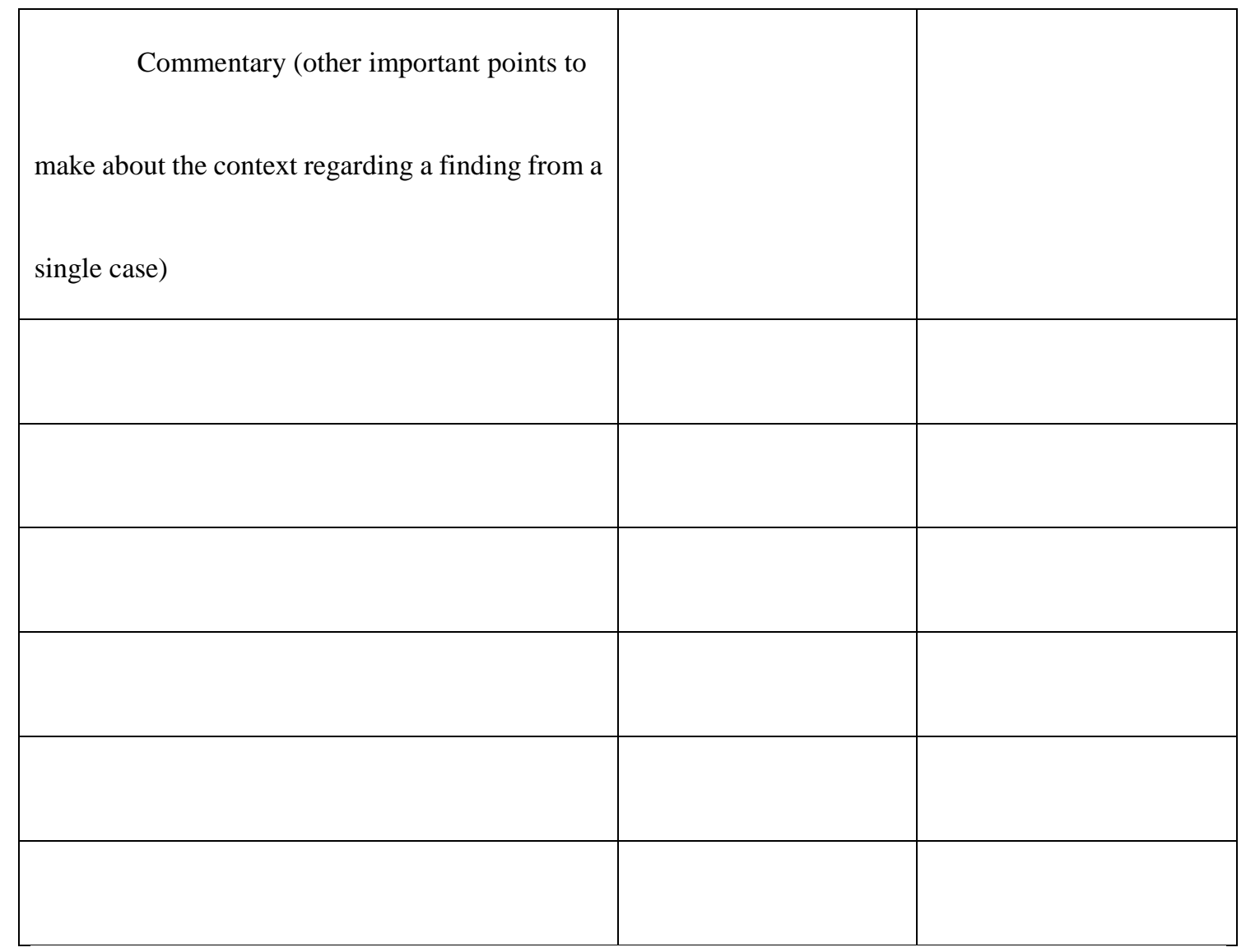

This form was modified from Multiple Case Study Analysis, by Robert E. Stake. Copyright 2006 by The Guilford Press. 


\section{Figure 1 Visual conceptual framework}

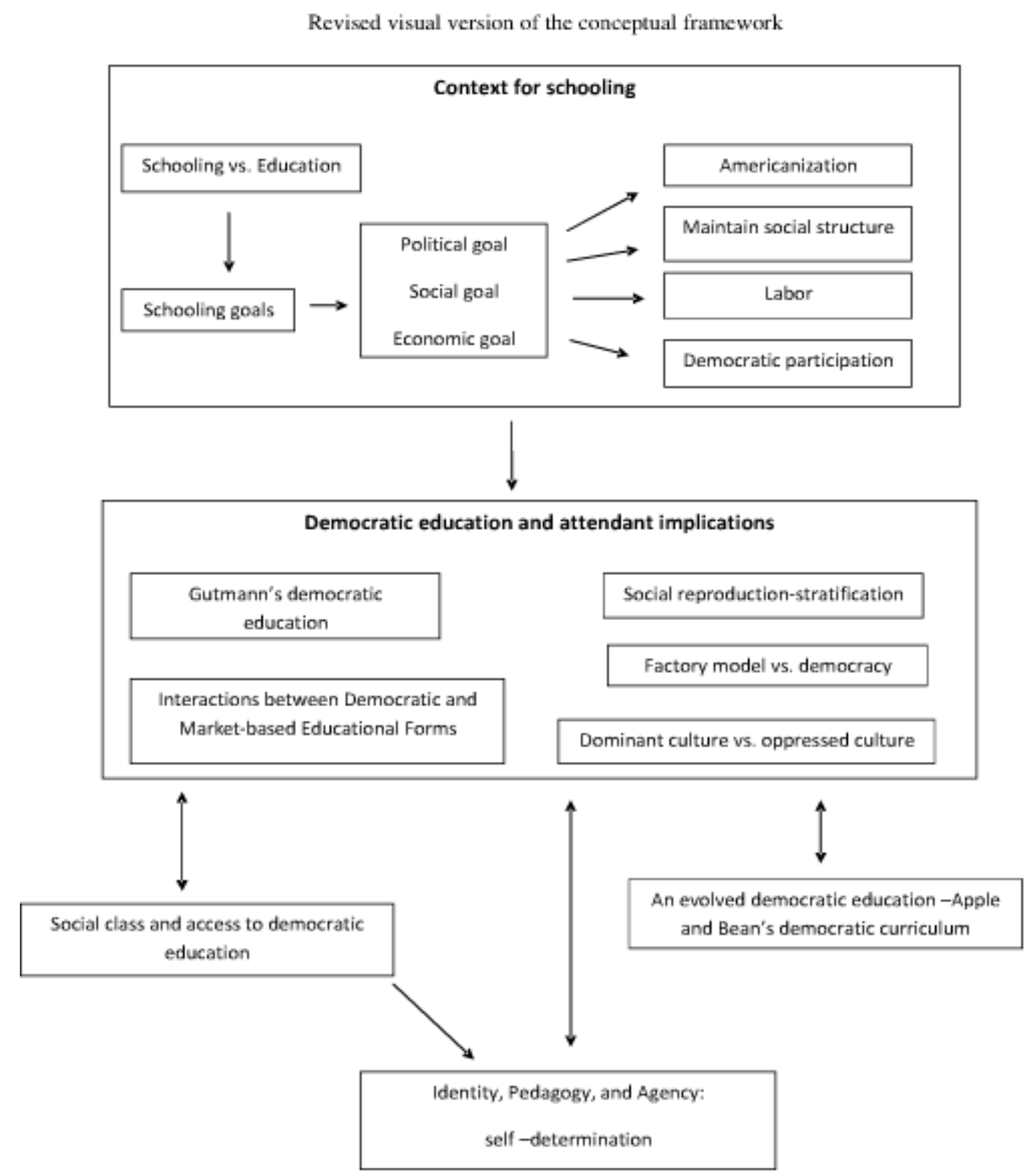

